UNIVERSIDADE DE SÃO PAULO

FACULDADE DE ECONOMIA, ADMINISTRAÇÃO E CONTABILIDADE DEPARTAMENTO DE CONTABILIDADE E ATUÁRIA PROGRAMA DE PÓS-GRADUAÇÃo EM CIÊNCIAS CONTÁBEIS

O IMPACTO DA PRIMEIRA ADOÇÃO DAS NORMAS IFRS NAS EMPRESAS EUROPÉIAS QUÍMICAS E DE MINERAÇÃO: PESQUISA DESCRITIVA

\author{
Marcelo Cambria
}

Orientador: Prof. Dr. L. Nelson Carvalho

SÃO PAULO 
Profa. Dra. Suely Vilela

Reitora da Universidade de São Paulo

Prof. Dr. Carlos Roberto Azzoni

Diretor da Faculdade de Economia, Administração e Contabilidade

Prof. Dr. Fábio Frezatti

Chefe do Departamento de Contabilidade e Atuária

Prof. Dr. Gilberto de Andrade Martins

Coordenador do Programa de Pós-Graduação em Ciências Contábeis 
MARCELO CAMBRIA

\title{
O IMPACTO DA PRIMEIRA ADOÇÃO DAS NORMAS IFRS NAS EMPRESAS EUROPÉIAS QUÍMICAS E DE MINERAÇÃO: PESQUISA DESCRITIVA
}

\begin{abstract}
Dissertação apresentada ao Departamento de Contabilidade e Atuária da Faculdade de Economia, Administração e Contabilidade da Universidade de São Paulo como requisito para a obtenção do título de Mestre em Ciências Contábeis.
\end{abstract}

Orientador: Prof. Dr. L. Nelson Carvalho

\section{SÃO PAULO}




\section{FICHA CATALOGRÁFICA}

Elaborada pela Seção de Processamento Técnico do SBD/FEA/USP

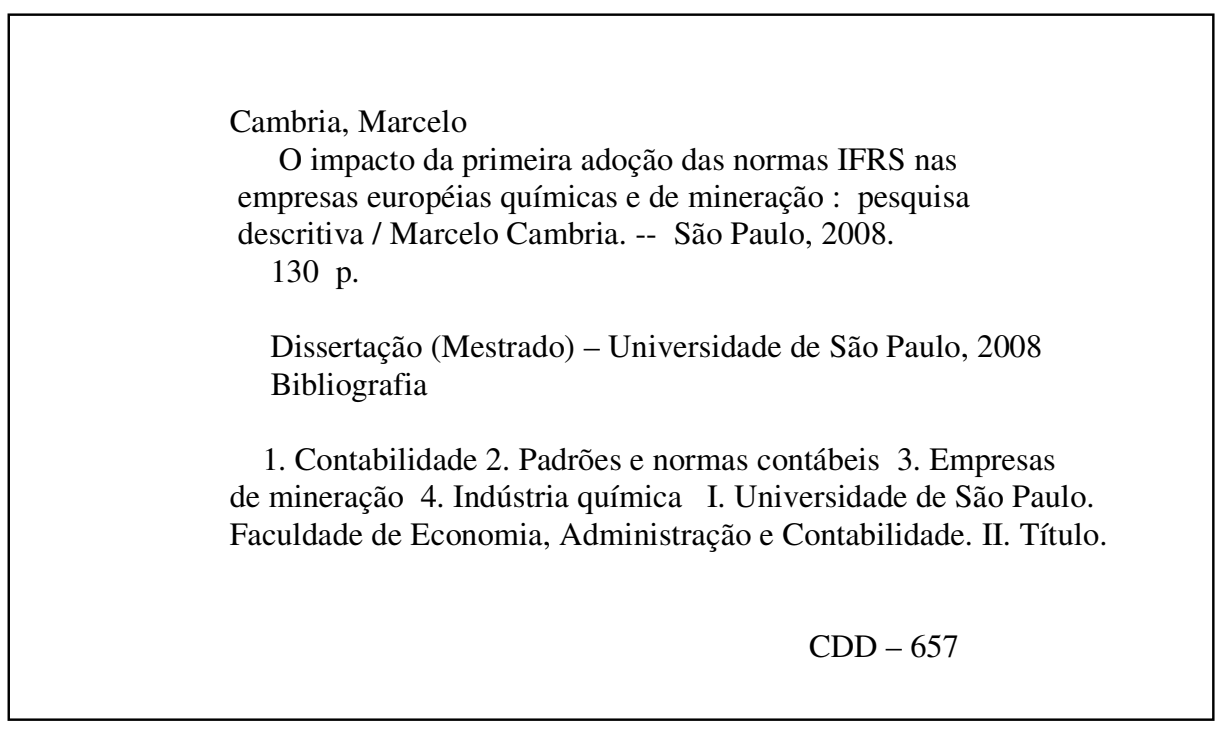


Para a minha mãe, pela imensa dedicação. 
Agradeço ao professor e orientador Dr. L. Nelson Carvalho pelo apoio e incentivo contínuos durante a pesquisa e por ter sido um grande inspirador na decisão do ingresso no Curso de Pós-Graduação em Controladoria e Contabilidade da FEA-USP.

À professora Dra . Elionor J. Weffort e ao professor Dr. Vinicius A. Martins, pelas sugestões no Exame de Qualificação e pelas novas colaborações e revisões na reta final deste estudo.

Agradeço também aos professores do Curso de Pós-Graduação da FEA-USP, especialmente ao Professor Dr. Luiz J. Corrar, pelas horas de contribuição a este estudo. Por fim, agradeço a todos os meus familiares, amigos, namorada e colegas de trabalho que participaram direta ou indiretamente desta fase importante da minha vida. 


\section{RESUMO}

A adoção crescente das normas internacionais de contabilidade, as IFRS, é o reflexo de que a comunicação entre empresas, credores, investidores e demais "stakeholders" acompanha as mudanças radicais observadas nos negócios. O trabalho de elaboração de tais normas internacionais ficou a cargo do "Board" do IASB e já se identifica ampla convergência no plano mundial rumo às citadas IFRS. A IFRS 1, denominada "First Time Adoption" refere-se aos requisitos a serem observados no primeiro exercício em que uma empresa publica suas demonstrações em norma contábil local e em IFRS. Este estudo tem por objetivo verificar se, no ano da primeira adoção, há diferença nos grupos de contas patrimoniais do ativo e do passivo nos balanços das empresas dos setores químico e de mineração listadas nas bolsas do Reino Unido, da França e da Alemanha, calculados com base no último balanço em norma contábil local, em relação aos mesmos grupos da primeira demonstração publicada em IFRS. Através da pesquisa nas bolsas de valores destes três países, foram analisadas 42 empresas, sendo 18 empresas de mineração e 24 companhias do segmento químico. Foram utilizados os testes estatísticos t-student para amostras emparelhadas e Wilcoxon para a comparação das médias das diferenças das proporções de cada grupo do patrimônio em relação ao ativo ou passivo total. Os resultados demonstram que existe diferença significativa na estrutura dos grupos do ativo e do passivo pré e pós-adoção das IFRS, tanto na comparação entre países quanto na comparação entre setores. Os resultados mostram também que cada grupo sofreu impactos de magnitudes diferentes. Para os setores e países desta amostra, a comparação dos resultados desfaz a conclusão equivocada de que a adoção das normas contábeis internacionais traz consigo o benefício da uniformidade do padrão contábil e que os efeitos das alterações nos grupos patrimoniais em decorrência da transição de um padrão contábil local para as IFRS devem ser levados em consideração quando da escolha do balanço para uma análise no ano da primeira adoção. 


\begin{abstract}
The increasing adoption of International Financial Reporting Standards, IFRS, is consequence of the communication among enterprises, creditors, investors and stakeholders that is following the deep changes that have been taken place in the businesses. The international standards were set by IASB and it has already been identified a worldwide convergence toward IFRS. IFRS 1, named as First Time Adoption, applies to the requisites that have to be considered in the first-year balance sheet in IFRS reconciled with the local GAAP. This study has for objective to verify if there are differences in the current and noncurrent assets as well as in the current and non-current liabilities groups stated within the balance sheets of mining and chemicals companies listed at London Stock Exchange, Frankfurt Stock Exchange and Paris-Euronext, considering the local GAAP for each country and the first time adoption of IFRS. After a research in the referred stock exchanges, 42 companies (18 mining and 24 chemicals) have been picked and taken into analysis. The statistics are based on Wilcoxon and t-student for paired samples tests. They have compared the average of the differences in the current and non-current groups in relation to total assets or liabilities. The results show there are significant differences in the groups of assets and liabilities taken before and after the first adoption of international financial reporting standards, considering both comparisons between countries and sectors. The results also demonstrate that the groups of current and non-current accounts were impacted in different percentiles with the adoption of IFRS 1. The comparison of results illustrates that, when the analysis of a balance sheet in the first year adoption is necessary, the IFRS have not benefited the uniformity on accounting standards for the sectors and countries that have been used in this study and the effects of changes within assets and liabilities groups have to be taken into account as consequence of the transition from UK-GAAP, GER-GAAP and FRAGAAP to IFRS.
\end{abstract}




\section{SUMÁRIO}

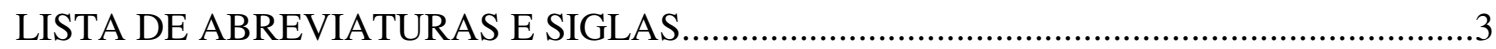

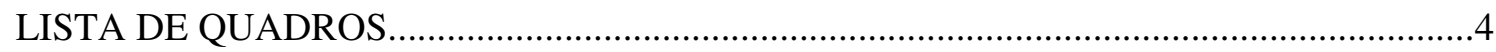

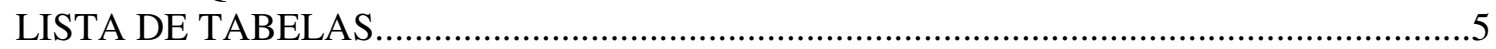

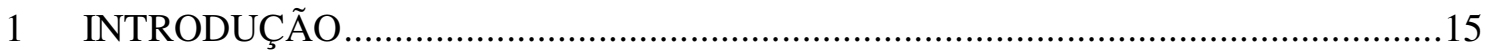

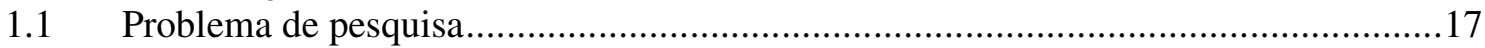

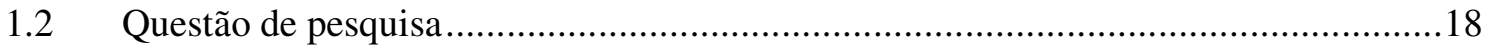

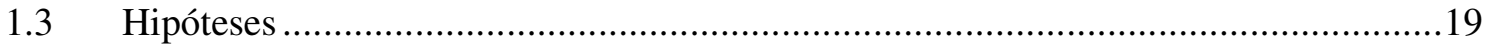

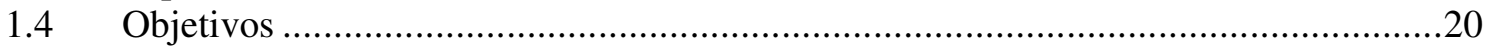

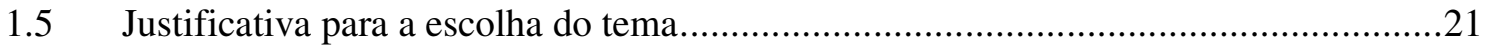

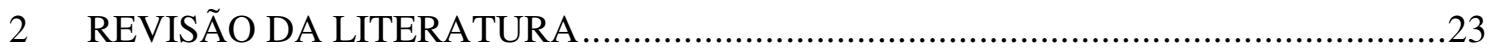

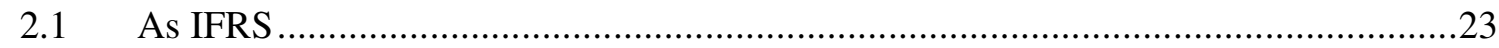

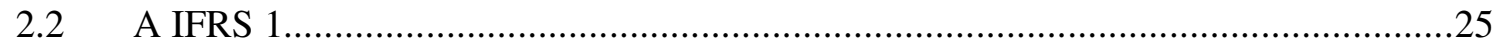

2.3 Primeiras reflexões sobre a aplicação da IFRS 1: um estudo francês ........................28

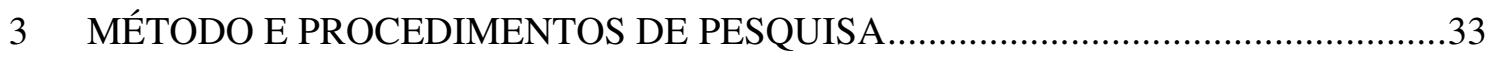

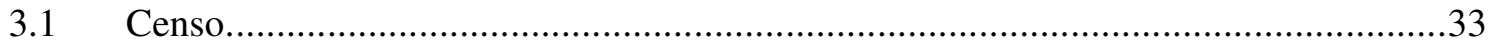

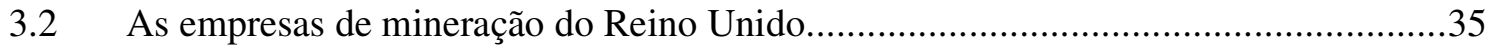

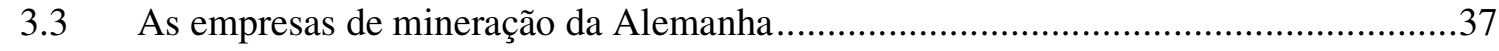

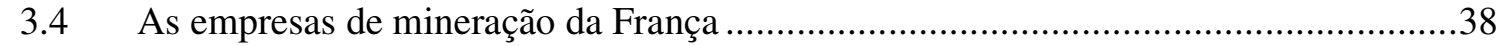

3.5 As empresas químicas do Reino Unido, da Alemanha e da França ...........................39

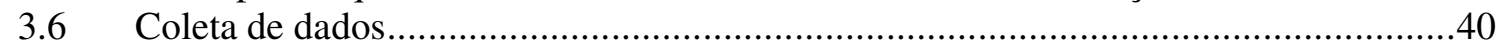

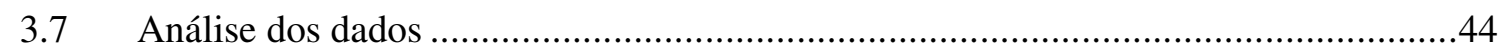

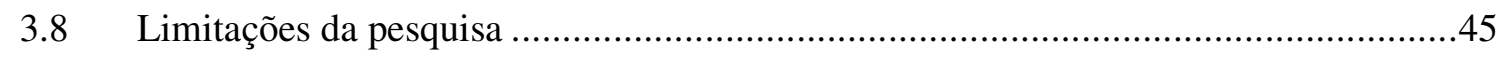

4 DESCRIÇÃO E ANÁLISE DOS DADOS DO SETOR DE MINERAÇÃO..................47

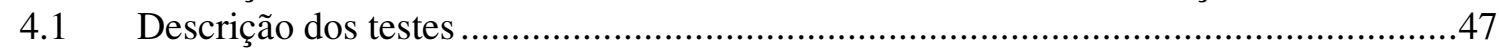

5 DESCRIÇÃO E ANÁLISE DOS DADOS DO SETOR QUÍMICO ............................65

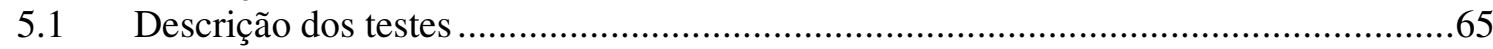

6 COMPARAÇÃO DAS PONDERAÇÕES ANTES E DEPOIS DA ADOÇÃO DAS IFRS 79

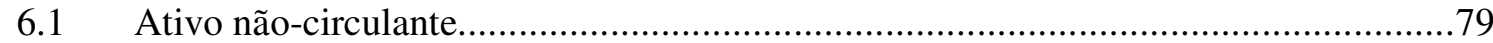

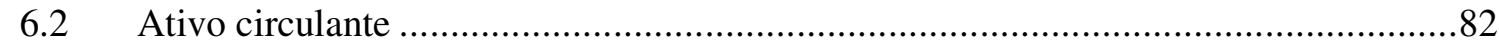

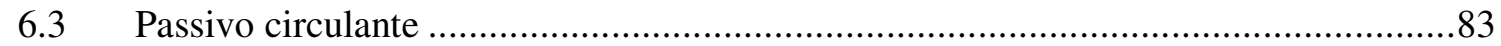

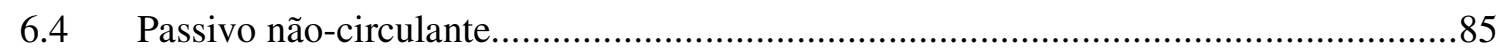

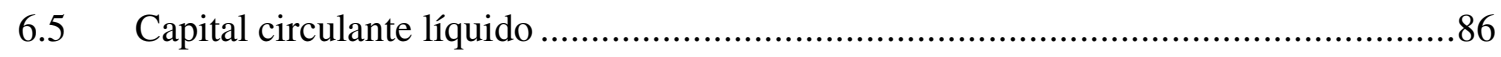

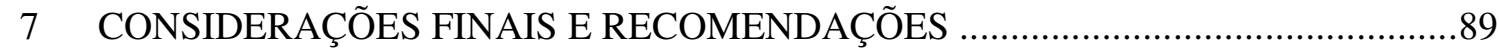

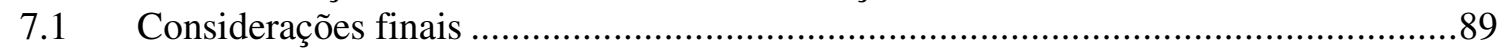

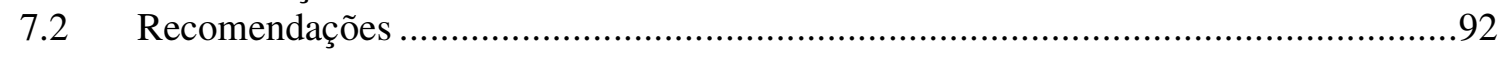

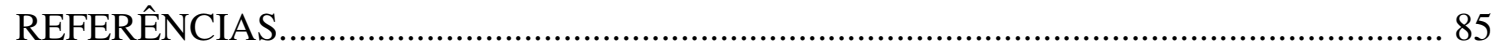




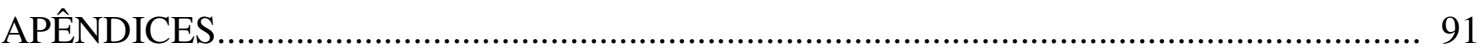




\section{LISTA DE ABREVIATURAS E SIGLAS}

AC: Ativo Circulante

ANC: Ativo Não Circulante

AT: Ativo Total

BOVESPA: Bolsa de Valores de São Paulo

CCL: Capital Circulante Líquido

DE-GAAP: Deutschland Generally Accepted German Accounting Principles

EUA: Estados Unidos da América

FASB: Financial Accounting Standards Board

FR-GAAP: Generally Accepted French Accounting Principles

FTO: Financial Times Industrial Ordinary Share Index

GER-GAAP: Generally Accepted German Accounting Principles ou Handelgesetzbuch

IAS: International Accounting Standards

IASB: International Accounting Standards Board

IASC: International Accounting Standards Committee

IFRS: International Financial Reporting Standards

LSE: London Stock Exchange

NYSE: New York Stock Exchange

PC: Passivo Circulante

PNC: Passivo Não-Circulante

PL: Patrimônio Líquido

PT: Passivo Total

PT + PL: Passivo Total + Patrimônio Líquido Total

SEC: Securities and Exchange Commission

UE: União Européia

UK-GAAP: United Kingdom Generally Accepted Accounting Principles

US-GAAP: United States Generally Accepted Accounting Principles 


\section{LISTA DE QUADROS}

Quadro 1 - Sumário dos resultados das pesquisas envolvendo a adoção das IFRS por empresas européias de diversos setores...................................................................... 22

Quadro 2 - Empresas de mineração listadas na LSE........................................................... 28

Quadro 3 - Empresas de recursos básicos listadas na Bolsa de Frankfurt............................ 29

Quadro 4 - Empresas de mineração listadas na bolsa de Frankfurt..................................... 29

Quadro 5 - Empresas de recursos básicos listadas na Euronext-Paris.................................. 30

Quadro 6 - Empresas de mineração listadas na Euronext-Paris........................................... 30

Quadro 7 - Empresas do setor químico na LSE, bolsa de Frankfurt e Euronext................... 31

Quadro 8 - Empresas do setor químico utilizadas na pesquisa........................................... 32

Quadro 9 - Número de balanços utilizados na pesquisa (por ano)..................................... 33

Quadro 10 - Cotações do dólar americano para $£ 1$ libra esterlina....................................... 34

Quadro 11 - Cotações do dólar americano para EUR 1 euro................................................. 34

Quadro 12 - Ponderações dos grupos de contas do balanço............................................... 35

Quadro 13 - Estatística do teste t-student para amostras emparelhadas................................ 37 


\section{LISTA DE TABELAS}

Tabela 1 - Grupos das contas do ativo das empresas do setor de mineração da LSE (em milhões de dólares)....................................................................................... 40

Tabela 2 - Grupo de contas do passivo das empresas do setor de mineração da LSE (em milhões de dólares)..................................................................................... 41

Tabela 3 - Demonstrações contábeis em IFRS referentes às empresas de mineração listadas na LSE.................................................................................................... 41

Tabela 4 - Demonstrações contábeis em IFRS escolhidas: empresas de mineração listadas na

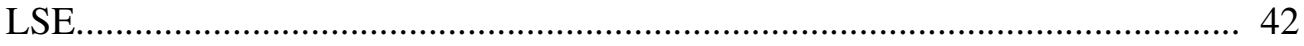

Tabela 5 - Ponderações referentes aos grupos de contas das empresas do setor de mineração da LSE (1 $1^{\text {a }}$ parte) .......................................................................................... 43

Tabela 6 - Ponderações e capital circulante líquido referentes às empresas do setor de mineração da LSE (2 $2^{\mathrm{a}}$ parte)........................................................................ 43

Tabela 7 - Normalidade e homogeneidade dos indicadores dos grupos de contas e CCL das empresas do setor de mineração da LSE............................................................ 45

Tabela 8 - Resultado do t-student para as ponderações dos grupos de contas do balanço...... 46

Tabela 9 - Grupos do ativo das mineradoras alemãs na bolsa de Frankfurt (em milhões de dólares).......................................................................................................... 47

Tabela 10 - Grupos de contas do passivo das mineradoras alemãs na bolsa de Frankfurt (em milhões de dólares)............................................................................ 47

Tabela 11 - Ponderações das empresas alemãs do setor de mineração da Bolsa de Frankfurt (1 ${ }^{\mathrm{a}}$

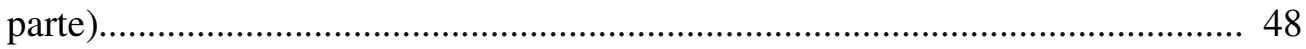

Tabela 12 - Ponderações das empresas alemãs do setor de mineração da Bolsa de Frankfurt ( $2^{\mathrm{a}}$ parte)

Tabela 13 - Normalidade das ponderações dos grupos de contas das mineradoras alemãs listadas na bolsa de Frankfurt................................................................................ 49

Tabela 14 - Resultado da aplicação do teste de Wilcoxon na ponderação dos grupos de contas do balanço..................................................................................................... 50

Tabela 15 - Sub-grupos do ativo das empresas francesas do setor de mineração na Euronext (em milhões de dólares)............................................................................. 52

Tabela 16 - Sub-grupos do passivo das empresas francesas do setor de mineração na Euronext (em milhões de dólares)............................................................................. 52

Tabela 17 - Ponderações referentes aos grupos de contas das empresas francesas do setor de

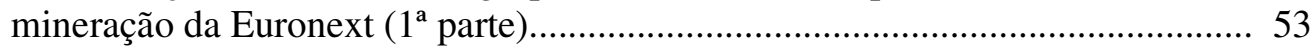

Tabela 18 - Ponderações e capital circulante líquido referentes aos grupos de contas das empresas francesas do setor de mineração da Euronext ( $2^{\mathrm{a}}$ parte) $) . . . . . . . . . . . . . . . . . . . . .53$

Tabela 19 - Normalidade e Homogeneidade das ponderações dos grupos de contas patrimoniais e do capital circulante líquido das empresas francesas do setor de mineração da Euronext..................................................................................... 54

Tabela 20 - Resultado da aplicação do t-student e do Wilcoxon nas ponderações dos grupos

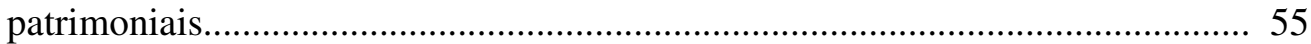

Tabela 21 - Ponderações referentes aos grupos de contas das empresas inglesas do setor químico da LSE (1 $1^{\mathrm{a}}$ parte).............................................................................. 58

Tabela 22 - Ponderações e capital circulante líquido referentes aos grupos de contas das empresas inglesas do setor químico da LSE ( $2^{\mathrm{a}}$ parte $)$...................................... 58

Tabela 23 - Normalidade e Homogeneidade das ponderações dos grupos de contas patrimoniais e do capital circulante líquido das empresas francesas do setor químico da LSE 
Tabela 24 - Resultado da aplicação dos testes t-student e Wilcoxon nas ponderações dos grupos patrimoniais das empresas do setor químico da LSE.............................. 60

Tabela 25 - Níveis de significância da diferença entre os grupos contábeis em UK-GAAP e IFRS das mineradoras e das empresas químicas pesquisadas na LSE................. 61

Tabela 26 - Normalidade e Homogeneidade das ponderações dos grupos de contas patrimoniais e do capital circulante líquido das empresas alemãs do setor químico da bolsa de Frankfurt......................................................................................... 63

Tabela 27 - Resultado da aplicação dos testes t-student e Wilcoxon nas ponderações dos grupos patrimoniais das empresas do setor químico da bolsa de Frankfurt.......... 64

Tabela 28 - Níveis de significância das diferenças entre os grupos contábeis em GER-GAAP e IFRS das mineradoras e das empresas químicas pesquisadas na bolsa de valores de Frankfurt.

Tabela 29 - Normalidade e Homogeneidade das ponderações dos grupos de contas patrimoniais e do capital circulante líquido das empresas francesas do setor químico da Euronext

Tabela 30 - Resultado da aplicação dos testes t-student e Wilcoxon nas ponderações dos grupos patrimoniais das empresas do setor químico da Euronext....................... 68

Tabela 31 - Níveis de significância das diferenças entre os grupos contábeis em FR-GAAP e IFRS das mineradoras e das empresas químicas pesquisadas na bolsa de valores

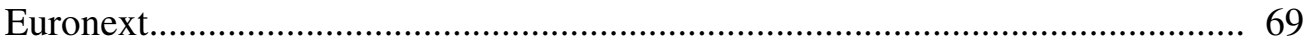

Tabela 32 - Acréscimo médio do ANC após a adoção das IFRS - Indústria de Mineração.. 72 Tabela 33 - Acréscimo médio do ANC após a adoção das IFRS - Indústria Química.......... 73 Tabela 34 - Decréscimo médio do AC após a adoção das IFRS - Indústria de Mineração... 74 Tabela 35 - Decréscimo médio do AC após a adoção das IFRS - Indústria Química............ 75 Tabela 36 - Decréscimo médio do PC após a adoção das IFRS - Indústria de Mineração.... 76 Tabela 37 - Decréscimo médio do PC após a adoção das IFRS - Indústria Química............ 76 Tabela 38 - Acréscimo médio do PNC após a adoção das IFRS - Indústria de Mineração... 77 Tabela 39 - Acréscimo médio do PNC após a adoção das IFRS - Indústria Química........... 78 Tabela 40 - Decréscimo médio do CCL após a adoção das IFRS - Indústria de

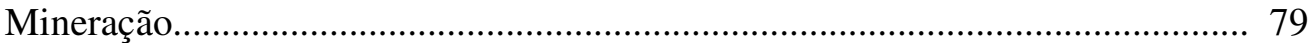

Tabela 41 - Decréscimo médio do CCL após a adoção das IFRS - Indústria Química.......... 79 


\section{INTRODUÇÃO}

O papel da informação nos mercados de capitais tem sido uma das áreas mais estudadas em finanças nas últimas décadas, período também de grande contribuição teórica sobre o assunto.

Entretanto, na primeira metade do século XX, a pesquisa realizada tinha mais um caráter normativo e dispunha sobre como deveriam ser as práticas contábeis ideais. Esta abordagem vem, desde então e progressivamente, sendo complementada e por vezes substituída pela abordagem positiva, que se propõe a descrever como a contabilidade acontece no mundo real e, portanto, auxiliar na predição daquilo que ocorrerá (BEAVER, 1967). O estágio avançado da teoria positiva é a abordagem da informação (information approach) (LOPES, 2002), que dispõe sobre o estudo da contabilidade como informação disponível aos usuários.

Nas últimas duas décadas, com a aceleração do processo de internacionalização dos mercados, a expansão do mercado de capitais vem influenciando a contabilidade através do aumento da exigência dos investidores internacionais, dos analistas, dos banqueiros e de outros usuários das informações contábeis no sentido de entenderem e analisarem melhor as demonstrações contábeis das companhias transnacionais, assim como pelo aumento significativo das fusões e aquisições de empresas nos últimos anos.

Essa globalização dos mercados trouxe consigo, quanto ao desenvolvimento do mercado de capitais internacional, o crescimento dos investimentos diretos estrangeiros e a formação de blocos econômicos e, com ele, a necessidade de se ter um conjunto de normas contábeis internacionais que viabilizassem também a comparação de informações entre companhias de um mesmo grupo ou de grupos empresariais diferentes.

Atualmente, muitos pesquisadores da área da contabilidade realizam trabalhos na tentativa de estudar o impacto da divulgação de informações contábeis, pois deseja-se verificar como os usuários reagem à informação emanada pela contabilidade em diferentes mercados e também quão relevante é a informação contábil para os administradores (CAMBRIA, 2006). 
Pesquisas sobre a convergência às IFRS têm sido objeto de estudo no Brasil nos últimos anos. Weffort (2003), que fez um estudo sobre os aspectos que podem afetar o Brasil durante o processo de convergência às normas contábeis internacionais, principalmente nas esferas jurídica, educacional, de mercado e da cultura e Melo Lopes (2001), que pesquisou as diferenças no tratamento contábil das formas de combinações de empresas segundo as normas contábeis internacionais e as normas de contabilidade brasileiras, são exemplos de trabalhos brasileiros na área.

As normas brasileiras de contabilidade sempre foram orientadas à obediência normativa. Atualmente exige-se a observação da prevalência da essência sobre a forma devido à influência das IFRS. Quando adotadas integralmente, elas colaborarão para que o ambiente contábil brasileiro evolua para uma avaliação de natureza mais subjetiva, fortemente embasada no investor-oriented, ou em outras palavras, na produção de demonstrações contábeis úteis aos investidores e analistas. O fair-value de instrumentos financeiros é um caso típico de remensuração a mercado.

Alguns trabalhos analisados fizeram estudos conceituais sobre a harmonização das normas. Outros pesquisadores analisaram as diferenças entre normas contábeis locais de alguns países e as IFRS, como é o caso do estudo de Schatt e Gross (2007) realizado na França que utilizou empresas listadas na Bolsa de Paris (Euronext) em 3 setores diferentes: Indústria de Base, TI e Imobiliário. $\mathrm{O}$ artigo em questão, que será abordado mais detalhadamente no capítulo II, teve o objetivo de analisar o impacto da adoção das IFRS na estrutura de capital das empresas. Para isso, ele analisou 37 empresas e fornece evidências de que a aplicação das IFRS impacta marginalmente o capital próprio, mas há diferenças significativas entre os setores de atividade.

No entanto, não foram encontrados trabalhos no Brasil que tivessem analisado alterações positivas ou negativas nos grupos de contas patrimoniais (ativos e passivos circulantes e permanentes e suas respectivas participações em relação ao ativo e passivo mais patrimônio líquido total) com a adoção das normas internacionais de contabilidade.

Não foram encontrados artigos ou trabalhos científicos, seja no âmbito local ou internacional, que fizessem a análise do impacto das mudanças nos grupos patrimoniais, no exercício em que o padrão contábil foi alterado do GAAP local para as IFRS. Dada essa escassez de artigos 
e trabalhos científicos, os números decorrentes da comparação entre os GAAPs ficaram restritos aos relatórios anuais das empresas. Considerando também que os acadêmicos da União Européia foram os principais responsáveis pela condução das discussões sobre a conceituação das IFRS e os pioneiros na sua aplicação, o resultado foi uma produção científica exígua no que tange à comprovação numérica das variações decorrentes do First Adoption.

\subsection{Problema de pesquisa}

Weffort (2003), na introdução da sua pesquisa sobre harmonização contábil internacional, ressalta que "a harmonização pode ser entendida como um processo por meio do qual as diferenças nas práticas contábeis entre os países são reduzidas". Ora, dado que o ambiente de negócios e a necessidade de prestação de contas de performance e evolução patrimonial das empresas está em constante mutação devido, principalmente, às empresas e aos negócios transnacionais, a contabilidade passa a exercer papel fundamental na divulgação dos relatórios financeiros apropriados aos grupos de usuários e seus objetivos.

As IFRS foram exigidas inicialmente na União Européia a partir de 2005. Atualmente, podese dizer que a norma internacional de contabilidade é o padrão contábil praticado na UE. As primeiras jurisdições a migrarem para as IFRS foram a África do Sul e a Austrália, além da UE.

Os setores escolhidos para o estudo foram os setores químicos e de mineração. O setor de mineração foi escolhido por representar um dos segmentos de base que se julgou ser o ideal para um primeiro setor de uma pesquisa exploratória, conforme critério definido pelo autor. Já o setor químico foi definido em sorteio e terá a mesma missão de ampliar as respostas às questões pertinentes à este estudo que envolvem a adoção das IFRS na Europa.

Acredita-se que com esse estudo seja possível explorar os impactos da convergência às normas contábeis internacionais e colaborar para o entendimento das diferenças nas estruturas dos grupos de contas patrimoniais do balanço bem como constatar se os indicadores do ativo e passivo circulantes e do ativo e passivo não-circulantes, calculados após a adoção das IFRS, 
são significativamente diferentes das ponderações calculadas com base nas normas contábeis locais dos segmentos químicos e de mineração nas companhias listadas nas principais bolsas de valores da Europa.

Caso as ponderações analisadas não sejam ou não demonstrem uma diferença significativa pós-adoção das IFRS, a pesquisa terá sido útil para demonstrar que, pelo menos para os dois setores escolhidos e para a utilização dos usuários do balanço patrimonial das empresas químicas e de mineração dos países pesquisados, não há diferença entre analisar o balanço em norma local ou em IFRS no ano do First Adoption, o que demonstra que as reclassificações do novo padrão adotado não modificam significativamente os grupos do $\mathrm{AC}, \mathrm{ANC}, \mathrm{PC}$ e PNC que são bastante empregados nas análises das demonstrações contábeis.

Por outro lado, caso os indicadores sejam diferentes, tanto em relação às demonstrações pré e pós-IFRS em cada país quanto na comparação desta relação entre países e entre setores, demonstrar-se-á que o propósito da adoção de normas internacionais de contabilidade por todos os países do mundo para obter uma unidade no padrão de publicação das demonstrações contábeis pode resultar em alterações nos grupos patrimoniais de grandezas distintas nas empresas dos países analisados. Também poderá evidenciar tendências distintas, ou seja: para alguns países pode ter havido acréscimo em determinada ponderação pesquisada e, para outros países, decréscimo, quando o resultado esperado, em princípio, seria o de tendência igual para indicadores de uma única norma internacional de contabilidade aplicada às empresas de igual setor na União Européia.

\subsection{Questão de pesquisa}

A questão geral de pesquisa que motiva esse estudo e será a questão a ser respondida pelo trabalho é: 
Há diferença significativa entre os grupos de contas patrimoniais nos balanços das empresas européias dos setores químicos e de mineração listadas nas principais bolsas de valores da Europa, calculados através da última demonstração em norma contábil local em relação aos mesmos grupos obtidos a partir da primeira demonstração publicada em IFRS, no ano do First Adoption?

A partir desta questão geral, outras questões específicas foram elaboradas:

- $\quad$ Existe diferenças nas ponderações dos grupos patrimoniais entre os três países, considerando o ano da primeira adoção das IFRS?

- Existe diferenças nas ponderações dos grupos patrimoniais entre os dois setores, no ano do First Adoption?

\title{
1.3 Hipóteses
}

Richardson (1999, p.27) define hipótese e explica a relação entre o contexto de investigação do pesquisador e a utilidade da hipótese na obtenção de uma resposta.

Em termos simples, uma hipótese é uma resposta possível de ser testada e fundamentada para uma pergunta feita relativa ao fenômeno escolhido. O pesquisador examina a literatura sobre o fenômeno, obtém a maior quantidade de conhecimento possível, para responder ao problema formulado. Essa tentativa de resposta é a hipótese.

Segundo Kerlinger (1980, p.38),

\begin{abstract}
Uma hipótese é um enunciado conjectural das relações entre duas ou mais variáveis. Hipóteses são sentenças declarativas e relacionam de alguma forma variáveis a variáveis. São enunciados de relações, e, como os problemas, devem implicar a testarem das relações enunciadas. Problemas e hipóteses são semelhantes. Ambos enunciam relações, só que os problemas são sentenças interrogativas e as hipóteses sentenças afirmativas. Âs vezes são quase idênticos em substância. Uma diferença importante, entretanto: as hipóteses geralmente são mais específicas do que os problemas; geralmente estão mais próximas das operações de teste e pesquisa.
\end{abstract}

Para responder ao problema formulado, as seguintes hipóteses em formato de sentenças afirmativas foram elaboradas: 
Há diferença significativa entre os sub-grupos de contas contábeis do balanço de

H1: empresas listadas nas bolsas de valores da Europa calculados através das demonstrações em normas contábeis locais em relação aos grupos de contas calculados a partir das demonstrações em normas internacionais, no ano da adoção das IFRS.

A diferença entre os sub-grupos de contas contábeis do balanço de empresas listadas

H0: nas bolsas de valores da Europa calculados através das demonstrações em normas contábeis locais em relação aos grupos de contas calculados a partir das demonstrações em normas internacionais, no ano da adoção das IFRS, não é significativa.

\subsection{Objetivos}

Esta pesquisa tem como objetivo principal verificar se há diferença nos grupos das contas contábeis do balanço de companhias mineradoras e químicas listadas nas principais bolsas de valores da Europa calculados através das demonstrações em normas contábeis locais, em relação aos grupos de contas calculados a partir das demonstrações em normas internacionais, no ano da adoção das IFRS.

Para Richardson (1999, p.63), é necessária a definição das etapas a serem cumpridas para alcançar o objetivo geral mediante o estabelecimento dos objetivos específicos ou secundários.

A partir do objetivo geral, foram elaborados os seguintes objetivos secundários:

- Examinar se há existe diferenças nas ponderações dos grupos patrimoniais entre os três países no ano da primeira adoção das IFRS

- Caso haja diferença entre as ponderações do AC, PC, ANC e PNC analisados, comparar a grandeza das diferenças entre os dois setores no ano do First Adoption 


\subsection{Justificativa para a escolha do tema}

Ao comparar os grupos de contas compreendidos dentro do ativo e do passivo reportados conforme os padrões contábeis aceitos nos principais países do bloco econômico europeu, em relação aos mesmos itens constantes do balanço patrimonial elaborado segundo as normas internacionais de contabilidade, esse trabalho procura analisar o impacto provocado nestes grupos de contas patrimoniais na publicação da primeira demonstração divulgada em IFRS.

Caso o impacto tenha sido pequeno, é possível fazer a inferência que as normas contábeis internacionais estão em consonância com os padrões contábeis do Reino Unido, da Alemanha e da França, no que diz respeito à diferença causada nos referidos segmentos de contas do ativo e do passivo.

Para a escolha dos países da UE a serem observados, foi utilizado o critério de volume de negócios das suas respectivas bolsas de valores, com base nos números de encerramento do ano de 2007 divulgados na página da internet das três bolsas. Constatou-se que a bolsa de valores de Londres é a principal da Europa em volume de negócios. Já a bolsa de Frankfurt, na Alemanha, é a segunda da UE em volume financeiro negociado. Em seguida, as bolsas de Bruxelas e Madrid também apareciam no ranking das bolsas mais importantes da Europa. A bolsa de Bruxelas se fundiu com a bolsa de Paris e a de Amsterdã, formando a Euronext Bruxelas, e esta foi a última delas a ser escolhida.

Em contrapartida, caso haja diferenças substanciais nas relações entre os grupos de contas contábeis calculados através das demonstrações em normas locais e internacionais das empresas listadas nas bolsas de valores dos seus países, será necessário investigar o porquê delas. No entanto, o porquê das distorções não fará parte do escopo dessa pesquisa.

Quanto à perspectiva teórica, a contribuição desse trabalho é explorar a pesquisa sobre a convergência contábil dos países envolvidos vis-à-vis os interesses brasileiros sobre o tema. Trata-se de um estudo exploratório que considera a experiência na UE para a inferência de conclusões que serão aplicáveis apenas às empresas químicas e de mineração listadas nas bolsas de Londres, Frankfurt e Euronext (Paris). 
Uma segunda contribuição é conhecer se o impacto nos indicadores dos grupos de contas do balanço entre as empresas mineradoras do Reino Unido, Alemanha e França (inter-países) ocorreu com a mesma intensidade e direção quando da adoção das normas internacionais. 


\section{REVISÃO DA LITERATURA}

Este capítulo apresenta a revisão teórica da pesquisa. Começa com um breve histórico das IFRS na Europa e algumas reflexões nos países que já adotaram o padrão do IASB. Depois traz a IFRS1, que é a norma internacional referente à adoção das IFRS pela primeira vez, destacando como ela é definida, quais as opções para a sua aplicação e as principais áreas das demonstrações contábeis afetadas. Na seqüência, faz uma reflexão sobre os resultados de um estudo exploratório feito por pesquisadores franceses de Strassbourg que se utilizaram de indicadores de capital para mensurar o impacto da adoção das IFRS em empresas francesas de três setores diferentes: Indústria de Base, Tecnologia da Informação e Imobiliário.

\subsection{As IFRS}

As IFRS são normas ou padrões contábeis elaborados pelo IASB, uma entidade independente situada em Londres. Essas normas foram desenvolvidas para serem aplicadas às demonstrações contábeis das companhias abertas listadas em bolsas de valores ao redor do mundo, de maneira igualitária e irrestrita.

Entre 1973 e 2000, as normas internacionais foram publicados pelo predecessor do IASB, o IASC, um comitê emissor de normas fundado em 1973 por profissionais de contabilidade e representantes da classe no Canadá, Austrália, França, Alemanha, Holanda, Japão, México, Reino Unido, Irlanda e Estados Unidos. Durante este período, as normas do IASC eram chamadas de IAS. A partir de 2001, a função normatizadora foi assumida pelo IASB. Desde então o IASB utiliza a nomenclatura de IFRS apesar de continuar a reconhecer as normas IAS formuladas anteriormente pelo IASC.

A introdução das IFRS se fez necessário para aprimorar a qualidade da informação contábil em um cenário em que as transações financeiras entre os países se tornaram inexoravelmente comum pois é sabido que a contabilidade é praticada e até influenciada por forças econômicas e políticas, bem como pela legislação tributária e a cultura inerente a cada país. 
A partir de 2005 as IFRS se tornaram compulsórias para as empresas que são listadas nas bolsas de valores da UE e que, portanto, necessitam publicar suas demonstrações. Antes desta data algumas empresas já haviam adotado este novo padrão contábil de maneira voluntária com o objetivo de acessar qualquer mercado financeiro importante no âmbito mundial e, também, para reduzir os seus custos de capital.

Amin Mawji, um dos sócios da divisão de consultoria para publicação de demonstrações contábeis da Ernst Young, fez uma avaliação após três anos da obrigatoriedade das IFRS na UE (HUGHES, 2008). Ele cita que a percepção da sociedade é a de que a transição européia foi um sucesso. Mas ao mesmo tempo foi um processo mais difícil do que se havia planejado, requerendo muita habilidade dos contadores através de ajustes aos sistemas contábeis para obter as demonstrações finais. Hughes mencionou que no primeiro dia da conversão do UKGAAP para as IFRS no Reino Unido, uma equipe da PriceWaterhouseCoopers monitorou o preço das ações diante da apresentação dos resultados sob o padrão internacional. As alterações dos preços das ações ficaram entre 1 e 2 por cento, o que não foi considerado ruim, mas ficou aquém do resultado esperado para uma transição que foi declarada apenas como uma mudança de registros contábeis.

Muitos pesquisadores e usuários ainda discutem a eficiência da aplicação das IFRS em escala global, alegando que há muitos países com políticas monetárias tradicionalistas que permanecerão limitados ao seu mercado local em um futuro próximo. Ball (2005) cita que há pouca teoria ou evidência estabelecida através da qual pudesse ser feita uma relação organizada de todas as vantagens e desvantagens na adoção das IFRS em determinado país, o que dizer internacionalmente.

Neste sentido, Ball (2005) menciona que um dos aspectos positivos é poder comemorar o sucesso dos órgãos normatizadores terem desenvolvido um conjunto de padrões contábeis de qualidade alta que fosse compreensível à todos os países e, mais além, que fosse possível convencer mais de 100 países à adotá-los. Do lado negativo, é possível enxergar problemas com a fascinação atual do IASB (e do FASB) com a contabilidade praticada à fair value, que é o valor que o mercado está disposto a pagar por um ativo no momento exato da sua apuração. Significa dizer que inevitavelmente haverá diferenças substanciais entre os países na aplicação da norma referente à este assunto, o que incorpora na contabilidade um risco grande mas inicialmente superável em prol da convergência. 
Para o Commonwealth Bank of Australia, o maior banco da Austrália e o primeiro dos quatro grandes bancos daquele país a publicar seus relatórios financeiros em IFRS, um dos maiores desafios é educar o mercado sobre o assunto da transição e a prioridade é explicar por que as alterações do padrão contábil podem causar volatilidade nas demonstrações (FRY, 2008). Nas instituições financeiras, por exemplo, as mudanças nas regras de contabilização dos instrumentos financeiros foram bastante complexas, tanto pelos detalhes quanto pelo efeito nos resultados, sendo o fair value a alteração responsável pelo maior efeito individual. Ocorre que as IFRS dispõem que mais ativos sejam apresentados à fair value do que as normas anteriores. À medida que uma companhia altera o valor de um ativo, essa mudança deve ser publicada como ganho ou perda na demonstração de resultados. Em uma empresa que detém diversos ativos financeiros, esta alteração à prática da contabilidade é uma fonte de ganhos e perdas imprevisível, independentemente da venda do ativo.

Para Aaron Anderson, diretor de políticas contábeis e responsável pela implementação das IFRS na IBM, empresa que atualmente está implementando as IFRS em 60 países de todos os continentes, entre as vantagens de mudar para um único sistema de contabilidade estão as economias de escala e a eficiência estrutural do sistema contábil da empresa (TAYLOR, 2008). Para ele, as IFRS permitirão à IBM a oportunidade de fazer negócios mais rapidamente, de uma forma melhor e mais eficiente.

Em abril de 2008, 27 países membros da UE, além da Austrália e da África do Sul, já haviam transitado integralmente para as IFRS. Nos próximos anos, esse conjunto de países aumentará com a participação do Japão, Coréia do Sul, Canadá e Estados Unidos. Atualmente, cerca de 100 países aceitam as IFRS, mas a expectativa do IASB é que esse número aumente para 150 países até 2011.

\subsection{A IFRS 1}

A norma IFRS 1 estabelece a divulgação das demonstrações contábeis em IFRS através da confirmação da aplicação ampla e irrestrita de todas as IFRS. 
A descrição da norma internacional esclarece que a IFRS 1 requer a aplicação retrospectiva de todas as IFRS em vigor na data do balanço patrimonial referente ao último exercício apresentado, exceto quanto à catorze isenções opcionais e quatro exceções mandatórias (CFC, 2006). O Credit Suisse, uma das instituições financeiras mais importantes do mundo, aplica as IFRS integralmente, sem restrições. Significa dizer que o banco aplica o conjunto de normas internacionais completo, além de considerar as 14 isenções permitidas pelo IFRS 1 - Adoção das IFRS pela primeira vez (Heffes, 2007).

Entre as isenções opcionais estão: operações de combinações de entidades, ativo imobilizado, benefícios a empregados, ajustes cumulativos de conversão, instrumentos financeiros compostos, data de transição para controladas, coligadas e joint-ventures, designação de ativos e passivos financeiros, pagamentos baseados em ações, informações comparativas para instrumentos financeiros e para contratos de seguros, obrigações por desmobilização, transações que contêm arrendamento, informações comparativas para ativos resultantes de atividades de exploração e avaliação de produtos minerais e avaliação a valor justo de ativos ou passivos financeiros no reconhecimento original. As exceções se referem à baixa de ativos e passivos financeiros, ativos mantidos para venda, contabilização de hedge e estimativas contábeis (CFC, 2006).

O banco HSBC nos Estados Unidos, aproveitando a concessão feita em novembro de 2007 pela $S E C$, a Comissão de Valores Mobiliários americana, de não exigir mais a reconciliação entre as IFRS e os US-GAAP de empresas estrangeiras com ações listadas na bolsa de valores dos EUA, e considerando as regras de transição da IFRS 1, decidiu congelar os valores de suas propriedades à valores de 1 de janeiro de 2004 (EDGAR Online-Glimpse, 2008). Assim, os custos de propriedade considerados sob as IFRS não serão mais reavaliados no futuro, pois ativos contabilizados a custo histórico são depreciados com exceção das propriedades cuja permanência em balanço por tempo ilimitado seja comprovada.

As propriedades detidas com o objetivo de investimento são reconhecidas a valor de mercado com ganhos e perdas reconhecidos na demonstração de resultados líquidos do período. Esses ativos não são depreciados.

Os US-GAAP não permitem a reavaliação de propriedades, incluindo a conta de investimento em propriedade, apesar de exigir o reconhecimento do impairment de ativos. Entende-se por 
impairment de ativos o excesso do valor contábil de um ativo ou da unidade geradora de caixa sobre o valor recuperável desse mesmo ativo. São exemplos de perdas por redução ao valor recuperável o declínio no valor de mercado de um ativo, as mudanças adversas da tecnologia, o aumento nas taxas de juros no mercado ou de outras taxas de retorno sobre os investimentos. Qualquer aumento ou déficit realizado em relação à conta de ativo permanente é, portanto, refletido na demonstração de resultados líquidos. Os US-GAAP preconizam que a depreciação seja calculada com base no custo do ativo permanente.

O impacto da adoção da IFRS 1 para o HSBC nos Estados Unidos, mais especificamente no que tange o seu ativo imobilizado, se dá no sentido de que, sob as IFRS, o valor da propriedade detida para geração do resultado operacional da empresa reflete as reavaliações anteriores a 1 de janeiro de 2004 somadas ao custo histórico. Por consequiência, os valores dos ativos fixos e do patrimônio líquido dos acionistas são menores sob os US-GAAP do que pelas IFRS. Há, também, uma depreciação correspondente menor em contraposição aos resultados líquidos maiores, bem como ganhos maiores (ou perdas menores) em relação aos ativos fixos registrados pelos US-GAAP. A demonstração de resultados líquidos por USGAAP não reflete os ganhos ou perdas não-realizados que são considerados pelas IFRS para a conta de investimento em propriedade.

Sobre as informações financeiras, a IFRS 1 esclarece que as demonstrações contábeis devem apresentar comparação entre dois ou mais exercícios além de se basear, obrigatoriamente, nas IFRS em vigor na data dos relatórios financeiros.

Segundo análise do CFC e do Ibracon, todos os componentes do balanço patrimonial são potencialmente afetados pela IFRS 1, já que é necessário o recálculo dos valores dos ativos e passivos para ajustá-los aos requerimentos contidos nas normas em vigor na data das primeiras demonstrações contábeis. Essas entidades especificam que as isenções e exceções contidas na IFRS 1 podem afetar ativos e passivos resultantes de combinações de entidades, ativo imobilizado, passivo por obrigações a empregados, ativos e passivos financeiros e passivo por desmobilização de ativos ou operações. 


\subsection{Primeiras reflexões sobre a aplicação da IFRS 1: um estudo francês}

O objetivo desse tópico é trazer uma pesquisa realizada na França sobre o impacto das adoção das IFRS no patrimônio líquido de 37 empresas francesas de três setores diferentes da bolsa Euronext: indústria de base e transformação, tecnologia da informação e de imóveis.

Em 2005, cerca de 8.000 sociedades européias listadas nas bolsas de valores daquele continente, tiveram que publicar suas contas anuais respeitando as normas internacionais IFRS. Schatt e Gross (2007), dois pesquisadores de Strassbourg, na França, afirmam que como conseqüência dessas reformas contábeis, tais demonstrações deveriam conter informações interessantes sobre as diferenças práticas entre as normas locais de cada país e as IFRS, no ano da primeira adoção das normas internacionais. Em função deste interesse, alguns estudos acerca do assunto foram feitos.

Benabdellah e Teller (2006), por sua vez, realizaram um estudo com 50 grupos franceses para compreender como a aplicação das normas IAS 16 (Ativo Imobilizado) e IAS 40 (Propriedades para Investimento) afetaram suas demonstrações contábeis. O resultado observado foi que analistas e contadores foram quase unânimes em afirmar que se sentem mais confortáveis com o custo histórico, alegando que as normas contábeis francesas anteriores às IFRS ainda transmitem um conforto maior à quem faz e à quem analisa os relatórios financeiros, além de transmitir uma impressão de maior homogeneidade

Um outro estudo (Tort, 2005) envolvendo 10 companhias financeiras da França negociadas em bolsa evidencia que o impacto financeiro da conversão às IFRS é positivo para aquelas instituições que já optavam pelo valor justo em comparação às instituições que ainda se baseavam muito fortemente no modelo de custo histórico.

As pesquisas de Benabdellah e Teller (2006) e Tort (2005) permitem inferir que a adoção das IFRS afetaram relativamente pouco as empresas francesas que já optavam pelo valor justo em comparação às instituições que ainda se baseavam predominantemente no modelo de custo histórico. 
Schatt e Gross (2007) justificam a escolha da análise do capital próprio para a execução da sua pesquisa, pois, segundo eles,

O capital próprio ocupa um lugar privilegiado dentro das informações publicadas nas demonstrações contábeis, em particular para os analistas financeiros, investidores e sociedade, por fornecer subsídios para o cálculo de rentabilidade e do risco das empresas" (tradução livre do autor).

O método de investigação dos pesquisadores de Strassbourg incluiu a seleção das 37 empresas francesas cujos critérios foram:

- Ser cotada em bolsa em 31 de dezembro de 2004 nos segmentos A, B e C da Eurolist

- Pertencer aos setores de indústria de base, de tecnologia da informação e imobiliário da Euronext, a bolsa de valores francesa

- Ter as demonstrações contábeis disponíveis nas suas respectivas páginas da internet durante o ano de 2006

- Apresentar notas explicativas detalhadas sobre o impacto das IFRS no patrimônio líquido

A aplicação desses quatro critérios de seleção permitiram a escolha de uma amostra de 37 empresas representantes dos três setores, dentre 115 existentes.

Quanto à incidência das IAS e IFRS no patrimônio líquido das 37 empresas selecionadas, a análise permitiu inferir que o capital próprio foi pouco afetado pelas mudanças das normas contábeis. A variação entre a aplicação das normas IAS e IFRS e as normas contábeis francesas, no montante de capital empregado pela empresa, foi negativa ou nula para 17 empresas e positiva para 20 empresas. E para 27 empresas, a variação do capital próprio ficou entre $-10 \% \mathrm{e}+10 \%$.

Além disso, as diferenças encontradas são independentes entre os três setores. Enquanto as indústrias de base apresentaram uma variação do capital próprio modesta, no setor imobiliário, 8 das 9 empresas registraram um aumento de capital próprio significativo, superior a $10 \%$. Por fim, nas empresas do setor de tecnologia da informação, o impacto da 
passagem para as normas IAS / IFRS mostraram variações entre $-10 \%$ e $+10 \%$ para 9 entre as 10 empresas analisadas.

Além dos estudos franceses citados, cumpre notar outro trabalho comparável feito pelo departamento de normas internacionais da Ernst Young (2006) que fornece evidências que a reforma contábil foi parcial, e que apesar da adoção de um padrão internacional, é possível identificar que algumas características da norma local promovem reflexos nos relatórios contábeis elaborados em IFRS. Tal pesquisa foi realizada com 65 empresas européias de setores diversos, como o de telecomunicações, automobilístico e imobiliário, selecionadas em função de sua capitalização bursátil alta, com base na publicação Financial Times Global 500.

Um sumário dos resultados encontrados nas pesquisas européias é evidenciado pelo Quadro 01 a seguir:

Quadro no 1 - Sumário dos resultados das pesquisas envolvendo a adoção das IFRS por empresas européias de diversos setores

\begin{tabular}{|c|c|c|}
\hline Estudo & Escopo & Resultados Encontrados \\
\hline Schatt e Gross & $\begin{array}{l}37 \text { empresas dos setores: Indústria } \\
\text { de Base, Tecnologia da Informação } \\
\text { e Imobiliário. }\end{array}$ & $\begin{array}{l}\text { O capital próprio foi pouco } \\
\text { afetado pelas mudanças no PL } \\
\text { em função das IFRS, havendo } \\
\text { diferenças independentes entre } \\
\text { os } 3 \text { setores. }\end{array}$ \\
\hline Ernst \& Young & $\begin{array}{l}65 \text { empresas européias de setores } \\
\text { diversos. }\end{array}$ & $\begin{array}{l}\text { A adoção das IFRS é uma } \\
\text { reforma contábil parcial. }\end{array}$ \\
\hline Benabdellah \& Teller & 50 grupos franceses. & $\begin{array}{l}\text { O custo hitórico transmite uma } \\
\text { impressão de maior } \\
\text { homogeneidade do que a aplicação } \\
\text { do IAS } 16 \text { (Ativo Imobilizado) e } \\
\text { IAS } 40 \text { (Propriedades para } \\
\text { Investimento). }\end{array}$ \\
\hline Tort & $\begin{array}{l}10 \text { companhias financeiras da } \\
\text { França. }\end{array}$ & $\begin{array}{l}\text { O impacto da conversão às IFRS } \\
\text { é positivo para aquelas } \\
\text { instituições que já praticavam o } \\
\text { valor justo em detrimento daquelas } \\
\text { que ainda utilizavam o custo } \\
\text { histórico. }\end{array}$ \\
\hline
\end{tabular}


Estes resultados desautorizam concluir antecipadamente que existe homogeneidade nos resultados da substituição de um padrão contábil local pelas IFRS, seja em relação às empresas do mesmo setor, seja na análise das empresas de setores diferentes. 


\section{MÉTODO E PROCEDIMENTOS DE PESQUISA}

Neste capítulo serão abordados o método e o procedimento de pesquisa. A fim de expô-los com clareza, a seguinte organização foi adotada: primeiramente serão caracterizadas as empresas utilizadas em cada país para, em seguida, expor as limitações do estudo.

Quanto ao período analisado, o estudo compreende as demonstrações contábeis de 1999 a 2005 constantes dos relatórios anuais publicados pelas empresas. A escolha deste período é justificada pela necessidade de se fazer um corte transversal ou seccional no intervalo de tempo que contempla a adoção compulsória das IFRS pelas empresas da União Européia em 2005.

\subsection{Censo}

Martins (2005) preconiza que "ao buscar solução para um problema ou encontrar evidências para testar uma hipótese de pesquisa, o investigador, assim como o profissional da área contábil, deve explicar com clareza e precisão o que significam os principais termos, conceitos, definições e constructos que estão sendo adotados e utilizados no estudo que realizam".

A população ou universo é definido por Stevenson (2001, p.158) como o grupo todo do qual se extrai a amostra. Martins (2002) explica que neste item o pesquisador irá caracterizar os sujeitos que serão objeto de estudo.

Com referência à definição de Stevenson, na pesquisa corrente foram utilizadas as populações de empresas dos setores químicos e de mineração do Reino Unido, Alemanha e França e, com base nas demonstrações contábeis destas companhias, mais precisamente os balanços patrimoniais, far-se-ão as ponderações dos grupos patrimoniais que serão demonstrados a seguir para analisar a mudança das características dos padrões contábeis locais em relação às IFRS. 
No Brasil, não há dados disponíveis de empresas brasileiras com normas locais e em IFRS porque as companhias ainda estão se preparando para atender a obrigatoriedade prevista localmente para 2009. Dificuldade de pesquisa semelhante já havia sido experimentada por Klann (2007) em sua pesquisa de empresas brasileiras que fossem listadas em alguma bolsa de valores na Europa, e que ao mesmo tempo possuíssem ADR's na NYSE. Seu trabalho de investigação englobou a Latibex, que é o segmento para companhias da América Latina na Bolsa de Valores de Madri, na Espanha, e a Bolsa de Valores de Frankfurt, na Alemanha. Klann (2007) foi obrigado a utilizar apenas dois grupos de empresas: empresas brasileiras listadas na BOVESPA e empresas européias listadas na Bolsa de Valores de Londres, desde que ambos os grupos possuíssem ações negociadas na NYSE.

Neste estudo foi utilizado o critério de volume de negócios para a escolha das bolsas de valores na Europa onde as IFRS se tornaram obrigatórias a partir de 2005. A partir da eleição deste critério, constatou-se que a bolsa de valores de Londres é a principal da Europa em volume de negócios, seguida pela bolsa de Frankfurt, na Alemanha e da Euronext, na França.

O pesquisador considerou o seguinte critério na decisão da escolha do primeiro setor a ser pesquisado: que fosse um setor da indústria de base, da atividade primária. Assim, dentre os segmentos de empresas comuns às três bolsas de valores, optou-se por pesquisar as empresas do setor de mineração (general mining) dos principais mercados de capitais do bloco econômico europeu segundo o critério exposto acima, ou seja, todas as empresas consideradas do segmento de mineração, que invariavelmente compreende não só o extrativismo mineral, mas também atividades de beneficiamento de determinado minério, como por exemplo as indústrias siderúrgicas, listadas nas bolsas de valores do Reino Unido, Alemanha e França.

O setor químico foi escolhido aleatoriamente entre os outros setores para ser observado o mesmo impacto da adoção das IFRS. Com base em uma relação dos segmentos disponíveis na LSE que são comuns às outras duas bolsas de valores deste estudo (bolsa de valores de Frankfurt e Euronext), utilizou-se a ferramenta Microsoft Excel 2003 e, através da função ALEATORIOENTRE, sorteou-se aquele setor que também seria utilizado para o cálculo das diferenças de médias dos grupos do ativo e do passivo após a adoção das IFRS. O resultado foi o setor das empresas químicas. 
Uma condição adicional que teve que ser observada para a companhia fazer parte da seleção de mineradoras ou químicas foi ter origem nacional. Por exemplo, foram consideradas as empresas de mineração no Reino Unido que têm origem e capital ingleses. O mesmo se aplica para as companhias do setor químico. O objetivo é expurgar as companhias estrangeiras que são negociadas em uma das três bolsas da pesquisa através de ADRs e que, portanto, envolveriam um padrão contábil diferente daqueles que estão propostos para este trabalho: UK-GAAP, GER-GAAP e FRA-GAAP.

Para efeito de interpretação dos resultados do capítulo seis, será considerada diferença significativa aquela que transpuser $5 \%$ de variação positiva ou negativa, na comparação de um grupo patrimonial em norma local, em relação ao mesmo grupo extraído do primeiro ano que a empresa publicou seu balanço em IFRS, tanto para a seleção das companhias mineradoras quanto para as químicas. O percentual de 5\% também foi fixado com base em um critério subjetivo do autor.

\subsection{As empresas de mineração do Reino Unido}

A bolsa londrina foi a principal bolsa de valores do mundo até 1920, quando a bolsa de Nova Iorque assumiu esse título.

$\mathrm{Na}$ bolsa de valores de Londres, os principais índices de preços de títulos são o Financial Times Industrial Ordinary Share Index (FTO), criado na década de 30 do século passado para representar as ações das 30 empresas mais importantes do mercado. Bem mais tarde, em 1984, foi criado o índice Financial Times Stock Exchange (FTSE) que representa as 100 maiores empresas multinacionais presentes na bolsa do Reino Unido.

A primeira seleção de empresas listadas em bolsas de valores da Europa com volume financeiro relevante foi a do Reino Unido. É nesta bolsa que se concentra também o maior número de empresas européias listadas. Em agosto de 2007 elas eram 1.294 empresas divididas em 98 setores. 
Para a certificação da escolha correta do segmento que compreendesse as empresas de mineração na LSE, foi extraída uma listagem disponível no sítio desta bolsa na internet em agosto de 2007.

Corrar (2004, p.20) define amostra como "um subconjunto de uma população que possa representá-la". Para Martins (2002), o estudo de toda a população garante a precisão do conhecimento das variáveis. Mas, como é freqüente a impossibilidade de analisar toda a população devido à limitação de recursos de tempo e custo, a amostragem é, então, justificada.

Entretanto, nesta pesquisa foi analisada a população de empresas do setor de mineração da LSE.

Considera-se, portanto, que o censo das empresas inglesas deste estudo deveriam possuir as seguintes características, concomitantemente:

- $\quad$ ser listada na LSE

- fazer parte do setor classificado como general mining

Do total de nove companhias inglesas constantes do setor de mineração e listadas na Bolsa de Valores de Londres em 15 de agosto de 2007, obteve-se os balanços patrimoniais no ano da transição para as IFRS de todas as companhias. A lista com os nomes das empresas de mineração listadas na LSE encontra-se a seguir:

Quadro no 2 - Empresas de mineração listadas na LSE

\begin{tabular}{|c|}
\hline Empresas \\
\hline Anglesey Mining plc \\
\hline Anglo American plc \\
\hline Anglo Pacific Group plc \\
\hline Antofagasta plc \\
\hline BHP Billiton plc \\
\hline Kazakhmys plc \\
\hline Rio Tinto plc \\
\hline Vedanta Resources plc \\
\hline Xstrata plc \\
\hline
\end{tabular}

FONTE: Bolsa de Valores de Londres 


\subsection{As empresas de mineração da Alemanha}

A bolsa de Frankfurt, na Alemanha, é a segunda da Europa em volume financeiro negociado e é a principal bolsa de valores alemã desde o final da Segunda Guerra Mundial. As ações são negociadas através de um sistema chamado Extra cujo principal índice, o DAX 30, representa a evolução financeira das 30 principais sociedades anônimas do país.

Na bolsa de Frankfurt, em 02 de novembro de 2007, constavam as seguintes empresas de mineração alemãs no setor de recursos básicos:

Quadro no 3 - Empresas de recursos básicos listadas na Bolsa de Frankfurt

\begin{tabular}{|c|}
\hline Empresas \\
\hline Asian Bamboo AG \\
\hline Graphit Kropfmühl AG \\
\hline Norddeutsche Affinerie AG \\
\hline Salzgitter AG \\
\hline Surteco SE \\
\hline
\end{tabular}

FONTE: página na internet da bolsa de valores de Frankfurt

Dentre estas empresas, foram eliminadas a Asian Bamboo AG, por se tratar de uma companhia cuja atividade envolve a extração e o beneficiamento de bambu e a Surteco SE, que é uma empresa relacionada ao setor químico.

Serão analisadas as demonstrações contábeis da Graphit Kropfmühl AG, Norddeutsche Affinerie AG e Salzgitter AG, que são as representantes do setor de mineração e extrativismo mineral de origem alemã.

\section{Quadro no 4 - Empresas de mineração listadas na bolsa de Frankfurt}

\section{Empresas}

Graphit Kropfmühl AG Norddeutsche Affinerie AG

Salzgitter AG

FONTE: página na internet da bolsa de valores de Frankfurt 


\subsection{As empresas de mineração da França}

Os postos seguintes ao inglês e ao alemão eram preenchidos pelas bolsas de Bruxelas e Madrid, que também figuravam no ranking das bolsas mais importantes da Europa. A primeira se fundiu com a bolsa de Paris e a de Amsterdã, formando a Euronext Bruxelas, a primeira bolsa pan-européia para se negociar derivativos e ações ordinárias. Seu principal índice é o BEL 20.

Quadro no 5 - Empresas de recursos básicos listadas na Euronext-Paris

\begin{tabular}{|c|}
\hline Empresas \\
\hline Eramet \\
\hline Euro Ressources \\
\hline Exacompta Clairef. \\
\hline IMS Intl Metal SCE \\
\hline Jacquet Metals \\
\hline Recylex \\
\hline Rocamat \\
\hline Sequana Capital \\
\hline
\end{tabular}

FONTE: página da Euronext na internet

Da relação do quadro $\mathrm{XX}$ acima, foram excluídas da análise desta pesquisa as empresas Exacompta Clairef e Sequana Capital porque na investigação da atividade dessas empresas verificou-se que ambas pertencem ao segmento de papel e celulose.

Portanto, foram utilizadas as seguintes empresas francesas do setor de mineração constantes da Euronext em 02 de novembro de 2007:

Quadro no 6 - Empresas de mineração listadas na Euronext-Paris

\begin{tabular}{|c|}
\hline Empresas \\
\hline Eramet \\
\hline Euro Ressources \\
\hline IMS Intl Metal SCE \\
\hline Jacquet Metals \\
\hline Recylex \\
\hline Rocamat \\
\hline
\end{tabular}

FONTE: página da Euronext na internet 


\subsection{As empresas químicas do Reino Unido, da Alemanha e da França}

A partir do resultado do segundo setor escolhido aleatoriamente, o setor químico, em 13 de janeiro de 2008 foram visitadas as páginas na internet das bolsas de valores de Londres, Frankfurt e de Paris (Euronext) para o reconhecimento das empresas constantes deste segmento.

O resultado da pesquisa pode ser visto a seguir.

Quadro no 7 - Empresas do setor químico na LSE, bolsa de Frankfurt e Euronext

\begin{tabular}{|l|l|l|}
\hline \multicolumn{1}{|c|}{ Reino Unido } & \multicolumn{1}{|c|}{ Alemanha } & \multicolumn{1}{c|}{ França } \\
\hline CRODA INTL & ALTANA AG & AIR LIQUIDE \\
\hline DELTA & BASF SE & APS-AUTOLUBRIFIC \\
\hline ELEMENTIS & BAYER AG & ARKEMA \\
\hline JOHNSON MATTH & FUCHS PETROLUB AG ST & DYNACTION \\
\hline VICTREX & H \& R WASAG AG & ENCRES DUBUIT \\
\hline YULE CATTO \& CO PLC & K+S AKTIENGESELLSCHAFT & EXPLOSIFS PROD. CHI \\
\hline & LANXESS AG & METABOLIC EXPLORER \\
\hline & LINDE AG & ORAPI \\
\hline & PONGS \& ZAHN AG & ORGASYNTH \\
\hline & SGL CARBON AG & PLAST. VAL LOIRE \\
\hline & WACKER CHEMIE AG & PRODUITS CHIM AUX \\
\hline & & RHODIA \\
\hline & & ROBERTET \\
\hline & &
\end{tabular}

As companhias químicas do quadro 08 são o resultado do censo efetuado para este setor na data mencionada anteriormente. Contudo, destas 30 empresas pertencentes às três bolsas de valores, não foram obtidos os balanços em norma local e em IFRS no primeiro ano da publicação das demonstrações em normas internacionais para as seguintes empresas: Pongs \& Zahn AG, na Alemanha; APS-Autolubrific, Explosifs Prod. Chi, Plast. Val Loire, Produits Chim Aux e Robertet, na França, totalizando 6 empresas. 
Quadro n $^{0} 8$ - Empresas do setor químico utilizadas na pesquisa

\begin{tabular}{|l|l|l|}
\hline \multicolumn{1}{|c|}{ Reino Unido } & \multicolumn{1}{|c|}{ Alemanha } & \multicolumn{1}{c|}{ França } \\
\hline CRODA INTL & ALTANA AG & AIR LIQUIDE \\
\hline DELTA & BASF SE & APS-AAIC \\
\hline ELEMENTIS & BAYER AG & ARKEMA \\
\hline JOHNSON MATTH & FUCHS PETROLUB AG ST & DYNACTION \\
\hline VICTREX & H \& R WASAG AG & ENCRES DUBUIT \\
\hline YULE CATTO \& CO PLC & K+S AKTIENGESELLSCHAFT & EXPLOS CHI \\
\hline & LANXESS AG & METABOLIC EXPLORER \\
\hline & LINDE AG & ORAPI \\
\hline & PONGS & ORGASYNTH \\
\hline & SGL CARBON AG & PLAST \\
\hline & WACKER CHEMIE AG & PRODU \\
\hline & & RHODIA \\
\hline & & ROBER \\
\hline
\end{tabular}

Como não foram fornecidos os balanços patrimoniais destas 6 empresas da população de companhias químicas alemãs e francesas, as conclusões obtidas neste capítulo não poderão ser generalizadas para o setor, apenas para o Reino Unido.

A despeito desta ausência, espera-se que o estudo das empresas químicas contribua muito com a pesquisa visto que os resultados possibilitarão a comparação do impacto da adoção das IFRS entre os dois setores.

\subsection{Coleta de dados}

A coleta de dados deste trabalho se deu nos relatórios anuais e nas demonstrações contábeis consolidadas disponíveis nas páginas da internet das empresas constantes da população de empresas de mineração e químicas do Reino Unido, França e Alemanha. Através destes relatórios, foram extraídos os saldos das contas dos grupos circulante e não-circulante segundo os padrões em normas contábeis locais de cada país e em IFRS, no ano em que as empresas publicaram seu primeiro balanço patrimonial utilizando as normas contábeis internacionais, reconciliando a mesma demonstração elaborada em padrão contábil local de cada país. 
Em um primeiro momento, o ano utilizado para a escolha das demonstrações seria apenas aquele referente ao exercício social de 2004 já que 2005 foi o ano estabelecido para que as empresas da União Européia adotassem compulsoriamente os padrões contábeis internacionais.

Uma exigência adicional cooperava para que as demonstrações contábeis do exercício de 2004 fossem as únicas a serem utilizadas: a determinação de que fossem publicadas as demonstrações contábeis comparativas de pelo menos um exercício social.

Assim, esperava-se encontrar as demonstrações contábeis consolidadas de acordo com os princípios contábeis vigentes em cada um dos três países reconciliados com as normas internacionais de contabilidade referentes ao exercício de 2004, divulgadas em 2005.

No entanto, a pesquisa aos relatórios anuais das empresas mineradoras e químicas listadas na LSE, na bolsa de Frankfurt e na Euronext evidenciou uma disparidade quanto ao ano da publicação do primeiro balanço no padrão das normas internacionais de contabilidade: para um total de quarenta e duas empresas do Reino Unido, França e Alemanha, dezoito mineradoras e vinte e quatro químicas, foram utilizadas demonstrações conforme a tabela a seguir:

Quadro no 9 - Número de balanços utilizados na pesquisa (por ano)
\begin{tabular}{|c|c|c|}
\hline Ano & $\begin{array}{c}\text { Número de Balanços das } \\
\text { Mineradoras }\end{array}$ & $\begin{array}{c}\text { Número de Balanços das } \\
\text { Químicas }\end{array}$ \\
\hline 1.999 & 1 & 0 \\
\hline 2.000 & 0 & 1 \\
\hline 2.001 & 1 & 3 \\
\hline 2.002 & 1 & 1 \\
\hline 2.003 & 3 & 5 \\
\hline 2.004 & 10 & 13 \\
\hline 2.005 & 2 & $\mathbf{2 4}$ \\
\hline Total & $\mathbf{1 8}$ & \\
\hline
\end{tabular}

Como o ano para a adoção compulsória das normas internacionais de contabilidade foi 2005 e considerando que houve também a concessão da opção por divulgar as demonstrações contábeis em IFRS no ano de 2004, viu-se que esta última opção foi a seguida pela maioria das empresas dos três países pesquisados, sendo o ano de 2004 representado por vinte e três 
balanços. Contudo, algumas publicaram as demonstrações em IFRS com certo atraso somente em 2005 (3 empresas), com reclassificações comparativamente a 2004. Outras empresas publicaram seus primeiros balanços em IFRS com uma antecipação bastante razoável entre 1.999 e 2.003 (16 empresas) em relação ao ano-exercício em que as IFRS se tornaram compulsórias na EU, em 2.004.

Neste sentido, para efeito deste estudo, foram considerados os primeiros balanços em IFRS aqueles publicados na página da internet de cada uma das companhias mineradoras ou químicas pesquisadas, sendo interpretado como informação confidencial ou gerencial a existência de qualquer outro primeiro balanço em IFRS que não estivesse à disposição publicamente.

A utilização dos balanços das empresas do Reino Unido, Alemanha e França pressupõe o uso das moedas libra esterlina e euro. A seguir são apresentadas as cotações em dólar em relação à cada uma delas em 31 de dezembro do ano correspondente, conforme informação extraída dos balanços patrimoniais e relatórios anuais das empresas pesquisadas.

\section{Quadro no 10 - Cotações do dólar americano para £ 1 libra esterlina}

\begin{tabular}{|c|c|}
\hline Data & US\$ \\
\hline $31 / 12 / 2003$ & 1,7727 \\
\hline $31 / 12 / 2004$ & 1,9257 \\
\hline $31 / 12 / 2005$ & 1,7179 \\
\hline
\end{tabular}

Quadro no 11 - Cotações do dólar americano para EUR 1 euro

\begin{tabular}{|c|c|}
\hline Data & US\$ \\
\hline $31 / 12 / 1999$ & 1,0701 \\
\hline $31 / 12 / 2000$ & 0,9399 \\
\hline $31 / 12 / 2001$ & 0,8813 \\
\hline $31 / 12 / 2002$ & 0,9536 \\
\hline $31 / 12 / 2003$ & 1,2552 \\
\hline $31 / 12 / 2004$ & 1,3620 \\
\hline
\end{tabular}

Como os indicadores que se referem às divisões dos grupos patrimoniais pelo total do grupo são expressos em moeda, eles não sofrem interferência de nenhuma moeda em particular (i.e. euro, libra esterlina, dólar) pois, ao se dividir um pelo outro, se anulam os efeitos. Por 
exemplo, ao dividir o total do ativo circulante de uma empresa do Reino Unido, que é fornecido na moeda libra esterlina, pelo total do ativo desta mesma companhia, que também é fornecido em libra esterlina, a moeda libra dividida pela moeda libra é eliminada da ponderação, restando apenas o resultado que é o indicador AC dividido pelo AT. A única exceção ao quadro que será apresentado a seguir é o CCL, que é sempre fornecido em moeda. Portanto, optou-se por converter os saldos de todas as contas patrimoniais para o dólar apenas para possibilitar a análise comparativa dos números absolutos do CCL .

O principal objetivo da utilização dos relatórios anuais disponíveis no website das empresas de mineração e químicas da UE é reunir as demonstrações contábeis para testar se as ponderações dos grupos de contas circulantes e não-circulantes do ativo e do passivo do balanço, calculados antes da adoção das normas internacionais, são significativamente diferentes dos indicadores calculados depois da adoção das IFRS.

Os relatórios anuais foram acessados via internet nos sites da LSE, da bolsa de Frankfurt e da Euronext entre agosto de 2007 e janeiro de 2008.

Apresenta-se a seguir um quadro com as ponderações dos grupos de contas que serão utilizados para identificar se eles apresentam diferença quando calculados através das demonstrações em normas contábeis locais em relação às demonstrações em normas internacionais, no ano da adoção das IFRS.

Quadro no 12 - Ponderações dos grupos de contas do balanço
\begin{tabular}{|c|}
\hline Ponderações elaboradas \\
\hline Ativo não-circulante / Ativo total \\
\hline Ativo circulante / Ativo total \\
\hline Passivo circulante / Passivo total + patrimônio líquido \\
\hline Capital circulante líquido \\
\hline Passivo não-circulante / Passivo total + patrimônio líquido \\
\hline
\end{tabular}




\subsection{Análise dos dados}

Com a elaboração dos indicadores descritos no quadro 03 e do cálculo do capital circulante líquido, não se pretendeu fazer uma avaliação de desempenho das empresas envolvidas na pesquisa através da qual a análise da situação das empresas é comumente estudada, qual seja, a descoberta da situação financeira (através dos índices financeiros de estrutura e liquidez) ou da situação econômica (através dos índices de rentabilidade) com o grau de profundidade suficiente para embasar determinada tomada de decisão

Embora se tenha preparado os seis indicadores, nenhum deles pode ser classificado como de estrutura, liquidez ou rentabilidade (MATARAZZO, 2007, p.152).

O que se pretendeu com a ponderação de cada sub-grupo das contas do ativo e do passivo (ativo e passivo circulantes; ativo e passivo não-circulantes) pelo seu respectivo grupo (ativo total e passivo total + patrimônio líquido) foi expurgar as diferenças dos números absolutos das contas das empresas em troca de indicadores que fornecessem, ao invés destes números, o peso dos sub-grupos das contas em relação aos seus respectivos blocos de contas principais, tal qual uma análise vertical.

Após a definição dos indicadores e da apresentação dos saldos das contas do balanço patrimonial, fez-se a análise dos dados coletados com a aplicação das técnicas estatísticas de testes de diferença de médias e teste t-student para amostras emparelhadas, com uma abordagem quantitativa e utilizando o programa de análises estatísticas Statistical Package for the Social Sciences (SPSS) 13.0 for Windows.

Maroco (2003, p.111) comenta a utilidade da comparação de parâmetros populacionais dos testes de hipóteses para diferença de médias.

A comparação de parâmetros populacionais (média, variância, mediana, etc.) a partir de amostras aleatórias é uma das necessidades mais freqüentes em análise estatística. Este tipo de inferência estatística é particularmente útil para testar a significância de tratamentos ou fatores que são capazes de influenciar a resposta da variável de medida e, em que se pretende testar se o tratamento teve ou não um efeito significativo.

Quanto ao teste t-student, Maroco (2003, p.122) afirma que: 
O teste t-student serve também para testar se as médias de duas populações são ou não significativamente diferentes. Este teste requer que [...] as variáveis dependentes possuam distribuição normal e variâncias homogêneas.

Por fim, Maroco (2003, p.123) estabelece as variações do teste t-student:

Existem diversas variações deste teste, nomeadamente para amostras independentes e amostras emparelhadas [...] e com variâncias populacionais conhecidas ou não. De uma forma geral, as variâncias populacionais não são conhecidas.

O quadro 04 apresenta a estatística teste para o t-student.

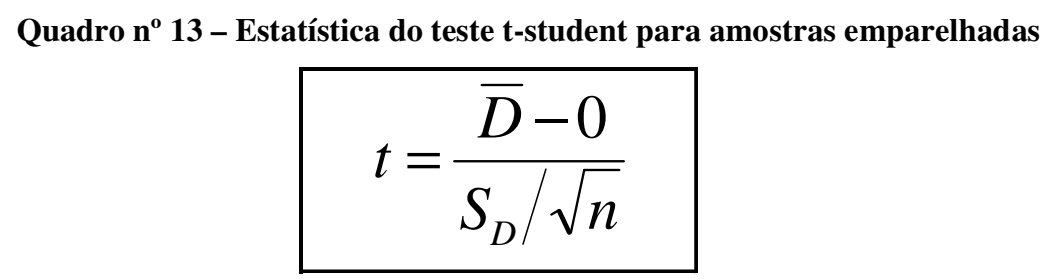

Através dos testes estatísticos, busca-se a ferramenta adequada para responder as questões de pesquisa do trabalho.

\subsection{Limitações da pesquisa}

A principal limitação à pesquisa se refere ao fato de que os resultados obtidos não podem ser generalizados para outras empresas e outros países. Ao considerar as peculiaridades da legislação de cada país e a influência cultural nas normas locais anteriores às IFRS (ambos não são objeto deste estudo), fica compreensível a necessidade de pesquisar o impacto da adoção das IFRS de uma maneira particular, ou seja, país a país.

Uma segunda limitação ao estudo diz respeito à dificuldade de acesso à normatização específica aos setores químicos e de mineração em cada um dos três países pesquisados para descobrir quais as contas ou transações que historicamente são mais polêmicas à cada país e setor, no intuito de verificar se a adoção das IFRS contribuiu para o aperfeiçoamento dos problemas clássicos das normas locais que eram vigentes anteriormente. 
Uma terceira limitação da pesquisa faz referência à ausência de uma análise mais detalhada aos sub-grupos de contas do ativo e passivo que são influenciados por transações nãorecorrentes que pudessem ter ocorrido no balanço referente à primeira adoção.

Apesar dessas limitações, entende-se que a pesquisa contribui com a compreensão de um momento importante na história contábil, o ano em que as empresas européias, as primeiras do mundo, adotaram oficialmente as IFRS.

O presente estudo também contribui para evidenciar, caso haja diferença nos grupos de contas após a adoção das IFRS, se a magnitude das diferenças são similares entre os três países pesquisados, dado o preceito que as IFRS foram promovidas para tornar comparáveis as demonstrações contábeis dos países que as adotarem. 


\section{DESCRIÇÃO E ANÁLISE DOS DADOS DO SETOR DE MINERAÇÃO}

Este capítulo apresenta as características e a análise dos dados empregados na pesquisa para o setor de mineração. Em tópicos separados por país, primeiramente ele traz à luz as demonstrações contábeis utilizadas para as empresas participantes do segmento minerador. Em segundo lugar, aponta o cálculo com a ponderação de cada grupo das contas do ativo e do passivo (ativo e passivo circulantes; ativo e passivo não-circulantes) pelo seu respectivo grupo (ativo total e passivo total + patrimônio líquido), evidenciando os indicadores com as proporções dos grupos das contas em relação aos seus respectivos blocos de contas principais. Por fim, analisa se os resultados dos testes de comparação dos grupos de conta do balanço patrimonial são significativamente diferentes entre as demonstrações em norma local européia e em IFRS.

\subsection{Descrição dos testes}

Para atender os objetivos do capítulo é necessário separar, para cada empresa, a demonstração cujo exercício tenha o primeiro balanço patrimonial em IFRS e seu correspondente par em norma local. O estudo foi segregado por país nos itens 4.1.1 à 4.1.3, país à país, para a aplicação dos testes de normalidade e homogeneidade de variâncias com o intuito de escolher adequadamente os testes de médias. No fim de cada tópico 4.1 serão exibidos individualmente os resultados dos testes de médias das diferenças dos grupos patrimoniais do ativo e do passivo entre a aplicação da norma contábil local e a adoção das IFRS pelo Reino Unido, pela Alemanha e pela França.

\subsubsection{Testes com as empresas do Reino Unido}

A partir da triagem nas nove empresas componentes da amostra do Reino Unido, foram coletados 11 balanços patrimoniais disponíveis em que houvesse a publicação em normas contábeis internacionais e as demonstrações respectivas em UK-GAAP. 
As tabelas 01 e 02 apresentam as companhias analisadas do Reino Unido e evidenciam os saldos dos grupos das contas do ativo e do passivo, respectivamente.

Tabela $n^{0} 1$ - Grupos das contas do ativo das empresas do setor de mineração da LSE (em milhões de dólares)

\begin{tabular}{|c|c|c|c|c|}
\hline Empresas & $\begin{array}{l}\text { Ativo não- } \\
\text { circulante } \\
\text { (em IFRS) }\end{array}$ & $\begin{array}{c}\text { Ativo não- } \\
\text { circulante } \\
\text { (em UK-GAAP) }\end{array}$ & $\begin{array}{c}\text { Ativo circulante } \\
\quad(\mathrm{em} \text { IFRS })\end{array}$ & $\begin{array}{l}\text { Ativo circulante } \\
\text { (em UK-GAAP) }\end{array}$ \\
\hline Anglesey Mining plc (2005) & 9,5678 & 9,3801 & 0,0780 & 0,2657 \\
\hline Anglesey Mining plc (2004) & 10,6107 & 10,4048 & 0,0061 & 0,2120 \\
\hline Anglo American plc (2004) & $41.754,0000$ & $40.476,0000$ & $12.844,0000$ & $11.730,0000$ \\
\hline Anglo Pacific Group plc (2004) & 151,5256 & 136,4089 & 10,7724 & 12,2147 \\
\hline Anglo Pacific Group plc (2003) & 96,9986 & 90,7410 & 4,7757 & 4,7757 \\
\hline Antofagasta plc (2004) & $1.897,1000$ & $1.900,7000$ & $1.302,3000$ & $1.250,6000$ \\
\hline BHP Billiton plc (2005) & $34.807,0000$ & $32.071,0000$ & $7.036,0000$ & $9.877,0000$ \\
\hline Kazakhmys plc (2004) & $1.701,4000$ & $1.590,1000$ & 850,6000 & 850,6000 \\
\hline Rio Tinto plc (2004) & $21.796,0000$ & $20.658,0000$ & $4.512,0000$ & $5.053,0000$ \\
\hline Vedanta Resources plc (2005) & $2.453,5000$ & $2.250,5000$ & $2.124,9000$ & $2.248,1000$ \\
\hline Xstrata plc (2004) & $10.049,0000$ & $10.297,0000$ & $2.237,0000$ & $2.136,0000$ \\
\hline
\end{tabular}


Tabela no 2 - Grupo de contas do passivo das empresas do setor de mineração da LSE (em milhões de dólares)

\begin{tabular}{|c|c|c|c|c|}
\hline Empresas & $\begin{array}{c}\text { Passivo } \\
\text { circulante } \\
\text { (em IFRS) } \\
\end{array}$ & $\begin{array}{c}\text { Passivo } \\
\text { circulante } \\
\text { (em UK- } \\
\end{array}$ & $\begin{array}{c}\text { Passivo não- } \\
\text { circulante } \\
\text { (em IFRS) } \\
\end{array}$ & $\begin{array}{c}\text { Passivo não- } \\
\text { circulante } \\
\text { (em UK-GAAP) } \\
\end{array}$ \\
\hline Anglesey Mining plc (2005) & $(2,8921)$ & $(2,8921)$ & - & - \\
\hline Anglesey Mining plc (2004) & $(2,8057)$ & $(2,8057)$ & - & - \\
\hline Anglo American plc (2004) & $(10.194,0000)$ & $(10.153,0000)$ & $(16.818,0000)$ & $(17.055,0000)$ \\
\hline Anglo Pacific Group plc (2004) & $(1,5983)$ & $(9,5977)$ & $(25,6908)$ & $(0,7125)$ \\
\hline Anglo Pacific Group plc (2003) & $(0,6719)$ & $(4,7189)$ & $(16,2362)$ & $(0,3971)$ \\
\hline Antofagasta plc (2004) & $(404,5000)$ & $(528,4000)$ & $(724,9000)$ & $(711,3000)$ \\
\hline BHP Billiton plc (2005) & $(7.449,0000)$ & $(8.994,0000)$ & $(16.478,0000)$ & $(15.465,0000)$ \\
\hline Kazakhmys plc (2004) & $(318,9000)$ & $(364,6000)$ & $(419,3000)$ & $(209,1000)$ \\
\hline Rio Tinto plc (2004) & $(2.943,0000)$ & $(3.395,0000)$ & $(10.774,0000)$ & $(9.732,0000)$ \\
\hline Vedanta Resources plc (2005) & $(945,5000)$ & $(941,6000)$ & $(1.886,2000)$ & $(2.509,9000)$ \\
\hline Xstrata plc (2004) & $(1.250,0000)$ & $(1.292,0000)$ & $(3.711,0000)$ & $(2.485,0000)$ \\
\hline
\end{tabular}

Tabela no 3 - Demonstrações contábeis em IFRS referentes às empresas de mineração listadas na LSE

\begin{tabular}{|c|c|c|c|c|c|c|}
\hline \multirow{2}{*}{ Empresas } & \multicolumn{2}{|c|}{2005} & \multicolumn{2}{c|}{2004} & \multicolumn{2}{c|}{2003} \\
\cline { 2 - 7 } & IFRS & UK-GAAP & IFRS & UK-GAAP & IFRS & UK-GAAP \\
\hline Anglesey Mining plc & $\mathrm{X}$ & $\mathrm{X}$ & $\mathrm{X}$ & $\mathrm{X}$ & & \\
\hline Anglo American plc & & & $\mathrm{X}$ & $\mathrm{X}$ & & \\
\hline Anglo Pacific Group plc & & & $\mathrm{X}$ & $\mathrm{X}$ & $\mathrm{X}$ & $\mathrm{X}$ \\
\hline Antofagasta plc & & & $\mathrm{X}$ & $\mathrm{X}$ & & \\
\hline BHP Billiton plc & $\mathrm{X}$ & $\mathrm{X}$ & & & & \\
\hline Kazakhmys plc & & & $\mathrm{X}$ & $\mathrm{X}$ & & \\
\hline Rio Tinto plc & & & $\mathrm{X}$ & $\mathrm{X}$ & & \\
\hline Vedanta Resources plc & $\mathrm{X}$ & $\mathrm{X}$ & & & & \\
\hline Xstrata plc & & & $\mathrm{X}$ & $\mathrm{X}$ & & \\
\hline
\end{tabular}

Todavia, conforme a tabela 03, entre as nove empresas da amostra do Reino Unido, duas (BHP Billiton plc e Vedanta Resources plc) não apresentaram as demonstrações consolidadas de 2004 em IFRS sequer nos relatórios anuais de 2006. Outro ponto a ser observado é que as empresas Anglesey Mining plc e Anglo Pacific Group plc publicaram demonstrações conforme as normas inglesas e internacionais em dois anos: em 2004 e 2005 e em 2003 e 2004, respectivamente. 
Diante desta disparidade de ano para a evidenciação da primeira demonstração em IFRS, justificada em grande parte pela concessão para o First Adoption detalhada no capítulo sobre coleta de dados e informações referencias da pesquisa, foi necessário atribuir um critério de escolha que minorasse qualquer possibilidade de efeito negativo para a pesquisa.

Optou-se por utilizar o primeiro conjunto de demonstrações em UK-GAAP e IFRS que tivesse sido publicado pela companhia. Julgou-se que este seria o First Adoption real das empresas e, desta forma, o momento de intervenção ideal para calcular os efeitos nas ponderações já apresentadas.

A tabela 04 demonstra o resultado da escolha.

Tabela no 4 - Demonstrações contábeis em IFRS escolhidas: empresas de mineração listadas na LSE

\begin{tabular}{|c|c|c|c|c|c|c|}
\hline \multirow{2}{*}{ Empresas } & \multicolumn{2}{|c|}{$\mathbf{2 0 0 5}$} & \multicolumn{2}{c|}{ 2004 } & \multicolumn{2}{c|}{ 2003 } \\
\cline { 2 - 7 } & IFRS & UK-GAAP & IFRS & UK-GAAP & IFRS & UK-GAAP \\
\hline Anglesey Mining plc & & & $\mathrm{X}$ & $\mathrm{X}$ & & \\
\hline Anglo American plc & & & $\mathrm{X}$ & $\mathrm{X}$ & & $\mathrm{X}$ \\
\hline Anglo Pacific Group plc & & & & & $\mathrm{X}$ & $\mathrm{X}$ \\
\hline Antofagasta plc & & & $\mathrm{X}$ & $\mathrm{X}$ & & \\
\hline BHP Billiton plc & $\mathrm{X}$ & $\mathrm{X}$ & & & & \\
\hline Kazakhmys plc & & & $\mathrm{X}$ & $\mathrm{X}$ & & \\
\hline Rio Tinto plc & & & $\mathrm{X}$ & $\mathrm{X}$ & & \\
\hline Vedanta Resources plc & $\mathrm{X}$ & $\mathrm{X}$ & & & & \\
\hline Xstrata plc & & & $\mathrm{X}$ & $\mathrm{X}$ & & \\
\hline
\end{tabular}

A partir desta definição, passou-se para a etapa seguinte de cálculo das ponderações em UKGAAP e IFRS para cada empresa.

Conforme descrito na seção de análise de dados, a ponderação dos grupos das contas do ativo e do passivo (ativo e passivo circulantes; ativo e passivo não-circulantes) pelo seu respectivo grupo (ativo total e passivo total + patrimônio líquido) através de indicadores, expurga as grandes diferenças dos saldos das contas das empresas. Estes indicadores fornecem a porcentagem dos grupos das contas em relação aos seus respectivos blocos de contas principais ao invés dos números absolutos, o que confere uma maior adequação com relação ao que se pretende para os testes. 
As tabelas 05 e 06 trazem todos os indicadores das companhias do Reino Unido utilizados na pesquisa.

Tabela $n^{\circ} 5$ - Ponderações referentes aos grupos de contas das empresas do setor de mineração da LSE ( ${ }^{\mathrm{a}}$ parte)

\begin{tabular}{|c|r|r|r|r|r|r|}
\hline Companhias & $\begin{array}{c}\text { Ativo não- } \\
\text { circulante } / \\
\text { Ativo total } \\
\text { (IFRS) }\end{array}$ & $\begin{array}{c}\text { Ativo não- } \\
\text { circulante / } \\
\text { Ativo total } \\
\text { (UK-GAAP) }\end{array}$ & $\begin{array}{c}\text { Ativo } \\
\text { circulante / } \\
\text { Ativo total } \\
\text { (IFRS) }\end{array}$ & $\begin{array}{c}\text { Ativo } \\
\text { circulante / } \\
\text { Ativo total } \\
\text { (UK-GAAP) }\end{array}$ & $\begin{array}{c}\text { Passivo circulante } \\
\text { / Passivo total + } \\
\text { patrimônio } \\
\text { líquido (IFRS) }\end{array}$ & $\begin{array}{c}\text { Passivo circulante } \\
\text { Passivo total + } \\
\text { patrimônio } \\
\text { líquido (UK- } \\
\text { GAAP) }\end{array}$ \\
\hline Anglesey Mining plc & 0,9994 & 0,9800 & 0,0006 & 0,0200 & 0,2643 & 0,2643 \\
\hline Anglo American plc & 0,7648 & 0,7753 & 0,2352 & 0,2246 & 0,1867 & 0,1945 \\
\hline Anglo Pacific Group plc & 0,9531 & 0,9500 & 0,0469 & 0,0500 & 0,0066 & 0,0494 \\
\hline Antofagasta plc & 0,5930 & 0,6031 & 0,4070 & 0,3969 & 0,1264 & 0,1677 \\
\hline BHP Billiton plc & 0,8318 & 0,7645 & 0,1682 & 0,2354 & 0,1780 & 0,2144 \\
\hline Kazakhmys plc & 0,6667 & 0,6515 & 0,3333 & 0,3485 & 0,1250 & 0,1494 \\
\hline Rio Tinto plc & 0,8285 & 0,8035 & 0,1715 & 0,1966 & 0,1119 & 0,1320 \\
\hline Vedanta Resources plc & 0,5359 & 0,5003 & 0,4641 & 0,4997 & 0,2065 & 0,2093 \\
\hline Xstrata plc & 0,8179 & 0,8282 & 0,1821 & 0,1718 & 0,1017 & 0,1039 \\
\hline
\end{tabular}

Tabela $\mathbf{n}^{0} 6$ - Ponderações e capital circulante líquido referentes às empresas do setor de mineração da LSE ( $2^{\mathrm{a}}$ parte)

\begin{tabular}{|c|r|r|r|r|r|r|}
\hline Companhias & $\begin{array}{c}\text { Capital } \\
\text { circulante } \\
\text { líquido } \\
\text { (IFRS) }\end{array}$ & $\begin{array}{c}\text { Capital } \\
\text { circulante } \\
\text { líquido } \\
\text { (UK-GAAP) }\end{array}$ & $\begin{array}{c}\text { Passivo não- } \\
\text { circulante / } \\
\text { Passivo total + } \\
\text { patrimônio líquido } \\
\text { (IFRS) }\end{array}$ & $\begin{array}{c}\text { Passivo não- } \\
\text { circulante / } \\
\text { Passivo total + } \\
\text { patrimônio líquido } \\
\text { (UK-GAAP) }\end{array}$ & $\begin{array}{c}\text { Passivo total / } \\
\text { Passivo total } \\
\text { + patrimônio } \\
\text { líquido } \\
\text { (IFRS) }\end{array}$ & $\begin{array}{c}\text { Passivo total/ } \\
\text { Passivo total } \\
\text { + patrimônio } \\
\text { líquido (UK- } \\
\text { GAAP) }\end{array}$ \\
\hline Anglesey Mining plc & $(2,7996)$ & $(2,5937)$ & - & - & 0,2643 & 0,2643 \\
\hline Anglo American plc & $2.650,0000$ & $1.577,0000$ & 0,3080 & 0,3279 & 0,4947 & 0,5212 \\
\hline Anglo Pacific Group plc & 4,1038 & 0,0567 & 0,1595 & 0,0037 & 0,1661 & 0,0536 \\
\hline Antofagasta plc & 897,8000 & 722,2000 & 0,2266 & 0,2339 & 0,3530 & 0,3934 \\
\hline BHP Billiton plc & $(413,0000)$ & 883,0000 & 0,3938 & 0,3734 & 0,5718 & 0,5831 \\
\hline Kazakhmys plc & 531,7000 & 486,0000 & 0,1643 & 0,0803 & 0,2893 & 0,2351 \\
\hline Rio Tinto plc & $1.569,0000$ & $1.658,0000$ & 0,4095 & 0,3700 & 0,5214 & 0,5106 \\
\hline Vedanta Resources plc & $1.179,4000$ & $1.306,5000$ & 0,4120 & 0,6471 & 0,6185 & 0,7672 \\
\hline Xstrata plc & 987,0000 & 844,0000 & 0,3021 & 0,1825 & 0,4038 & 0,3038 \\
\hline
\end{tabular}

Após escolher as demonstrações contábeis a serem utilizadas no teste e calcular os indicadores dos grupos de contas do ativo e do passivo ponderados pelos seus respectivos blocos de contas principais, foram aplicados os testes estatísticos para atender ao objetivo geral do estudo, qual seja: analisar se os grupos de contas patrimoniais dos balanços em norma local européia e em IFRS possuem diferenças significativas.

Em um primeiro momento, os testes estatísticos compararam o conjunto de indicadores utilizando os balanços em UK-GAAP e em IFRS através da ferramenta teste de hipóteses para 
diferenças de médias. Segundo Gabriel (2003), o objetivo principal desses testes é validar ou rejeitar uma hipótese através dos resultados da amostra.

As decisões envolvendo testes de hipóteses contêm um determinado nível de risco. Foi utilizado um erro tipo I (probabilidade de rejeitar uma hipótese quando ela for verdadeira) a um nível de significância de $5 \%$. Assim, há $95 \%$ de probabilidade da diferença entre as médias dos indicadores não decorrer apenas da variação da amostra quando da rejeição da hipótese nula.

Para testar a normalidade das variáveis quantitativas, foram aplicados os testes de Kolmogorov-Smirnov e Shapiro-Wilk. Foi utilizado o teste de Shapiro-Wilk, em detrimento ao Kolmogorov-Smirnov na interpretação dos resultados dos testes de médias ano-a-ano, pois ele é preferível para amostras de pequena dimensão $(\mathrm{n}<30)$.

O Kolmogorov-Smirnov foi utilizado para o teste com todas as ponderações em UK-GAAP e em IFRS, quando o número de participantes da amostra chegou a 54, incluindo os indicadores do capital circulante líquido, e a $n=45$, excluindo os indicadores do capital circulante líquido.

O teste Kolmogorov-Smirnov, que é gerado com o Shapiro-Wilk, é corrigido conforme o fator Lilliefors e, por isso, é mais forte. Ele deve ser empregado nos testes sem o fator de correção quando as amostras forem aleatórias e representativas concomitantemente.

Para testar a homogeneidade das variâncias (homocedasticidade), foi utilizado o teste de Levene, que é um dos mais potentes para este fim.

Para a tomada de decisão a respeito da aceitação ou rejeição da hipótese nula, procedeu-se à avaliação do "p-value", que representa a área calculada da distribuição depois da estatística teste. $\mathrm{O}$ "p-value" indica a probabilidade de ocorrer valores da estatística mais extremos do que o observado.

A tabela 07 a seguir apresenta o resultado dos testes de normalidade e homogeneidade das variâncias realizados no software Statistical Package of Social Science (SPSS), versão 13.0: 
Tabela $\mathbf{n}^{0} 7$ - Normalidade e homogeneidade dos indicadores dos grupos de contas e CCL das empresas do setor de mineração da LSE

\begin{tabular}{|c|c|c|c|c|c|c|}
\hline Indicadores dos grupos do ativo e do passivo & $P$-value & $\begin{array}{l}\text { Normalidade } \\
\text { Interpretação }\end{array}$ & Geral & $\begin{array}{r}\mathrm{I} \\
P \text {-value }\end{array}$ & $\begin{array}{r}\text { Iomogeneidade } \\
\text { Interpretação }\end{array}$ & Geral \\
\hline $\begin{array}{l}\text { ANC / AT - UK-GAAP } \\
\text { ANC / AT - IFRS } \\
\end{array}$ & $\begin{array}{l}0,836 \\
0,749 \\
\end{array}$ & $\begin{array}{l}\text { Sim } \\
\text { Sim }\end{array}$ & Sim & $\begin{array}{l}0,933 \\
0,933 \\
\end{array}$ & $\begin{array}{l}\text { Sim } \\
\text { Sim }\end{array}$ & Sim \\
\hline $\begin{array}{l}\text { AC / AT - UK-GAAP } \\
\text { AC / AT - IFRS }\end{array}$ & $\begin{array}{l}0,836 \\
0,749 \\
\end{array}$ & $\begin{array}{l}\text { Sim } \\
\text { Sim }\end{array}$ & Sim & $\begin{array}{l}0,933 \\
0,933 \\
\end{array}$ & $\begin{array}{l}\text { Sim } \\
\text { Sim }\end{array}$ & Sim \\
\hline $\begin{array}{l}\mathrm{PC} / \mathrm{PT}+\mathrm{PL} \text { - UK-GAAP } \\
\mathrm{PC} / \mathrm{PT}+\mathrm{PL} \text { - IFRS }\end{array}$ & $\begin{array}{l}0,988 \\
0,863\end{array}$ & $\begin{array}{l}\mathrm{Sim} \\
\mathrm{Sim}\end{array}$ & Sim & $\begin{array}{l}0,735 \\
0,735 \\
\end{array}$ & $\begin{array}{l}\text { Sim } \\
\text { Sim }\end{array}$ & Sim \\
\hline $\begin{array}{l}\text { CCL - UK-GAAP } \\
\text { CCL - IFRS } \\
\end{array}$ & $\begin{array}{l}0,486 \\
0,744 \\
\end{array}$ & $\begin{array}{l}\text { Sim } \\
\text { Sim }\end{array}$ & Sim & $\begin{array}{l}0,307 \\
0,307 \\
\end{array}$ & $\begin{array}{l}\text { Sim } \\
\text { Sim }\end{array}$ & Sim \\
\hline $\begin{array}{l}\mathrm{PNC} / \mathrm{PT}+\mathrm{PL} \text { - UK-GAAP } \\
\mathrm{PNC} / \mathrm{PT}+\mathrm{PL} \text { - IFRS } \\
\end{array}$ & $\begin{array}{l}0,529 \\
0,349 \\
\end{array}$ & $\begin{array}{l}\text { Sim } \\
\text { Sim } \\
\end{array}$ & Sim & $\begin{array}{l}0,291 \\
0,291 \\
\end{array}$ & $\begin{array}{l}\text { Sim } \\
\text { Sim } \\
\end{array}$ & Sim \\
\hline $\begin{array}{l}\mathrm{PT} / \mathrm{PT}+\mathrm{PL} \text { - UK-GAAP } \\
\mathrm{PT} / \mathrm{PT}+\mathrm{PL} \text { - IFRS }\end{array}$ & $\begin{array}{l}0,982 \\
0,839 \\
\end{array}$ & $\begin{array}{l}\text { Sim } \\
\text { Sim } \\
\end{array}$ & Sim & $\begin{array}{l}0,352 \\
0,352 \\
\end{array}$ & $\begin{array}{l}\text { Sim } \\
\text { Sim }\end{array}$ & Sim \\
\hline
\end{tabular}

Ao analisar a tabela 07, constata-se que o teste de Shapiro-Wilk empregado para todas as ponderações apresentou "p-values" maiores que o nível de significância de 0,05. Ao mesmo tempo, estes mesmos indicadores agrupados e testados por Kolmogorov-Smirnov apresentaram "p-values" menores do que 0,05 para a verificação da normalidade de todas as empresas e serão descartados para a próxima etapa de testes estatísticos pelo baixo poder de aderência à distribuição normal.

Portanto, se aceita a hipótese de que as ponderações dos grupos de contas do ativo e passivo das empresas da LSE seguem uma distribuição normal.

Com base nessas informações, aplicar-se-á o teste de médias paramétrico para amostras emparelhadas denominado t-student.

O teste paramétrico t-student foi realizado para cada ponderação dos grupos de contas, comparando a média da ponderação na primeira adoção das IFRS com a média do mesmo indicador calculado através das demonstrações apresentadas em UK-GAAP, considerando nível de confiança de $95 \%$. 
Com isso, se obteve os seguintes resultados:

Tabela $n^{\circ} 8$ - Resultado do t-student para as ponderações dos grupos de contas do balanço

\begin{tabular}{|c|c|c|c|c|}
\hline $\begin{array}{c}\text { Indicadores dos grupos } \\
\text { do ativo e do passivo } \\
\end{array}$ & \multicolumn{2}{|c|}{ Resultado das médias (Sig de 5\%) } & \multicolumn{2}{|c|}{ Resultado do t-student } \\
\hline \begin{tabular}{|l} 
ANC / AT - UK-GAAP \\
ANC / AT - IFRS
\end{tabular} & $\begin{array}{l}0,761830 \\
0,776784 \\
\end{array}$ & Sim & 0,121 & Sim \\
\hline $\begin{array}{l}\mathrm{AC} / \mathrm{AT} \text { - UK-GAAP } \\
\mathrm{AC} \text { / AT - IFRS }\end{array}$ & $\begin{array}{l}0,238170 \\
0,223216\end{array}$ & Sim & 0,121 & Sim \\
\hline $\begin{array}{l}\mathrm{PC} / \mathrm{PT}+\mathrm{PL} \text { - UK-GAAP } \\
\mathrm{PC} / \mathrm{PT}+\mathrm{PL} \text { - IFRS }\end{array}$ & $\begin{array}{l}0,164989 \\
0,145236 \\
\end{array}$ & Não & 0,009 & Não \\
\hline $\begin{array}{l}\text { CCL - UK-GAAP } \\
\text { CCL - IFRS } \\
\end{array}$ & $\begin{array}{l}830,4626 \\
822,5782 \\
\end{array}$ & Sim & 0,970 & Sim \\
\hline $\begin{array}{l}\mathrm{PNC} / \mathrm{PT}+\mathrm{PL} \text { - UK-GAAP } \\
\mathrm{PNC} / \mathrm{PT}+\mathrm{PL} \text { - IFRS }\end{array}$ & $\begin{array}{l}0,246532 \\
0,263979 \\
\end{array}$ & Sim & 0,653 & Sim \\
\hline $\begin{array}{l}\text { PT / PT + PL - UK-GAAP } \\
\text { PT / PT + PL - IFRS }\end{array}$ & $\begin{array}{l}0,403568 \\
0,409214\end{array}$ & Sim & 0,836 & Sim \\
\hline
\end{tabular}

A hipótese que os grupos de contas contábeis do balanço de empresas listadas nas bolsas de valores de Londres calculados através das demonstrações em normas contábeis locais são significativamente diferentes em relação aos grupos de contas calculados a partir das demonstrações em normas internacionais, no ano da adoção das IFRS, foi testada pela significância estatística da diferença entre as médias das ponderações das companhias de mineração da LSE.

Para todas as ponderações, exceto aquela que relaciona o passivo circulante ao passivo total mais o patrimônio líquido, o intervalo de confiança contém o " $p$-value" maior do que 0,05 .

Portanto, exceção feita ao passivo circulante dos balanços das mineradoras inglesas, não há evidências para rejeitar a hipótese de que as médias das diferenças entre as ponderações dos grupos de contas patrimoniais das empresas de mineração listadas na LSE, calculadas através das demonstrações em normas contábeis locais e em normas internacionais, no ano da adoção das IFRS, não são significativas. Ou seja, está estatisticamente comprovado que as diferenças entre as ponderações dos grupos circulantes e não-circulantes dos balanços das mineradoras inglesas, tanto em UK-GAAP quanto em IFRS, têm que ser levadas em consideração para a 
grande maioria dos grupos de contas de um balanço patrimonial extraído de uma empresa de mineração inglesa quando a análise pretendida envolver as proporções destes grupos em relação ao ativo ou passivo totais.

\subsubsection{Testes com as empresas da Alemanha}

Da mesma forma com que foi iniciada a descrição dos dados das companhias inglesas, o tópico dos testes com as empresas de mineração alemãs começa com a apresentação dos saldos dos grupos patrimoniais recolhidos do último balanço patrimonial publicado em norma local e o primeiro em IFRS, ambos referentes ao mesmo exercício fiscal.

Através da pesquisa aos balanços patrimoniais das mineradoras alemãs, foram extraídos os seguintes saldos dos grupos patrimoniais já convertidos pela taxa de câmbio do euro para dólares americanos no último dia do ano correspondente à demonstração (i.e. 31/12/2000):

Tabela no 9 - Grupos do ativo das mineradoras alemãs na bolsa de Frankfurt (em milhões de dólares)

\begin{tabular}{|c|c|r|r|r|}
\hline Empresas & $\begin{array}{c}\text { Ativo não- } \\
\text { circulante } \\
\text { (em IFRS) }\end{array}$ & $\begin{array}{c}\text { Ativo não- } \\
\text { circulante } \\
\text { (em DE-GAAP) }\end{array}$ & $\begin{array}{c}\text { Ativo circulante } \\
\text { (em IFRS) }\end{array}$ & $\begin{array}{l}\text { Ativo circulante } \\
\text { (em DE-GAAP) }\end{array}$ \\
\hline & & & & \\
\hline GRAPHIT KROPFMÜHL AG & 46,7780 & 39,1165 & 32,5341 & 32,5341 \\
\hline NORDDEUTSCHE AFFINERII & 442,9300 & 324,6226 & 466,8740 & 460,4820 \\
\hline & & & & $1.085,1199$ \\
\hline SALZGITTER AG & $1.259,8972$ & 724,0232 & $1.103,0987$ & \\
\hline
\end{tabular}

Tabela $\mathbf{n}^{0} 10$ - Grupos de contas do passivo das mineradoras alemãs na bolsa de Frankfurt (em milhões de dólares)

\begin{tabular}{|c|c|c|c|r|}
\hline Empresas & $\begin{array}{c}\text { Passivo } \\
\text { circulante } \\
\text { (em IFRS) }\end{array}$ & $\begin{array}{c}\text { Passivo } \\
\text { circulante } \\
\text { (em DE-GAAP) }\end{array}$ & $\begin{array}{c}\text { Passivo não- } \\
\text { circulante } \\
\text { (em IFRS) }\end{array}$ & $\begin{array}{c}\text { Passivo não- } \\
\text { circulante } \\
\text { (em DE-GAAP) }\end{array}$ \\
\hline & & & & \\
\hline GRAPHIT KROPFMÜHL AG & $(40,3976)$ & $(38,1929)$ & $(16,2330)$ & $(14,5798)$ \\
\hline NORDDEUTSCHE AFFINERII & $(263,8468)$ & $(363,0803)$ & $(268,2849)$ & $(159,4486)$ \\
\hline SALZGITTER AG & & & & $(844,8728)$ \\
\hline
\end{tabular}


Os primeiros conjuntos de demonstrações publicados ao mesmo tempo em norma contábil local e em IFRS, que foram considerados no estudo foram: em 1999, o balanço da Salzgitter AG; em 2001, o da Graphit Kropfmühl e em 2002, da Norddeutsche Affinerie AG.

O passo seguinte foi o cálculo da ponderação dos grupos de contas do ativo e do passivo (ativo e passivo circulantes; ativo e passivo não-circulantes) pelo seu respectivo grupo (ativo total e passivo total + patrimônio líquido) para obter os indicadores da porcentagem dos grupos de contas em relação aos seus respectivos blocos de contas principais.

As tabelas 11 e 12 trazem todas ponderações das companhias mineradoras alemãs a serem utilizadas na pesquisa.

Tabela no 11 - Ponderações das empresas alemãs do setor de mineração da Bolsa de Frankfurt $\left(1^{\mathrm{a}}\right.$ parte $)$

\begin{tabular}{|l|r|r|r|r|r|r|}
\hline \multicolumn{1}{|c|}{ Empresas } & $\begin{array}{c}\text { Ativo não- } \\
\text { circulante / } \\
\text { Ativo total } \\
\text { (IFRS) }\end{array}$ & $\begin{array}{c}\text { Ativo não- } \\
\text { circulante / } \\
\text { Ativo total } \\
\text { (DE-GAAP) }\end{array}$ & $\begin{array}{c}\text { Ativo } \\
\text { circulante / } \\
\text { Ativo total } \\
\text { (IFRS) }\end{array}$ & $\begin{array}{c}\text { Ativo } \\
\text { circulante / } \\
\text { Ativo total } \\
\text { (DE-GAAP) }\end{array}$ & $\begin{array}{c}\text { Passivo circulante } \\
\text { / Passivo total + } \\
\text { patrimônio } \\
\text { líquido (IFRS) }\end{array}$ & $\begin{array}{c}\text { Passivo circulante } \\
\text { / Passivo total + } \\
\text { patrimônio } \\
\text { líquido (DE- } \\
\text { GAAP) }\end{array}$ \\
\hline GRAPHIT KROPFMÜHL AG & 0,5898 & 0,5459 & 0,4102 & 0,4541 & 0,5093 & 0,5330 \\
\hline NORDDEUTSCHE AFFINERIE AG & 0,4868 & 0,4135 & 0,5132 & 0,5865 & 0,2900 & 0,4625 \\
\hline SALZGITTER AG & 0,5332 & 0,4002 & 0,4668 & 0,5998 & 0,2088 & 0,1505 \\
\hline
\end{tabular}

Tabela $n^{0} 12$ - Ponderações das empresas alemãs do setor de mineração da Bolsa de Frankfurt (2a parte)

\begin{tabular}{|l|c|c|c|c|c|c|}
\hline \multirow{2}{*}{ Empresas } & $\begin{array}{c}\text { Capital } \\
\text { circulante } \\
\text { líquido } \\
\text { (IFRS) }\end{array}$ & $\begin{array}{c}\text { Capital } \\
\text { circulante } \\
\text { líquido } \\
\text { (DE-GAAP) }\end{array}$ & $\begin{array}{c}\text { Passivo não- } \\
\text { circulante / } \\
\text { Passivo total + } \\
\text { patrimônio líquido } \\
\text { (IFRS) }\end{array}$ & $\begin{array}{c}\text { Passivo não- } \\
\text { circulante / } \\
\text { Passivo total + } \\
\text { patrimônio líquido } \\
\text { (DE-GAAP) }\end{array}$ & $\begin{array}{c}\text { Passivo total / } \\
\text { Passivo total } \\
\text { + patrimônio } \\
\text { líquido } \\
\text { (IFRS) }\end{array}$ & $\begin{array}{c}\text { Passivo total / } \\
\text { Passivo total + } \\
\text { patrimônio } \\
\text { líquido (DE- } \\
\text { GAAP) }\end{array}$ \\
\hline GRAPHIT KROPFMÜHL AG & $(7,8635)$ & $(5,6587)$ & 0,2047 & 0,2035 & 0,7140 & 0,7365 \\
\hline NORDDEUTSCHE AFFINERIE AG & 203,0272 & 97,4017 & 0,2949 & 0,2031 & 0,5849 & 0,6656 \\
\hline SALZGITTER AG & 609,7826 & 812,8383 & 0,3836 & 0,4670 & 0,5923 & 0,6175 \\
\hline
\end{tabular}

Há de se ressaltar que as ponderações ilustradas pelas tabelas 11 e 12 têm um conteúdo informacional bastante relevante se consideradas isoladamente. Significa dizer que a ponderação do ativo circulante pelo ativo total da companhia Graphit Kropfmühl AG em IFRS e em DE-GAAP fornece com razoável clareza o peso do grupo ativo circulante dentro do ativo total da companhia e a diferença desta participação entre os padrões contábeis. 
A mesma clareza não é tão fácil de ser observada quando se pretende comparar as variações das ponderações em mais companhias. Neste caso, os testes estatísticos, mais precisamente os testes de diferenças de médias e o teste t-student para amostras emparelhadas apresentados no tópico 3.4, são altamente recomendados para analisar se as ponderações dos grupos do balanço possuem diferenças significativas em norma local européia e em IFRS, para um conjunto de empresas analisadas ao mesmo tempo.

A tabela 13 demonstra o resultado dos testes de normalidade de variâncias realizados através do SPSS:

Tabela $\mathbf{n}^{0} 13$ - Normalidade das ponderações dos grupos de contas das mineradoras alemãs listadas na bolsa de Frankfurt

\begin{tabular}{|c|c|c|c|}
\hline Ponderações dos grupos do ativo e do passivo & $P$ P-value & $\begin{array}{l}\text { alid: } \\
\text { rpret }\end{array}$ & Geral \\
\hline $\begin{array}{l}\text { ANC / AT - GER-GAAP } \\
\text { ANC / AT - IFRS } \\
\end{array}$ & $\begin{array}{l}0,157 \\
0,890 \\
\end{array}$ & $\begin{array}{l}\text { Sim } \\
\text { Sim }\end{array}$ & $\operatorname{Sim}$ \\
\hline $\begin{array}{l}\mathrm{AC} / \mathrm{AT} \text { - GER-GAAP } \\
\mathrm{AC} / \mathrm{AT} \text { - IFRS }\end{array}$ & $\begin{array}{l}0,157 \\
0,890\end{array}$ & $\begin{array}{l}\text { Sim } \\
\text { Sim }\end{array}$ & Sim \\
\hline $\begin{array}{l}\mathrm{PC} / \mathrm{PT}+\mathrm{PL} \text { - GER-GAAP } \\
\mathrm{PC} / \mathrm{PT}+\mathrm{PL} \text { - IFRS }\end{array}$ & $\begin{array}{l}0,333 \\
0,505\end{array}$ & $\begin{array}{l}\text { Sim } \\
\text { Sim }\end{array}$ & Sim \\
\hline $\begin{array}{l}\text { CCL - GER-GAAP } \\
\text { CCL - IFRS } \\
\end{array}$ & $\begin{array}{l}0,221 \\
0,654\end{array}$ & $\begin{array}{l}\mathrm{Sim} \\
\mathrm{Sim}\end{array}$ & Sim \\
\hline $\begin{array}{l}\text { PNC / PT + PL - GER-GAAP } \\
\text { PNC / PT + PL - IFRS }\end{array}$ & $\begin{array}{l}0,002 \\
0,991 \\
\end{array}$ & $\begin{array}{l}\text { Não } \\
\text { Sim } \\
\end{array}$ & Não \\
\hline $\begin{array}{l}\text { PT / PT + PL - GER-GAAP } \\
\text { PT / PT + PL - IFRS }\end{array}$ & $\begin{array}{l}0,788 \\
0,098\end{array}$ & $\begin{array}{l}\text { Sim } \\
\text { Sim }\end{array}$ & Sim \\
\hline
\end{tabular}

Novamente foram considerados os resultados da normalidade obtidos a um nível de significância de 5\% através do teste de Shapiro-Wilk, dado que ele é preferível para amostras de pequena dimensão $(\mathrm{n}<30)$.

Os $p$-values obtidos ( $\mathrm{p}>5 \%$ ) justificariam o uso de um teste paramétrico, exceto para a ponderação do passivo não-circulante em relação à soma do passivo total mais patrimônio líquido. E o teste mais indicado seria o teste t-student. 
Entretanto, como o relatório de saída do SPSS não imprimiu o resultado dos testes de homogeneidade das variâncias e esta é uma das três condições para a utilização de testes paramétricos ao lado da necessidade de ter variáveis com distribuição normal e ser variáveis dependentes quantitativas, devido ao baixo número de participantes da população de mineradoras alemãs, procedeu-se ao teste não-paramétrico.

Portanto, não foi possível aceitar que a ponderação dos grupos de contas do ativo e passivo das empresas da Bolsa de Frankfurt segue uma distribuição normal.

Entre as opções de testes não-paramétricos, o mais apropriado e o escolhido para o teste das ponderações foi o teste de Wilcoxon. O teste de Wilcoxon para uma mediana populacional é o teste não paramétrico a usar, em alternativa ao teste t-student, quando se pretende comparar a medida de tendência central da população sob estudo com um determinado valor teórico.

Tabela no 14 - Resultado da aplicação do teste de Wilcoxon na ponderação dos grupos de contas do balanço

\begin{tabular}{|c|c|c|c|c|}
\hline $\begin{array}{c}\text { Ponderação dos grupos } \\
\text { do ativo e do passivo }\end{array}$ & \multicolumn{2}{|c|}{$\begin{array}{l}\text { Resultado das médias (Sig de 5\%) } \\
\text { Mean Rank } \quad \text { Geral }\end{array}$} & $\begin{array}{r}\text { Resultado } \\
P \text {-value }\end{array}$ & $\begin{array}{l}\text {-paramétrico } \\
\text { Aceita Ho? }\end{array}$ \\
\hline $\begin{array}{l}\text { ANC / AT - GER-GAAP } \\
\text { ANC / AT - IFRS }\end{array}$ & $\begin{array}{l}0,453204 \\
0,536605\end{array}$ & Sim & 0,109 & Sim \\
\hline $\begin{array}{l}\text { AC / AT - GER-GAAP } \\
\text { AC / AT - IFRS } \\
\end{array}$ & $\begin{array}{l}0,546796 \\
0,463395 \\
\end{array}$ & Sim & 0,109 & Sim \\
\hline $\begin{array}{l}\text { PC / PT + PL - GER-GAAP } \\
\text { PC / PT + PL - IFRS }\end{array}$ & $\begin{array}{l}0,382002 \\
0,336040\end{array}$ & Sim & 0,593 & Sim \\
\hline $\begin{array}{l}\text { CCL - GER-GAAP } \\
\text { CCL - IFRS }\end{array}$ & $\begin{array}{l}301,5271 \\
268,3154 \\
\end{array}$ & Sim & 0,593 & Sim \\
\hline $\begin{array}{l}\mathrm{PNC} / \mathrm{PT}+\mathrm{PL} \text { - GER-GAAP } \\
\mathrm{PNC} / \mathrm{PT}+\mathrm{PL} \text { - IFRS }\end{array}$ & $\begin{array}{l}0,291193 \\
0,294375\end{array}$ & Sim & 0,593 & Sim \\
\hline $\begin{array}{l}\text { PT / PT + PL - GER-GAAP } \\
\text { PT / PT + PL - IFRS }\end{array}$ & $\begin{array}{l}0,673195 \\
0,630415\end{array}$ & Sim & 0,109 & Sim \\
\hline
\end{tabular}

O teste não-paramétrico de Wilcoxon foi realizado para cada ponderação de grupos de contas, comparando a média obtida através dos balanços em IFRS com a média da mesma 
ponderação calculada através das demonstrações apresentadas em GER-GAAP, considerando nível de confiança de $95 \%$.

Com base na tabela 14, não é possível rejeitar a hipótese de que as médias das diferenças entre as ponderações dos grupos de contas patrimoniais das empresas de mineração listadas na bolsa de valores de Frankfurt, calculadas através do balanço em normas contábeis locais e em normas internacionais, no ano em que cada empresa publicou as primeiras demonstrações contábeis em IFRS, não são significativas.

Comprovou-se que as diferenças entre as ponderações dos grupos circulantes e nãocirculantes dos balanços das mineradoras alemãs, tanto em GER-GAAP quanto em IFRS, também têm que ser levadas em consideração quando a análise pretendida envolver as proporções dos grupos patrimoniais do ativo e do passivo em relação ao ativo ou passivo totais.

\subsubsection{Testes com as empresas da França}

Através da pesquisa aos últimos balanços patrimoniais em FR-GAAP e aos primeiros balanços publicados em IFRS para cada uma das mineradoras francesas, foram extraídos os saldos dos grupos patrimoniais já convertidos pela taxa de câmbio do euro para dólares americanos no último dia do ano correspondente à demonstração: 
Tabela 15 - Sub-grupos do ativo das empresas francesas do setor de mineração na Euronext (em milhões de dólares)

\begin{tabular}{|c|c|c|c|c|}
\hline Empresas & $\begin{array}{l}\text { Ativo não- } \\
\text { circulante } \\
\text { (em IFRS) } \\
\end{array}$ & $\begin{array}{c}\text { Ativo não- } \\
\text { circulante } \\
\text { (em FR-GAAP) }\end{array}$ & $\begin{array}{l}\text { Ativo circulante } \\
\quad(\mathrm{em} \text { IFRS })\end{array}$ & $\begin{array}{l}\text { Ativo circulante } \\
\text { (em FR-GAAP) }\end{array}$ \\
\hline ERAMET & 1838,7000 & 1563,5760 & 2176,4760 & 2171,0280 \\
\hline EURO RESSOURCES & 24,2490 & 18,4837 & 4,1405 & 0,7736 \\
\hline IMS INTL METAL SCE & 169,1972 & 133,9445 & 537,2123 & 504,9506 \\
\hline JACQUET METALS & 29,4608 & 26,1458 & 59,3333 & 59,3333 \\
\hline RECYLEX & 106,9851 & 100,1206 & 80,5868 & 80,7775 \\
\hline ROCAMAT & 23,2388 & 15,2984 & 52,8991 & 51,2850 \\
\hline
\end{tabular}

Tabela 16 - Sub-grupos do passivo das empresas francesas do setor de mineração na Euronext (em milhões de dólares)

\begin{tabular}{|c|c|c|c|c|}
\hline Empresas & $\begin{array}{c}\text { Passivo } \\
\text { circulante } \\
\text { (em IFRS) } \\
\end{array}$ & $\begin{array}{c}\text { Passivo } \\
\text { circulante } \\
(\text { em FR-GAAP }) \\
\end{array}$ & $\begin{array}{c}\text { Passivo não- } \\
\text { circulante } \\
\text { (em IFRS) }\end{array}$ & $\begin{array}{c}\text { Passivo não- } \\
\text { circulante } \\
\text { (em FR-GAAP) } \\
\end{array}$ \\
\hline ERAMET & $(1101,8580)$ & $(1186,3020)$ & $(867,5940)$ & $(536,6280)$ \\
\hline EURO RESSOURCES & $(4,6635)$ & $(17,7332)$ & $(24,2504)$ & $(1,6153)$ \\
\hline IMS INTL METAL SCE & $(311,7032)$ & $(249,0866)$ & $(136,2518)$ & $(152,6121)$ \\
\hline JACQUET METALS & $(38,3677)$ & $(38,3677)$ & $(18,4326)$ & $(17,3393)$ \\
\hline RECYLEX & $(136,5242)$ & $(128,6995)$ & $(88,6894)$ & $(75,4357)$ \\
\hline ROCAMAT & $(34,3699)$ & $(20,6292)$ & $(15,1628)$ & $(22,9564)$ \\
\hline
\end{tabular}

$\mathrm{Na}$ pesquisa aos saldos patrimoniais circulantes e não-circulantes das companhias francesas, foram utilizados os balanços patrimoniais referentes ao encerramento em 31/12/2004 para as seis companhias constantes das tabelas 15 e 16, exceto para as empresas Jacquet Metals e Rocamat, para as quais o ano da publicação do primeiro conjunto de demonstrações contábeis em IFRS foi em 2003. 
As tabelas 17 e 18 sintetizam a ponderação dos grupos de contas do ativo e do passivo circulantes e não-circulantes pelo seu respectivo grupo do ativo ou passivo total, para as companhias mineradoras francesas.

Tabela 17 - Ponderações referentes aos grupos de contas das empresas francesas do setor de mineração da Euronext (1 $1^{\mathrm{a}}$ parte)

\begin{tabular}{|l|r|r|r|r|r|r|}
\hline Empresas & $\begin{array}{c}\text { Ativo não- } \\
\text { circulante / } \\
\text { Ativo total } \\
\text { (IFRS) }\end{array}$ & $\begin{array}{c}\text { Ativo não- } \\
\text { circulante / } \\
\text { Ativo total } \\
\text { (FR-GAAP) }\end{array}$ & $\begin{array}{c}\text { Ativo } \\
\text { circulante / } \\
\text { Ativo total } \\
\text { (IFRS) }\end{array}$ & $\begin{array}{c}\text { Ativo } \\
\text { circulante / } \\
\text { Ativo total } \\
\text { (FR-GAAP) }\end{array}$ & $\begin{array}{c}\text { Passivo circulante } \\
/ \text { Passivo total + } \\
\text { patrimônio } \\
\text { líquido (IFRS) }\end{array}$ & $\begin{array}{c}\text { Passivo circulante } \\
/ \text { Passivo total + } \\
\text { patrimônio } \\
\text { líquido (FR- } \\
\text { GAAP) }\end{array}$ \\
\hline ERAMET & 0,4579 & 0,4187 & 0,5421 & 0,5813 & 0,2744 & 0,3177 \\
\hline EURO RESSOURCES & 0,8542 & 0,9598 & 0,1458 & 0,0402 & 0,1584 & 0,9122 \\
\hline IMS INTL METAL SCE & 0,2395 & 0,2097 & 0,7605 & 0,7903 & 0,4413 & 0,3899 \\
\hline JACQUET METALS & 0,3318 & 0,3059 & 0,6682 & 0,6941 & 0,4321 & 0,5194 \\
\hline RECYLEX & 0,5704 & 0,5535 & 0,4296 & 0,4465 & 0,4589 \\
\hline ROCAMAT & 0,3052 & 0,2298 & 0,6948 & 0,7702 & 0,5660 \\
\hline
\end{tabular}

Tabela 18 - Ponderações e capital circulante líquido referentes aos grupos de contas das empresas francesas do setor de mineração da Euronext ( $2^{\mathrm{a}}$ parte)

\begin{tabular}{|l|r|r|r|r|r|r|}
\hline \multicolumn{1}{|c|}{ Empresas } & $\begin{array}{c}\text { Capital } \\
\text { circulante } \\
\text { líquido } \\
\text { (IFRS) }\end{array}$ & $\begin{array}{c}\text { Capital } \\
\text { circulante } \\
\text { líquido } \\
\text { (FR-GAAP) }\end{array}$ & $\begin{array}{c}\text { Passivo não- } \\
\text { circulante / } \\
\text { Passivo total + } \\
\text { patrimônio líquido } \\
\text { (IFRS) }\end{array}$ & $\begin{array}{c}\text { Passivo não- } \\
\text { circulante / } \\
\text { Passivo total + } \\
\text { patrimônio líquido } \\
\text { (FR-GAAP) }\end{array}$ & $\begin{array}{c}\text { Passivo total / } \\
\text { Passivo total } \\
\text { + patrimônio } \\
\text { líquido } \\
\text { (IFRS) }\end{array}$ & $\begin{array}{c}\text { Passivo total / } \\
\text { Passivo total + } \\
\text { patrimônio } \\
\text { líquido (FR- } \\
\text { GAAP) }\end{array}$ \\
\hline ERAMET & 1074,6180 & 984,7260 & 0,2161 & 0,1437 & 0,4905 & 0,4613 \\
\hline EURO RESSOURCES & $(0,5230)$ & $(16,9596)$ & 0,8238 & 0,0831 & 0,9822 & 0,9953 \\
\hline IMS INTL METAL SCE & 225,5091 & 255,8640 & 0,1929 & 0,2389 & 0,6341 & 0,6287 \\
\hline JACQUET METALS & 20,9656 & 20,9656 & 0,2076 & 0,2028 & 0,6397 & 0,6517 \\
\hline RECYLEX & $(55,9373)$ & $(47,9220)$ & 0,3374 & 0,3318 & 0,8568 & \\
\hline ROCAMAT & 18,5293 & 30,6557 & 0,1991 & 0,3448 & 0,6506 & 0,8978 \\
\hline
\end{tabular}

Sobre as ponderações destacadas nas tabelas 17 e 18, serão aplicadas técnicas estatísticas para a identificação da presença ou não da distribuição normal para, enfim, proceder a escolha do teste de médias adequado para cada uma das ponderações.

A tabela 19 traz um resumo dos resultados dos testes de normalidade e homogeneidade de variâncias realizados através do SPSS utilizando o teste de Shapiro-Wilk, para identificar se as ponderações obtidas nas tabelas 17 e 18 seguem uma distribuição normal: 
Tabela 19 - Normalidade e Homogeneidade das ponderações dos grupos de contas patrimoniais e do capital circulante líquido das empresas francesas do setor de mineração da Euronext

\begin{tabular}{|c|c|c|c|c|c|c|}
\hline Ponderações dos grupos do ativo e passivo & P-value & $\begin{array}{l}\text { Normalidade } \\
\text { Interpretação }\end{array}$ & Geral & $\begin{array}{r}\text { H } \\
\text { P-value }\end{array}$ & $\begin{array}{r}\text { omogeneidade } \\
\text { Interpretação }\end{array}$ & Geral \\
\hline $\begin{array}{l}\text { ANC / AT - FRA-GAAP } \\
\text { ANC / AT - IFRS }\end{array}$ & $\begin{array}{l}0,167 \\
0,379\end{array}$ & $\begin{array}{l}\text { Sim } \\
\text { Sim } \\
\end{array}$ & Sim & 0,667 & Sim & Sim \\
\hline $\begin{array}{l}\mathrm{AC} / \mathrm{AT} \text { - FRA-GAAP } \\
\mathrm{AC} / \mathrm{AT} \text { - IFRS }\end{array}$ & $\begin{array}{l}0,167 \\
0,379 \\
\end{array}$ & $\begin{array}{l}\text { Sim } \\
\text { Sim } \\
\end{array}$ & Sim & 0,667 & Sim & Sim \\
\hline $\begin{array}{l}\mathrm{PC} \text { / PT + PL - FRA-GAAP } \\
\mathrm{PC} \text { / PT + PL - IFRS }\end{array}$ & $\begin{array}{l}0,104 \\
0,248\end{array}$ & $\begin{array}{l}\text { Sim } \\
\text { Sim } \\
\end{array}$ & Sim & 0,377 & Sim & Sim \\
\hline $\begin{array}{l}\text { CCL - FRA-GAAP } \\
\text { CCL - IFRS } \\
\end{array}$ & $\begin{array}{l}0,006 \\
0,003 \\
\end{array}$ & $\begin{array}{l}\text { Não } \\
\text { Não } \\
\end{array}$ & Não & 0,933 & Sim & Sim \\
\hline $\begin{array}{l}\mathrm{PNC} / \mathrm{PT}+\mathrm{PL} \text { - FRA-GAAP } \\
\mathrm{PNC} / \mathrm{PT}+\mathrm{PL} \text { - IFRS }\end{array}$ & $\begin{array}{l}0,704 \\
0,002 \\
\end{array}$ & $\begin{array}{l}\text { Sim } \\
\text { Não }\end{array}$ & Não & 0,255 & Sim & Sim \\
\hline $\begin{array}{l}\mathrm{PT} / \mathrm{PT}+\mathrm{PL} \text { - FRA-GAAP } \\
\mathrm{PT} / \mathrm{PT}+\mathrm{PL} \text { - IFRS }\end{array}$ & $\begin{array}{l}0,488 \\
0,448\end{array}$ & $\begin{array}{l}\text { Sim } \\
\text { Sim }\end{array}$ & Sim & 0,800 & Sim & Sim \\
\hline
\end{tabular}

Os p-values maiores do que 5\% para as ponderações envolvendo os ativos circulante e nãocirculante, o passivo circulante e o passivo total justificam o uso de um teste paramétrico. Para estas ponderações será utilizado o teste t-student para amostras emparelhadas, pois foi possível constatar que tais ponderações têm a tendência de uma distribuição normal.

Quanto às ponderações do capital circulante líquido e do passivo não-circulante em relação à soma do passivo total mais patrimônio líquido, será utilizado o teste de Wilcoxon para o teste das médias e diferenças de médias.

A tabela 20 ilustra o resultado da aplicação das técnicas estatísticas dos testes de diferenças de médias, incluindo os valores de testes paramétricos e não-paramétricos cuja distinção foi feita nos dois parágrafos acima: 
Tabela 20 - Resultado da aplicação do T-student e do Wilcoxon nas ponderações dos grupos patrimoniais

\begin{tabular}{|c|c|c|c|c|}
\hline \multirow{2}{*}{$\begin{array}{c}\text { Ponderações dos grupos } \\
\text { do ativo e do passivo } \\
\end{array}$} & \multicolumn{2}{|c|}{ Resultado das Médias (Sig de 5\%) } & \multicolumn{2}{|c|}{ Resultado dos Testes } \\
\hline & Mean Rank & Geral & $P$-value & $>\operatorname{Sig} 5 \%$ \\
\hline $\begin{array}{l}\text { ANC / AT - FRA-GAAP } \\
\text { ANC / AT - IFRS } \\
\end{array}$ & $\begin{array}{l}0,446208 \\
0,459831\end{array}$ & Sim & 0,613 & Sim \\
\hline $\begin{array}{l}\text { AC / AT - FRA-GAAP } \\
\text { AC / AT - IFRS }\end{array}$ & $\begin{array}{l}0,553792 \\
0,540169\end{array}$ & Sim & 0,613 & Sim \\
\hline $\begin{array}{l}\mathrm{PC} / \mathrm{PT}+\mathrm{PL} \text { - FRA-GAAP } \\
\mathrm{PC} / \mathrm{PT}+\mathrm{PL} \text { - IFRS }\end{array}$ & $\begin{array}{l}0,490741 \\
0,379499 \\
\end{array}$ & Sim & 0,437 & Sim \\
\hline $\begin{array}{l}\text { CCL - FRA-GAAP } \\
\text { CCL - IFRS }\end{array}$ & $\begin{array}{l}204,5550 \\
213,8603 \\
\end{array}$ & Sim & 0,893 & Sim \\
\hline $\begin{array}{l}\mathrm{PNC} / \mathrm{PT}+\mathrm{PL} \text { - FRA-GAAP } \\
\mathrm{PNC} / \mathrm{PT}+\mathrm{PL} \text { - IFRS }\end{array}$ & $\begin{array}{l}0,224175 \\
0,329479 \\
\end{array}$ & Sim & 0,600 & Sim \\
\hline $\begin{array}{l}\text { PT / PT + PL - FRA-GAAP } \\
\text { PT / PT + PL - IFRS } \\
\end{array}$ & $\begin{array}{l}0,714916 \\
0,708978 \\
\end{array}$ & Sim & 0,558 & Sim \\
\hline
\end{tabular}

Os testes paramétricos e não-paramétricos foram realizados para cada ponderação de grupos de contas, comparando a média obtida através dos primeiros balanços em IFRS com a média da mesma ponderação calculada através das últimas demonstrações apresentadas em FRGAAP, considerando nível de confiança de $95 \%$.

Com base na tabela 20, não é possível rejeitar a hipótese de que as médias das diferenças entre as ponderações dos grupos de contas patrimoniais das empresas de mineração listadas na bolsa de valores Euronext, calculadas através do balanço em normas contábeis locais e em normas internacionais, no ano em que cada empresa publicou as primeiras demonstrações contábeis em IFRS, não são significativas.

Tal qual para as mineradoras inglesas listadas na LSE e as alemãs listadas na bolsa de Frankfurt, comprovou-se estatisticamente que as diferenças entre as ponderações dos grupos circulantes e não-circulantes dos balanços das mineradoras francesas em FR-GAAP e na primeira adoção das IFRS, também têm que ser consideradas quando a análise pretendida envolver as proporções destes grupos (i.e. AC, ANC, PC...) em relação ao ativo ou passivo totais. 


\section{DESCRIÇÃo E ANÁLISE DOS DADOS DO SETOR QUÍMICO}

Este capítulo apresenta a pesquisa com as companhias do setor químico das bolsas de Londres, Frankfurt e de Paris. Inicialmente, ele caracteriza as populações utilizadas no estudo. Em seguida, evidencia os cálculos das ponderações dos grupos patrimoniais pelas respectivas proporções dentro dos grupos do ativo ou do passivo totais. Por fim, analisa se os resultados dos testes da comparação dos grupos de conta do balanço patrimonial são significativamente diferentes entre as demonstrações em norma local européia e em IFRS, vis-a-vis os resultados dos testes de médias encontrados para as empresas do setor de mineração listadas nas principais bolsas de valores européias.

\subsection{Descrição dos testes}

Para atender os objetivos do capítulo foi necessário separar, para cada empresa, a demonstração cujo exercício tenha o primeiro balanço patrimonial em IFRS e seu correspondente par em norma local, aplicar os testes de normalidade e homogeneidade de variâncias para a escolha adequada dos testes de médias das diferenças dos grupos patrimoniais do ativo e do passivo e, por último, analisar e comparar os resultados dos testes de médias entre a aplicação da norma contábil local e a adoção das IFRS pelo Reino Unido, pela Alemanha e pela França para as empresas mineradoras e para as químicas

\subsubsection{Testes com as empresas do Reino Unido}

As tabelas 21 e 22 caracterizam a ponderação dos grupos de contas do ativo e do passivo circulantes e não-circulantes pelo seu respectivo grupo do ativo ou passivo total das companhias inglesas do setor químico. 
Tabela 21 - Ponderações referentes aos grupos de contas das empresas inglesas do setor químico da $\operatorname{LSE}\left(1^{\mathrm{a}}\right.$ parte $)$

\begin{tabular}{|l|r|r|r|r|r|r|}
\hline \multicolumn{1}{|c|}{ Empresas } & $\begin{array}{c}\text { Ativo não- } \\
\text { circulante / } \\
\text { Ativo total } \\
\text { (IFRS) }\end{array}$ & $\begin{array}{c}\text { Ativo não- } \\
\text { circulante / } \\
\text { Ativo total } \\
\text { (UK-GAAP) }\end{array}$ & $\begin{array}{c}\text { Ativo } \\
\text { circulante } / \\
\text { Ativo total } \\
\text { (IFRS) }\end{array}$ & $\begin{array}{c}\text { Ativo } \\
\text { circulante / } \\
\text { Ativo total } \\
\text { (UK-GAAP) }\end{array}$ & $\begin{array}{c}\text { Passivo circulante } \\
/ \text { Passivo total + } \\
\text { patrimônio } \\
\text { líquido (IFRS) }\end{array}$ & $\begin{array}{c}\text { Passivo circulante } / \\
\text { Passivo total + } \\
\text { patrimônio líquido } \\
\text { (UK-GAAP) }\end{array}$ \\
\hline CRODA INTL & 0,5622 & 0,4517 & 0,4378 & 0,5483 & 0,1930 & 0,2793 \\
\hline DELTA & 0,4202 & 0,3764 & 0,5798 & 0,6236 & 0,1676 & 0,3400 \\
\hline ELEMENTIS & 0,6748 & 0,6567 & 0,3252 & 0,3433 & 0,1754 \\
\hline JOHNSON MATTH & 0,5805 & 0,5379 & 0,4195 & 0,4621 & 0,2044 & 0,1684 \\
\hline VICTREX & 0,5566 & 0,5482 & 0,4434 & 0,4518 & 0,2591 \\
\hline YULE CATTO \& CO PLC & 0,5437 & 0,6602 & 0,4563 & 0,3398 & 0,2210 \\
\hline
\end{tabular}

Tabela 22 - Ponderações e capital circulante líquido referentes aos grupos de contas das empresas inglesas do setor químico da LSE ( $2^{\mathrm{a}}$ parte)

\begin{tabular}{|l|c|c|c|c|c|c|}
\hline \multicolumn{1}{|c|}{ Empresas } & $\begin{array}{c}\text { Capital } \\
\text { circulante } \\
\text { líquido } \\
\text { (IFRS) }\end{array}$ & $\begin{array}{c}\text { Capital } \\
\text { circulante } \\
\text { líquido } \\
\text { (UK-GAAP) }\end{array}$ & $\begin{array}{c}\text { Passivo não- } \\
\text { circulante / } \\
\text { Passivo total + } \\
\text { patrimônio líquido } \\
\text { (IFRS) }\end{array}$ & $\begin{array}{c}\text { Passivo não- } \\
\text { circulante / } \\
\text { Passivo total + } \\
\text { patrimônio líquido } \\
\text { (UK-GAAP) }\end{array}$ & $\begin{array}{c}\text { Passivo total / } \\
\text { Passivo total } \\
+ \text { patrimônio } \\
\text { líquido } \\
\text { (IFRS) }\end{array}$ & $\begin{array}{c}\text { Passivo total / } \\
\text { Passivo total + } \\
\text { patrimônio líquido } \\
\text { (UK-GAAP) }\end{array}$ \\
\hline CRODA INTL & 150,0120 & 179,8604 & 0,5255 & 0,2088 & 0,7184 & 0,4643 \\
\hline DELTA & 185,6375 & 165,0325 & 0,1125 & 0,0854 & 0,3918 & 0,4254 \\
\hline ELEMENTIS & 156,3668 & 157,3297 & 0,3992 & 0,2048 & 0,5668 & 0,3802 \\
\hline JOHNSON MATTH & 749,8676 & 726,7592 & 0,2823 & 0,2736 & 0,4867 & \\
\hline VICTREX & 56,6156 & 45,6603 & 0,1506 & 0,0591 & 0,3190 & 0,5328 \\
\hline YULE CATTO \& CO PLQ & $(39,0166)$ & $(10,4893)$ & 0,4336 & 0,3533 & 0,9236 & 0,2801 \\
\hline
\end{tabular}

As ponderações resumidas nas tabelas 21 e 22 fornecem os subsídios necessários para a aplicação das técnicas estatísticas para a identificação da presença ou não da distribuição normal para, enfim, proceder à escolha do teste de médias adequado para cada uma das ponderações.

A tabela 23 traz um resumo dos resultados dos testes de normalidade e homogeneidade de variâncias realizados através do SPSS utilizando o teste de Shapiro-Wilk, para identificar se as ponderações obtidas seguem uma distribuição normal: 
Tabela 23 - Normalidade e Homogeneidade das ponderações dos grupos de contas patrimoniais e do capital circulantє líquido das empresas do setor químico da LSE

\begin{tabular}{|c|c|c|c|c|c|c|}
\hline Ponderações dos grupos do ativo e passivo & \multicolumn{3}{|c|}{ Normalidade } & \multicolumn{3}{|c|}{ Homogeneidade } \\
\hline $\begin{array}{l}\text { ANC / AT - UK-GAAP } \\
\text { ANC / AT - IFRS } \\
\end{array}$ & $\begin{array}{l}0,550 \\
0,459 \\
\end{array}$ & $\begin{array}{l}\text { Sim } \\
\text { Sim } \\
\end{array}$ & Sim & 0,377 & Sim & Sim \\
\hline $\begin{array}{l}\mathrm{AC} / \mathrm{AT} \text { - UK-GAAP } \\
\mathrm{AC} / \mathrm{AT} \text { - IFRS } \\
\end{array}$ & $\begin{array}{l}0,550 \\
0,459 \\
\end{array}$ & $\begin{array}{l}\text { Sim } \\
\text { Sim } \\
\end{array}$ & Sim & 0,377 & Sim & Sim \\
\hline $\begin{array}{l}\mathrm{PC} / \mathrm{PT}+\mathrm{PL} \text { - UK-GAAP } \\
\mathrm{PC} / \mathrm{PT}+\mathrm{PL} \text { - IFRS } \\
\end{array}$ & $\begin{array}{l}0,570 \\
0,017 \\
\end{array}$ & $\begin{array}{l}\text { Sim } \\
\text { Não } \\
\end{array}$ & Não & 0,302 & Sim & Sim \\
\hline $\begin{array}{l}\text { CCL - UK-GAAP } \\
\text { CCL - IFRS } \\
\end{array}$ & $\begin{array}{l}0,022 \\
0,031 \\
\end{array}$ & $\begin{array}{l}\text { Não } \\
\text { Não } \\
\end{array}$ & Não & 0,944 & Sim & Sim \\
\hline $\begin{array}{l}\mathrm{PNC} / \mathrm{PT}+\mathrm{PL} \text { - UK-GAAP } \\
\mathrm{PNC} / \mathrm{PT}+\mathrm{PL} \text { - IFRS } \\
\end{array}$ & $\begin{array}{l}0,722 \\
0,645 \\
\end{array}$ & $\begin{array}{l}\text { Sim } \\
\text { Sim } \\
\end{array}$ & Sim & 0,207 & Sim & Sim \\
\hline $\begin{array}{l}\mathrm{PT} / \mathrm{PT}+\mathrm{PL} \text { - UK-GAAP } \\
\mathrm{PT} / \mathrm{PT}+\mathrm{PL} \text { - IFRS } \\
\end{array}$ & $\begin{array}{l}0,906 \\
0,784 \\
\end{array}$ & $\begin{array}{l}\text { Sim } \\
\text { Sim } \\
\end{array}$ & Sim & 0,315 & Sim & Sim \\
\hline
\end{tabular}

Baseado na tabela 23, se pode utilizar o teste paramétrico de t-student para amostras emparelhadas para as ponderações que envolvem o ativo não-circulante, o ativo circulante, o passivo não-circulante e o passivo total. Por não atender a característica de normalidade, será empregado o teste não-paramétrico de Wilcoxon para as ponderações do passivo não circulante e do capital circulante líquido.

À tabela 24 foi atribuído o papel de apresentar o resultado da aplicação dos testes de médias, incluindo os valores dos testes paramétricos e não-paramétricos: 
Tabela 24 - Resultado da aplicação dos testes T-student e Wilcoxon nas ponderações dos grupos patrimoniais das empresas do setor químico da LSE

\begin{tabular}{|c|c|c|c|c|}
\hline \multirow{2}{*}{$\begin{array}{c}\text { Ponderações dos sub-grupos } \\
\text { do ativo e do passivo }\end{array}$} & \multicolumn{2}{|c|}{ Resultado das Médias (Sig de 5\%) } & \multicolumn{2}{|c|}{ Resultado dos Testes } \\
\hline & Mean Rank & Geral & $P$-value & Sig $>5 \%$ \\
\hline $\begin{array}{l}\text { ANC / AT - UK-GAAP } \\
\text { ANC / AT - IFRS }\end{array}$ & $\begin{array}{l}0,538520 \\
0,556329\end{array}$ & Sim & 0,585 & Sim \\
\hline $\begin{array}{l}\text { AC / AT - UK-GAAP } \\
\text { AC / AT - IFRS }\end{array}$ & $\begin{array}{l}0,461480 \\
0,443671\end{array}$ & Sim & 0,585 & Sim \\
\hline $\begin{array}{l}\mathrm{PC} / \mathrm{PT}+\mathrm{PL} \text { - UK-GAAP } \\
\mathrm{PC} / \mathrm{PT}+\mathrm{PL} \text { - IFRS }\end{array}$ & $\begin{array}{l}0,266683 \\
0,250429\end{array}$ & Sim & 0,345 & Sim \\
\hline $\begin{array}{l}\text { CCL - UK-GAAP } \\
\text { CCL - IFRS }\end{array}$ & $\begin{array}{l}210,6921 \\
209,9138\end{array}$ & Sim & 0,753 & Sim \\
\hline $\begin{array}{l}\mathrm{PNC} / \mathrm{PT}+\mathrm{PL} \text { - UK-GAAP } \\
\mathrm{PNC} / \mathrm{PT}+\mathrm{PL} \text { - IFRS }\end{array}$ & $\begin{array}{l}0,197495 \\
0,317289 \\
\end{array}$ & Sim & 0,053 & Sim \\
\hline $\begin{array}{l}\text { PT / PT + PL - UK-GAAP } \\
\text { PT / PT + PL - IFRS }\end{array}$ & $\begin{array}{l}0,464178 \\
0,567718\end{array}$ & Sim & 0,115 & Sim \\
\hline
\end{tabular}

A tabela 24 permite inferir que não é possível rejeitar a hipótese de que as médias das diferenças entre as ponderações dos grupos de contas patrimoniais das empresas químicas listadas na LSE e calculadas através do balanço em normas contábeis locais e em normas internacionais, no ano em que cada empresa publicou as primeiras demonstrações contábeis em IFRS, não são significativas.

\subsubsection{Comparação do nível de significância das mineradoras e das empresas químicas do Reino Unido}

Neste tópico será possível comparar a intensidade com que se relacionam os grupos patrimoniais (AC, ANC, PC, CCL e PNC) calculados através do padrão contábil UK-GAAP e em IFRS para as empresas de mineração e químicas do Reino Unido.

Através do nível de significância de 5\% para o qual os cálculos foram demonstrados passo-apasso nos itens 4.1.1 e 5.2, espera-se que a comparação do nível de significância das diferenças de médias entre os setores químico e de mineração contribua com o entendimento dos impactos da adoção das IFRS em ambos setores.

A tabela 25 organiza os $p$-values dos dois setores pesquisados da LSE: 
Tabela 25 - Níveis de significância da diferença entre os grupos contábeis em UK-GAAP e IFRS das mineradoras e das empresas químicas pesquisadas na LSE

\begin{tabular}{|c|c|c|c|}
\hline $\begin{array}{c}\text { Ponderações dos grupos } \\
\text { do ativo e do passivo }\end{array}$ & $\begin{array}{r}P \text {-values } \\
\text { Mineradoras }\end{array}$ & $\begin{array}{l}\text { (Sig) } \\
\text { Químicas }\end{array}$ & $\begin{array}{l}\text { Sig Mineradoras / } \\
\text { Sig Químicas }\end{array}$ \\
\hline $\begin{array}{l}\text { ANC / AT - UK-GAAP } \\
\text { ANC / AT - IFRS } \\
\end{array}$ & 0,121 & 0,585 & $20,68 \%$ \\
\hline $\begin{array}{l}\text { AC / AT - UK-GAAP } \\
\text { AC / AT - IFRS } \\
\end{array}$ & 0,121 & 0,585 & $20,68 \%$ \\
\hline $\begin{array}{l}\text { PC / PT + PL - UK-GAAP } \\
\text { PC / PT + PL - IFRS }\end{array}$ & 0,009 & 0,345 & $2,61 \%$ \\
\hline $\begin{array}{l}\text { CCL - UK-GAAP } \\
\text { CCL - IFRS } \\
\end{array}$ & 0,970 & 0,753 & $128,82 \%$ \\
\hline $\begin{array}{l}\mathrm{PNC} / \mathrm{PT}+\mathrm{PL} \text { - UK-GAAP } \\
\mathrm{PNC} / \mathrm{PT}+\mathrm{PL} \text { - IFRS }\end{array}$ & 0,653 & 0,053 & $1232,08 \%$ \\
\hline
\end{tabular}

O resultado acima demonstra uma disparidade acentuada quanto aos resultados dos níveis de significância das diferenças entre os grupos contábeis contabilizados segundo as normas do UK-GAAP e as IFRS para os setores de mineração e químico das empresas da LSE.

Se a comparação entre os níveis de significância das ponderações dos AC, PC, ANC, CCL e PNC para os dois setores estivesse próxima dos $100 \%$, o resultado seria interpretado como uma tendência de homogeneidade na adoção das IFRS comum aos dois setores analisados. Em outras palavras, dado que foi apurado que existem diferenças significativas nos grupos que compõem o ativo e o passivo quando da aplicação do UK-GAAP e das IFRS e que estas diferenças, portanto, têm que ser observadas se um usuário utilizar o balanço de qualquer uma das companhias pertencentes ao setor de mineração ou químico da LSE no ano da adoção das IFRS e, por conseguinte, no último ano da prática da contabilidade em UK-GAAP, e considerando também que as IFRS têm a propriedade de ser um novo padrão cujo conjunto de técnicas se aplica eqüitativamente para todos os setores, se poderia interpretar, equivocadamente, que o resultado esperado seria uma tendência semelhante quanto à grandeza e a tendência do $p$-value para ambos os setores. 
No entanto, as diferenças entre os níveis de significância alertam para a seguinte inferência: a adoção das IFRS promoveu impactos diferentes nas mineradoras e nas companhias químicas inglesas, ou por razões vinculadas às especificidades de regimentos e leis inerentes a estes dois setores no período em que o UK-GAAP era o padrão que vigorava no Reino Unido ou porque as IFRS têm propriedades que foram responsáveis por alterar diferentemente os grupos patrimoniais do ativo e do passivo dos setores em estudo, no ano em que as normas internacionais de contabilidade foram adotadas.

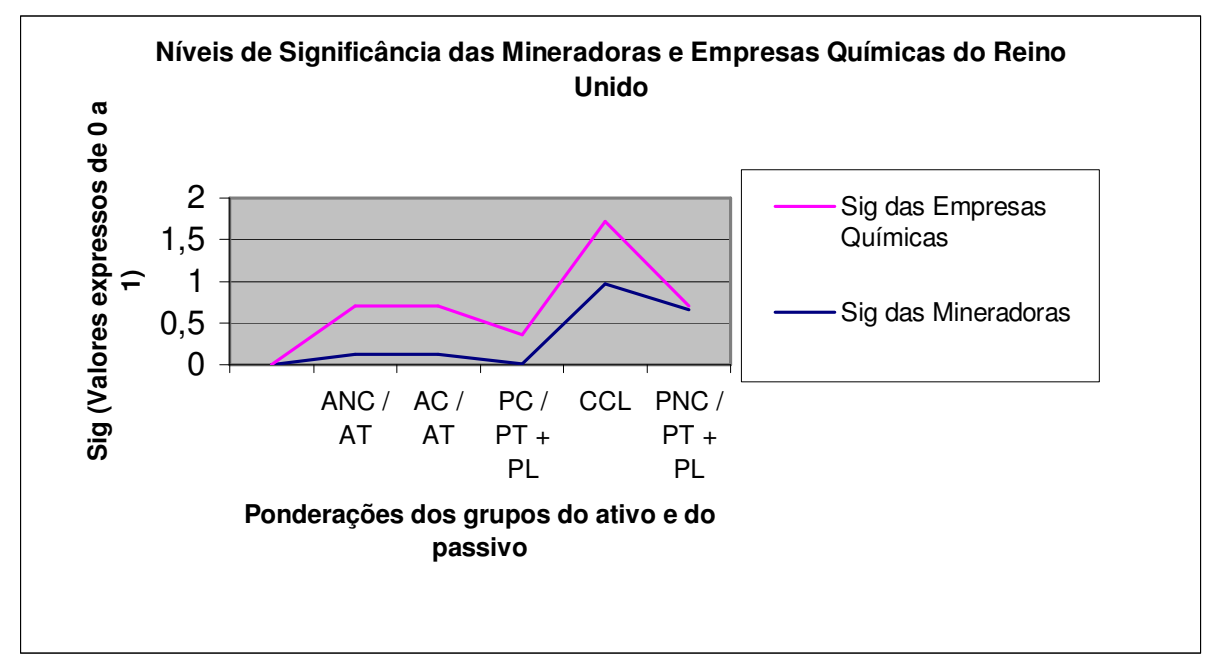

As duas hipóteses descritas no parágrafo anterior têm boas chances de justificar o "descolamento" gráfico dos p-values nos grupos patrimoniais dos setores conduzidos por esta pesquisa, mas fogem do escopo e do objetivo deste estudo.

\subsubsection{Testes com as empresas da Alemanha}

Com os mesmos procedimentos empregados no tópico 5.2 referentes aos testes de média das companhias químicas do Reino Unido, no item 5.3 foram separados os saldos dos grupos patrimoniais do ativo e do passivo das empresas químicas alemãs para o cálculo das ponderações de cada grupo em relação à participação total no respectivo grupo do ativo ou passivo total, tal qual uma análise vertical. 
Como resultado, obteve-se as variáveis quantitativas necessárias para a execução dos testes de normalidade e homogeneidade de variâncias.

A tabela 26 traz os resultados dos testes obtidos através do SPSS, empregando o teste de Shapiro-Wilk para identificar se as ponderações obtidas seguem uma distribuição normal.

Tabela 26 - Normalidade e Homogeneidade das ponderações dos grupos de contas patrimoniais e do capital circulantє líquido das empresas alemãs do setor químico da Bolsa de Frankfurt

\begin{tabular}{|c|c|c|c|c|c|c|}
\hline \multirow[t]{2}{*}{ Ponderações dos grupos do ativo e passivo } & \multicolumn{3}{|c|}{ Normalidade } & \multicolumn{3}{|c|}{ Homogeneidade } \\
\hline & P-value & Interpretação & Geral & P-value & Interpretação & Geral \\
\hline $\begin{array}{l}\text { ANC / AT - GER-GAAP } \\
\text { ANC / AT - IFRS }\end{array}$ & $\begin{array}{l}0,349 \\
0,803\end{array}$ & $\begin{array}{l}\text { Sim } \\
\text { Sim }\end{array}$ & Sim & 0,480 & Sim & Sim \\
\hline $\begin{array}{l}\text { AC / AT - GER-GAAP } \\
\text { AC / AT - IFRS }\end{array}$ & $\begin{array}{l}0,349 \\
0,803\end{array}$ & $\begin{array}{l}\text { Sim } \\
\text { Sim }\end{array}$ & Sim & 0,480 & Sim & Sim \\
\hline $\begin{array}{l}\mathrm{PC} / \mathrm{PT}+\mathrm{PL} \text { - GER-GAAP } \\
\mathrm{PC} / \mathrm{PT}+\mathrm{PL} \text { - IFRS }\end{array}$ & $\begin{array}{l}0,400 \\
0,062\end{array}$ & $\begin{array}{l}\text { Sim } \\
\text { Sim }\end{array}$ & Sim & 0,330 & Sim & Sim \\
\hline $\begin{array}{l}\text { CCL - GER-GAAP } \\
\text { CCL - IFRS }\end{array}$ & $\begin{array}{l}0,000 \\
0,001\end{array}$ & $\begin{array}{l}\text { Não } \\
\text { Não }\end{array}$ & Não & 0,909 & Sim & Sim \\
\hline $\begin{array}{l}\text { PNC / PT + PL - GER-GAAP } \\
\text { PNC / PT + PL - IFRS }\end{array}$ & $\begin{array}{l}0,982 \\
0,966\end{array}$ & $\begin{array}{l}\text { Sim } \\
\text { Sim }\end{array}$ & Sim & 0,498 & Sim & Sim \\
\hline $\begin{array}{l}\text { PT / PT + PL - GER-GAAP } \\
\text { PT / PT + PL - IFRS }\end{array}$ & $\begin{array}{l}0,219 \\
0,902\end{array}$ & $\begin{array}{l}\text { Sim } \\
\text { Sim }\end{array}$ & Sim & 0,290 & Sim & Sim \\
\hline
\end{tabular}

Devido ao resultado negativo de normalidade para o CCL, será utilizado para esta ponderação o teste não-paramétrico de Wilcoxon. Para as demais ponderações será empregado o teste de t-student para amostras emparelhadas.

A próxima tabela retrata os $p$-values para as ponderações que foram sujeitas aos testes de médias paramétrico e não-paramétrico: 
Tabela 27 - Resultado da aplicação dos testes T-student e Wilcoxon nas ponderações dos grupos patrimoniais das empresas do setor químico da bolsa de Frankfurt

\begin{tabular}{|c|c|c|c|c|}
\hline $\begin{array}{l}\text { Ponderações dos grupos } \\
\text { do ativo e do passivo }\end{array}$ & $\begin{array}{r}\text { Resultado da } \\
\text { Mean Rank }\end{array}$ & $\begin{array}{l}\text { Sig de 5\%) } \\
\text { Geral }\end{array}$ & $\begin{array}{r}\text { Resu } \\
P \text {-value }\end{array}$ & $\begin{array}{l}\text { Testes } \\
\text { Sig }>5 \%\end{array}$ \\
\hline $\begin{array}{l}\text { ANC / AT - GER-GAAP } \\
\text { ANC / AT - IFRS }\end{array}$ & $\begin{array}{l}0,529176 \\
0,520251 \\
\end{array}$ & Sim & 0,657 & Sim \\
\hline $\begin{array}{l}\text { AC / AT - GER-GAAP } \\
\text { AC / AT - IFRS }\end{array}$ & $\begin{array}{l}0,470824 \\
0,479749 \\
\end{array}$ & Sim & 0,657 & Sim \\
\hline $\begin{array}{l}\mathrm{PC} / \mathrm{PT}+\mathrm{PL} \text { - GER-GAAP } \\
\mathrm{PC} / \mathrm{PT}+\mathrm{PL} \text { - IFRS }\end{array}$ & $\begin{array}{l}0,348527 \\
0,347311 \\
\end{array}$ & Sim & 0,970 & Sim \\
\hline $\begin{array}{l}\text { CCL - GER-GAAP } \\
\text { CCL - IFRS }\end{array}$ & $\begin{array}{l}2226,7680 \\
2217,0440 \\
\end{array}$ & Sim & 0,575 & Sim \\
\hline $\begin{array}{l}\text { PNC / PT + PL - GER-GAAP } \\
\text { PNC / PT + PL - IFRS }\end{array}$ & $\begin{array}{l}0,275989 \\
0,273026 \\
\end{array}$ & Sim & 0,910 & Sim \\
\hline $\begin{array}{l}\text { PT / PT + PL - GER-GAAP } \\
\text { PT / PT + PL - IFRS }\end{array}$ & $\begin{array}{l}0,624516 \\
0,620337\end{array}$ & Sim & 0,936 & Sim \\
\hline
\end{tabular}

Da mesma forma com que foram demonstrados os resultados para as companhias químicas do Reino Unido, a tabela acima permite inferir que não é possível rejeitar a hipótese de que as médias das diferenças entre as ponderações dos grupos de contas patrimoniais das empresas químicas listadas na bolsa de Frankfurt e calculadas através do balanço em GER-GAAP e em normas internacionais, no ano em que cada empresa publicou as primeiras demonstrações contábeis em IFRS, não são significativas.

\subsubsection{Comparação do nível de significância das mineradoras e das empresas} químicas da Alemanha

O objetivo deste tópico é comparar a intensidade com que se relacionam os grupos patrimoniais (AC, ANC, PC, CCL e PNC) calculados através do padrão contábil GER-GAAP e em IFRS para as empresas de mineração e químicas da Alemanha.

Considerando um nível de significância de 5\% calculados nos tópicos 4.1 .2 e 5.3, entende-se que a comparação gráfica dos p-values possa auxiliar no entendimento dos impactos da adoção das IFRS em ambos os setores. 
A seguir, são trazidos novamente os p-values dos dois setores pesquisados na bolsa de valores de Frankfurt:

Tabela 28 - Níveis de significância das diferenças entre os grupos contábeis em GER-GAAP e IFRS das mineradoras e das empresas químicas pesquisadas na bolsa de valores de Frankfurt

\begin{tabular}{|c|c|c|c|}
\hline $\begin{array}{c}\text { Ponderações dos grupos } \\
\text { do ativo e do passivo }\end{array}$ & $\begin{array}{r}P \text {-values } \\
\text { Mineradoras }\end{array}$ & $\begin{array}{l}\text { (Sig) } \\
\text { Químicas }\end{array}$ & $\begin{array}{l}\text { Sig Mineradoras / } \\
\text { Sig Químicas }\end{array}$ \\
\hline $\begin{array}{l}\text { ANC / AT - UK-GAAP } \\
\text { ANC / AT - IFRS }\end{array}$ & 0,109 & 0,657 & $16,59 \%$ \\
\hline $\begin{array}{l}\text { AC / AT - UK-GAAP } \\
\text { AC / AT - IFRS }\end{array}$ & 0,109 & 0,657 & $16,59 \%$ \\
\hline $\begin{array}{l}\mathrm{PC} / \mathrm{PT}+\mathrm{PL} \text { - UK-GAAP } \\
\mathrm{PC} / \mathrm{PT}+\mathrm{PL} \text { - IFRS }\end{array}$ & 0,593 & 0,970 & $61,13 \%$ \\
\hline $\begin{array}{l}\text { CCL - UK-GAAP } \\
\text { CCL - IFRS }\end{array}$ & 0,593 & 0,575 & $103,13 \%$ \\
\hline $\begin{array}{l}\mathrm{PNC} / \mathrm{PT}+\mathrm{PL} \text { - UK-GAAP } \\
\mathrm{PNC} / \mathrm{PT}+\mathrm{PL} \text { - IFRS }\end{array}$ & 0,593 & 0,910 & $65,16 \%$ \\
\hline MÉDIA & & & $52,52 \%$ \\
\hline
\end{tabular}

Desta vez, o comparativo dos p-values das diferenças entre os grupos contábeis contabilizados segundo as normas preconizadas pelo GER-GAAP e pelas IFRS para os setores de mineração e químico das empresas da bolsa de valores de Frankfurt apresentou um resultado muito mais próximo dos $100 \%$, que é considerado o ideal conforme explicado no tópico das empresas do Reino Unido. É importante ressaltar que os resultados obtidos com os mesmos cálculos na LSE foram muito piores.

Para comprovar tal constatação, foi feito o cálculo da média do comparativo entre os $p$-values. E ele também reflete esta observação: na média, as diferenças entre os grupos do ativo e do passivo quando da aplicação do GER-GAAP e as IFRS para os setores de mineração e químico ficaram mais próximas do que para as companhias inglesas, o que pode ser ratificado 
pelas porcentagens médias dos p-values: $53 \%$ para as empresas analisadas na bolsa de Frankfurt contra $281 \%$ com as empresas da LSE.

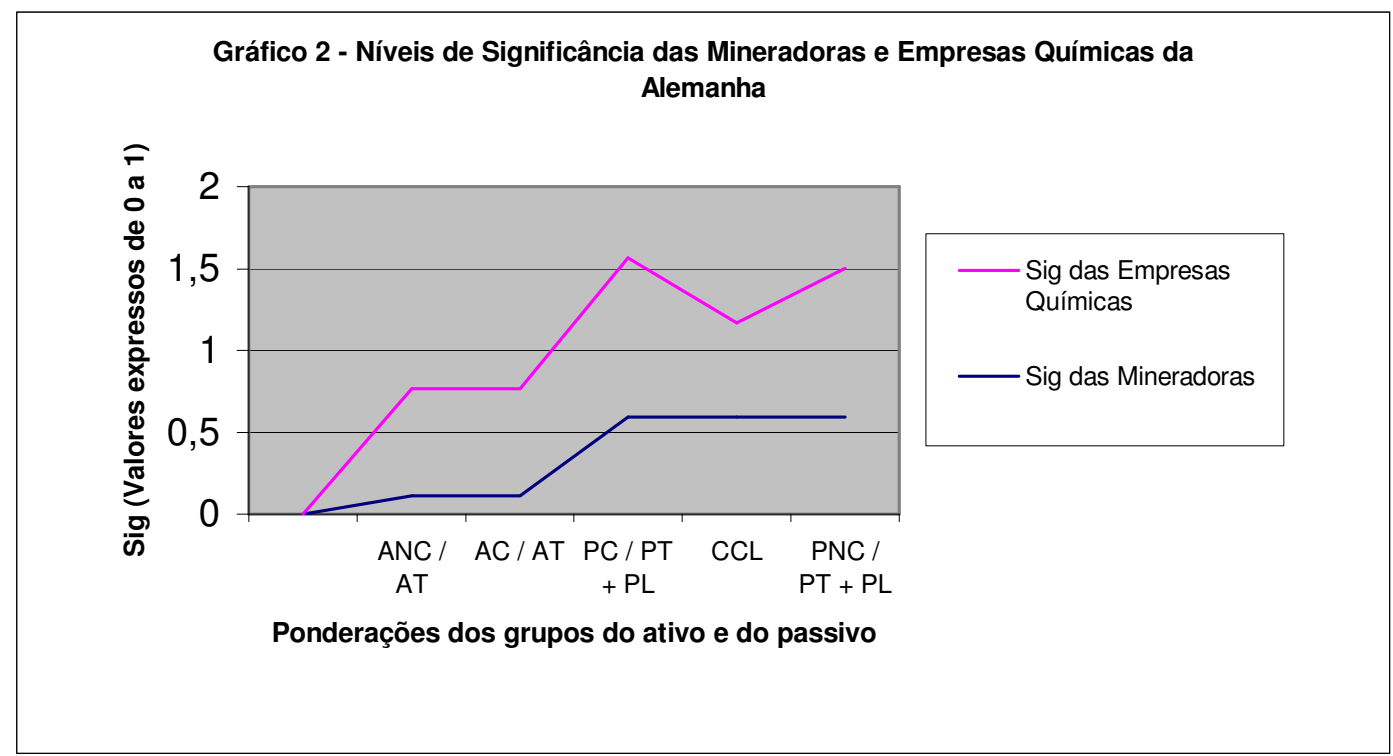

Portanto, se um usuário utilizar o balanço em IFRS de qualquer uma das companhias pertencentes ao setor de mineração ou químico da bolsa de valores de Frankfurt no ano da adoção das IFRS, terá em mãos uma demonstração para cujos efeitos da adoção das normas internacionais foram muito mais semelhantes entre os dois setores pesquisados do que foram para os mesmos setores na LSE.

Significa dizer também que a adoção das IFRS promoveu impactos mais próximos nas mineradoras e nas companhias químicas alemãs do que nas empresas do mesmo setor da LSE, considerando as pretensões de harmonização das IFRS.

As mesmas razões da discrepância de resultado com as mineradoras e químicas inglesas poderiam justificar o sucesso com a comparação das empresas da bolsa de Frankfurt: as especificidades de regimentos e leis em conformidade com os GER-GAAP ou mesmo as propriedades das IFRS que foram responsáveis por alterar diferentemente os grupos patrimoniais do ativo e do passivo dos setores em estudo, no ano em que as normas internacionais de contabilidade foram adotadas. Conforme já foi realçado, tal análise não é parte integrante deste trabalho. 


\subsubsection{Testes com as empresas da França}

Por último e repetindo a mesma técnica empregada no tópico 5.2 e 5.3 referentes aos testes de média das companhias químicas do Reino Unido e da Alemanha, neste item foram separados os saldos dos grupos patrimoniais do ativo e do passivo das empresas químicas francesas apresentadas no quadro 09 do tópico 5.1.1 para o cálculo das ponderações dos grupos patrimoniais em relação à participação total no respectivo grupo.

A aplicação da técnica descrita acima originou as variáveis quantitativas necessárias para a execução dos testes de normalidade e homogeneidade de variâncias.

A tabela 29 traz os resultados dos testes obtidos no SPSS através do emprego do ShapiroWilk para a identificação se as ponderações obtidas seguem uma distribuição normal.

Tabela 29 - Normalidade e Homogeneidade das ponderações dos grupos de contas patrimoniais e do capital circulant líquido das empresas francesas do setor químico da Euronext

\begin{tabular}{|c|c|c|c|c|c|c|}
\hline Ponderações dos grupos do ativo e do passivo & $P$-value & $\begin{array}{l}\text { Normalidade } \\
\text { Interpretação }\end{array}$ & Geral & $\begin{array}{r}\mathbf{H} \\
P \text {-value }\end{array}$ & $\begin{array}{c}\text { omogeneidade } \\
\text { Interpretação }\end{array}$ & Geral \\
\hline $\begin{array}{l}\text { ANC / AT - FR-GAAP } \\
\text { ANC / AT - IFRS }\end{array}$ & $\begin{array}{l}0,638 \\
0,550\end{array}$ & $\begin{array}{l}\text { Sim } \\
\text { Sim }\end{array}$ & Sim & 0,753 & Sim & Sim \\
\hline $\begin{array}{l}\mathrm{AC} / \mathrm{AT} \text { - FR-GAAP } \\
\mathrm{AC} / \mathrm{AT} \text { - IFRS } \\
\end{array}$ & $\begin{array}{l}0,838 \\
0,550 \\
\end{array}$ & $\begin{array}{l}\text { Sim } \\
\text { Sim }\end{array}$ & Sim & 0,753 & Sim & Sim \\
\hline $\begin{array}{l}\mathrm{PC} / \mathrm{PT}+\mathrm{PL} \text { - FR-GAAP } \\
\mathrm{PC} / \mathrm{PT}+\mathrm{PL} \text { - IFRS } \\
\end{array}$ & $\begin{array}{l}0,130 \\
0,335 \\
\end{array}$ & $\begin{array}{l}\text { Sim } \\
\text { Sim } \\
\end{array}$ & Sim & 0,251 & Sim & Sim \\
\hline $\begin{array}{l}\text { CCL - FR-GAAP } \\
\text { CCL - IFRS } \\
\end{array}$ & $\begin{array}{l}0,061 \\
0,032 \\
\end{array}$ & $\begin{array}{l}\text { Sim } \\
\text { Não }\end{array}$ & Não & 0,925 & Sim & Sim \\
\hline $\begin{array}{l}\mathrm{PNC} / \mathrm{PT}+\mathrm{PL} \text { - FR-GAAP } \\
\mathrm{PNC} / \mathrm{PT}+\mathrm{PL} \text { - IFRS }\end{array}$ & $\begin{array}{l}0,358 \\
0,312 \\
\end{array}$ & $\begin{array}{l}\text { Sim } \\
\text { Sim } \\
\end{array}$ & Sim & 0,418 & Sim & Sim \\
\hline $\begin{array}{l}\mathrm{PT} / \mathrm{PT}+\mathrm{PL} \text { - FR-GAAP } \\
\mathrm{PT} / \mathrm{PT}+\mathrm{PL} \text { - IFRS }\end{array}$ & $\begin{array}{l}0,900 \\
0,914\end{array}$ & $\begin{array}{l}\text { Sim } \\
\text { Sim }\end{array}$ & Sim & 0,942 & Sim & Sim \\
\hline
\end{tabular}

Houve apenas o resultado negativo para a normalidade do CCL. Desta forma, para esta ponderação será utilizado o teste não-paramétrico de Wilcoxon. Para as demais ponderações será empregado o teste de t-student para amostras emparelhadas.

Para atender esta finalidade, está abaixo a tabela que ilustra os p-values para as ponderações que foram sujeitas aos testes de médias paramétrico e não-paramétrico: 
Tabela 30 - Resultado da aplicação dos testes T-student e Wilcoxon nas ponderações dos grupos patrimoniais das empresas do setor químico da Euronext

\begin{tabular}{|c|c|c|c|c|}
\hline \multirow{2}{*}{$\begin{array}{c}\text { Ponderações dos grupos } \\
\text { do ativo e do passivo }\end{array}$} & \multicolumn{2}{|c|}{ Resultado das Médias (Sig de 5\%) } & \multicolumn{2}{|c|}{ Resultado dos Testes } \\
\hline & Mean Rank & Geral & $P$-value & $\mathrm{Sig}>5 \%$ \\
\hline \begin{tabular}{|l} 
ANC / AT - FR-GAAP \\
ANC / AT - IFRS
\end{tabular} & $\begin{array}{l}0,469151 \\
0,507179\end{array}$ & Sim & 0,285 & Sim \\
\hline $\begin{array}{l}\text { AC / AT - FR-GAAP } \\
\text { AC / AT - IFRS }\end{array}$ & $\begin{array}{l}0,530849 \\
0,492821\end{array}$ & Sim & 0,285 & Sim \\
\hline $\begin{array}{l}\text { PC / PT + PL - FR-GAAP } \\
\text { PC / PT + PL - IFRS }\end{array}$ & $\begin{array}{l}0,361159 \\
0,372839\end{array}$ & Sim & 0,684 & Sim \\
\hline $\begin{array}{l}\text { CCL - FR-GAAP } \\
\text { CCL - IFRS }\end{array}$ & $\begin{array}{l}315,8364 \\
330,7104\end{array}$ & Sim & 0,889 & Sim \\
\hline $\begin{array}{l}\mathrm{PNC} / \mathrm{PT}+\mathrm{PL} \text { - FR-GAAP } \\
\mathrm{PNC} / \mathrm{PT}+\mathrm{PL} \text { - IFRS }\end{array}$ & $\begin{array}{l}0,288316 \\
0,316412\end{array}$ & Sim & 0,534 & Sim \\
\hline $\begin{array}{l}\text { PT / PT + PL - FR-GAAP } \\
\text { PT / PT + PL - IFRS }\end{array}$ & $\begin{array}{l}0,649475 \\
0,689251\end{array}$ & Sim & 0,556 & Sim \\
\hline
\end{tabular}

Novamente, a tabela acima mostra que não é possível rejeitar a hipótese de que as médias das diferenças entre as ponderações dos grupos de contas patrimoniais das empresas químicas listadas na bolsa de Paris, a Euronext, calculadas através do balanço em FR-GAAP e em normas internacionais, no ano em que cada empresa publicou as primeiras demonstrações contábeis em IFRS, não são significativas.

\subsubsection{Comparação do nível de significância das mineradoras e das empresas químicas da França}

Para comparar a intensidade com que se relacionam os grupos patrimoniais sob análise, calculados através do padrão contábil FR-GAAP e em IFRS para as empresas de mineração e químicas da França, e utilizando o nível de significância de 5\% praticado nos testes estatísticos descritos em tópicos anteriores, proceder-se-á à comparação quantitativa e gráfica dos $p$-values referentes aos impactos da adoção das IFRS em ambos os setores franceses. 
$\mathrm{Na}$ tabela 31 foram elencados os p-values dos dois setores pesquisados na bolsa ParisEuronext:

\section{Tabela 31 - Níveis de significância das diferenças entre os grupos contábeis em FR-GAAP e IFRS das mineradoras e das empresas químicas pesquisadas na Euronext}

\begin{tabular}{|c|c|c|c|}
\hline $\begin{array}{c}\text { Ponderações dos grupos } \\
\text { do ativo e do passivo }\end{array}$ & $\begin{array}{r}P \text {-values } \\
\text { Mineradoras }\end{array}$ & $\begin{array}{l}\text { (Sig) } \\
\text { Químicas }\end{array}$ & \begin{tabular}{|c|} 
Sig Mineradoras / \\
Sig Químicas \\
\end{tabular} \\
\hline $\begin{array}{l}\text { ANC / AT - UK-GAAP } \\
\text { ANC / AT - IFRS }\end{array}$ & 0,613 & 0,285 & $215,09 \%$ \\
\hline $\begin{array}{l}\mathrm{AC} / \mathrm{AT} \text { - UK-GAAP } \\
\mathrm{AC} / \mathrm{AT} \text { - IFRS } \\
\end{array}$ & 0,613 & 0,285 & $215,09 \%$ \\
\hline $\begin{array}{l}\mathrm{PC} / \mathrm{PT}+\mathrm{PL} \text { - UK-GAAP } \\
\mathrm{PC} / \mathrm{PT}+\mathrm{PL} \text { - IFRS }\end{array}$ & 0,437 & 0,684 & $63,89 \%$ \\
\hline $\begin{array}{l}\text { CCL - UK-GAAP } \\
\text { CCL - IFRS } \\
\end{array}$ & 0,893 & 0,889 & $100,45 \%$ \\
\hline $\begin{array}{l}\mathrm{PNC} / \mathrm{PT}+\mathrm{PL} \text { - UK-GAAP } \\
\mathrm{PNC} / \mathrm{PT}+\mathrm{PL} \text { - IFRS } \\
\end{array}$ & 0,600 & 0,534 & $112,36 \%$ \\
\hline MÉDIA & & & $141,37 \%$ \\
\hline
\end{tabular}

O comparativo dos p-values referentes às diferenças entre os grupos contábeis contabilizados segundo as normas preconizadas pelo FR-GAAP e pelas IFRS para os setores de mineração e químico das empresas da Paris-Euronext apresentou também um resultado satisfatório, tanto quanto aquele obtido com os mesmos cálculos com as companhias da bolsa de valores de Frankfurt.

Percebe-se o mesmo efeito no cálculo da média do comparativo entre os p-values: na média, as diferenças entre os grupos do ativo e do passivo quando da aplicação do FR-GAAP e das IFRS para os setores de mineração e químico ficaram próximos de ter uma tendência igual, o que pode ser percebido pela porcentagem médias dos p-values: $141 \%$ para as empresas 
analisadas da Euronext. Vale lembrar que as empresas da bolsa de Frankfurt desempenharam uma média geral dos níveis de significância bastante próxima do resultado francês: $53 \%$.

O ideal para a comparação entre os níveis de significância das ponderações dos AC, PC, ANC, CCL e PNC dos dois setores seria $100 \%$.

A visualização gráfica demonstra que os níveis de significância têm números diferentes entre um setor francês e o outro, porém as tendências das retas apresentam quase os mesmos desenhos:

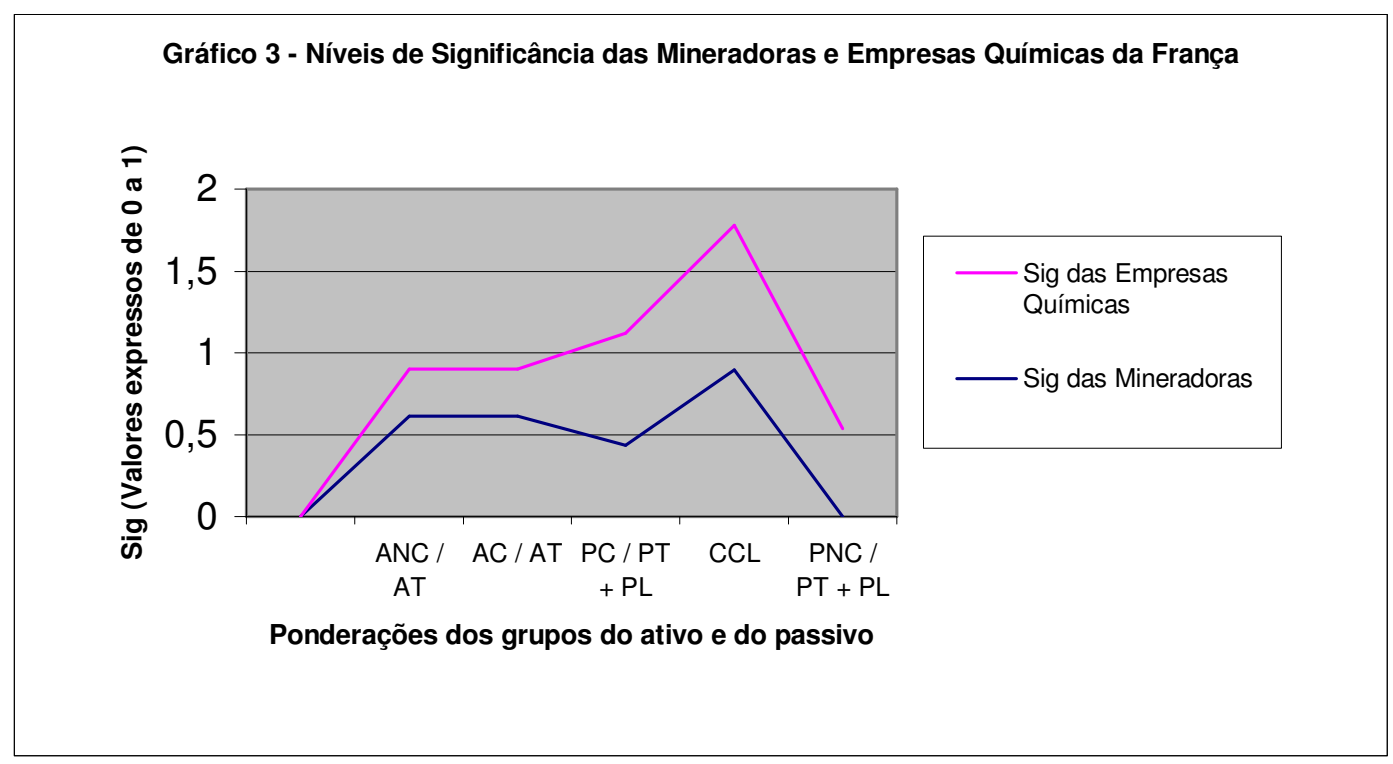

Mais uma vez há a indicação de que os balanços de quaisquer companhias francesas analisadas apresentaram efeitos semelhantes quando da adoção das normas internacionais.

A adoção das IFRS para as companhias alemãs e francesas teve quase o mesmo efeito nos grupos patrimoniais pesquisados, seja no setor de mineração, seja no setor químico. 


\section{COMPARAÇÃO DAS PONDERAÇÕES ANTES E DEPOIS DA ADOÇÃO DAS IFRS}

Neste tópico serão comparadas as médias das ponderações, antes e depois da adoção das IFRS, calculadas para os grupos do ativo e do passivo das mineradoras e das companhias químicas.

O procedimento preparatório para a análise pretendida com este capítulo é simples: serão emparelhados os grupos patrimoniais ponderados pelos respectivos ativo ou passivo total, de cada uma das empresas dos dois setores e dos três países analisados, em norma local (UKGAAP, GER-GAAP e FR-GAAP) e em IFRS, no ano da adoção do padrão internacional, para identificar o comportamento médio de cada ponderação em função da adoção das IFRS.

Para atender tal objetivo, optou-se por analisar separadamente os grupos patrimoniais.

\subsection{Ativo não-circulante}

A tabela a seguir responde pelas diferenças médias do ativo não circulante para as empresas de mineração. 
Tabela no 32 - Acréscimo médio do ANC após a adoção das IFRS - Indústria de Mineração

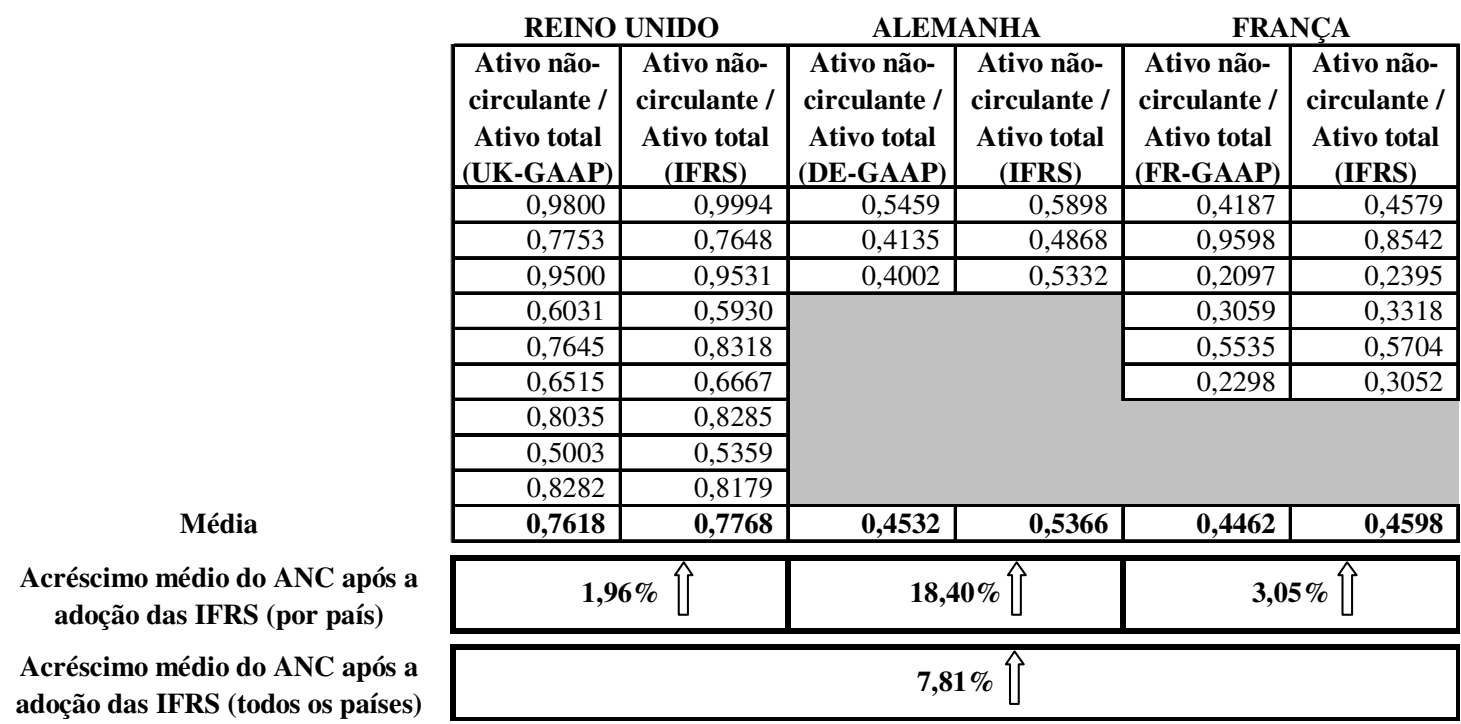

Em média, o ANC aumentou sua participação dentro do ativo total em todos os países pesquisados: no Reino Unido, 1,96\%, na Alemanha, 18,40\% e na França, 3,05\%.

Todavia, chama a atenção a disparidade dos aumentos do ANC em função da adoção das IFRS: enquanto na Alemanha o incremento médio foi de $18,4 \%$, no Reino Unido a mudança deste grupo do ativo foi elevado em apenas $1,96 \%$. Isto significa um aumento cerca de nove vezes superior no ativo não-circulante nas empresas de mineração alemãs. Entre as mineradoras inglesas e francesas há uma diferença de apenas $1 \%$.

Percebe-se a ausência de uniformidade nos resultados obtidos para o ANC das mineradoras dos três países.

No comparativo com as empresas do setor químico chega-se a uma conclusão quanto aos ANC: há pouca relação na alteração média deste grupo para os dois setores, o que é corroborado com os resultados expostos na tabela a seguir. 
Tabela n 33 - Acréscimo médio do ANC após a adoção das IFRS - Indústria Química

\begin{tabular}{|c|c|c|c|c|c|c|}
\hline & \multicolumn{2}{|c|}{ REINO UNIDO } & \multicolumn{2}{|c|}{ ALEMANHA } & \multicolumn{2}{|c|}{ FRANÇA } \\
\hline & $\begin{array}{c}\text { Ativo não- } \\
\text { circulante / } \\
\text { Ativo total } \\
\text { (UK-GAAP) } \\
\end{array}$ & $\begin{array}{c}\text { Ativo não- } \\
\text { circulante / } \\
\text { Ativo total } \\
\text { (IFRS) } \\
\end{array}$ & $\begin{array}{l}\text { Ativo não- } \\
\text { circulante / } \\
\text { Ativo total } \\
\text { (DE-GAAP) } \\
\end{array}$ & $\begin{array}{c}\text { Ativo não- } \\
\text { circulante / } \\
\text { Ativo total } \\
\text { (IFRS) } \\
\end{array}$ & $\begin{array}{c}\text { Ativo não- } \\
\text { circulante / } \\
\text { Ativo total } \\
\text { (FR-GAAP) } \\
\end{array}$ & $\begin{array}{l}\text { Ativo não- } \\
\text { circulante / } \\
\text { Ativo total } \\
\text { (IFRS) }\end{array}$ \\
\hline & 0,4517 & 0,5622 & 0,4730 & 0,3484 & 0,7095 & 0,7305 \\
\hline & 0,3764 & 0,4202 & 0,5439 & 0,5788 & 0,5006 & 0,4910 \\
\hline & 0,6567 & 0,6748 & 0,4630 & 0,4485 & 0,4282 & 0,4498 \\
\hline & 0,5379 & 0,5805 & 0,4662 & 0,4932 & 0,2536 & 0,2877 \\
\hline & 0,5482 & 0,5566 & 0,5801 & 0,5740 & 0,4555 & 0,7100 \\
\hline & 0,6602 & 0,5437 & 0,4195 & 0,4983 & 0,4010 & 0,4100 \\
\hline & & & 0,5270 & 0,4343 & 0,3838 & 0,4194 \\
\hline & & & 0,6852 & 0,6640 & 0,6209 & 0,5591 \\
\hline & & & 0,4838 & 0,4719 & & \\
\hline & & & 0,6502 & 0,6911 & & \\
\hline Média & $\mathbf{0 , 5 3 8 5}$ & 0,5563 & 0,5292 & 0,5203 & 0,4692 & 0,5072 \\
\hline $\begin{array}{c}\text { Acréscimo / Decréscimo médio } \\
\text { do ANC após a adoção das IFRS } \\
\text { (por país) }\end{array}$ & 3,3 & & $-1,6$ & $9 \%$ & & $\% \Uparrow$ \\
\hline $\begin{array}{l}\text { Acréscimo médio do ANC após a } \\
\text { adoção das IFRS (todos os países) }\end{array}$ & & & & & & \\
\hline
\end{tabular}

O caso mais extremo aconteceu com as companhias alemãs: na comparação da evolução média dos ANC para a Alemanha, considerando as empresas mineradoras e químicas negociadas na bolsa de Frankfurt, enquanto o ANC das mineradoras foi acrescido em 18,4\%, o ANC das empresas químicas decresceu 1,69\% nos balanços da primeira adoção das IFRS.

No comparativo entre os setores para o Reino Unido e França, as diferenças se comportaram no mesmo sentido positivo, porém apresentaram proporções bastante diferentes.

Portanto, com base no critério de significância de 5\% definido no final do tópico 3.1 para os resultados deste capítulo, consideram-se diferenças significativas quando da adoção das IFRS aquelas obtidas com as mineradoras alemãs, a médias das mineradoras dos três países e o incremento médio do ANC das empresas químicas francesas, todas elas com diferenças entre o padrão contábil local e as IFRS para este grupo superiores a $5 \%$. 


\subsection{Ativo circulante}

Ao comparar os ativos circulantes ponderados pelos respectivos ativos totais de cada uma das empresas dos três países analisados, em norma local (UK-GAAP, GER-GAAP e FR-GAAP) e em IFRS, no ano da adoção do padrão internacional, chegou-se aos seguintes resultados:

Tabela no 34 - Decréscimo médio do AC após a adoção das IFRS - Indústria de Mineração

\begin{tabular}{|c|c|c|c|c|c|c|}
\hline & \multicolumn{2}{|c|}{ REINO UNIDO } & \multicolumn{2}{|c|}{ ALEMANHA } & \multicolumn{2}{|c|}{ FRANÇA } \\
\hline & \begin{tabular}{|c|} 
Ativo \\
circulante / \\
Ativo total \\
(UK-GAAP) \\
\end{tabular} & $\begin{array}{c}\text { Ativo } \\
\text { circulante / } \\
\text { Ativo total } \\
\text { (IFRS) } \\
\end{array}$ & \begin{tabular}{|c|} 
Ativo \\
circulante / \\
Ativo total \\
(DE-GAAP) \\
\end{tabular} & $\begin{array}{c}\text { Ativo } \\
\text { circulante / } \\
\text { Ativo total } \\
\text { (IFRS) } \\
\end{array}$ & \begin{tabular}{|c|} 
Ativo \\
circulante / \\
Ativo total \\
(FR-GAAP) \\
\end{tabular} & $\begin{array}{c}\text { Ativo } \\
\text { circulante / } \\
\text { Ativo total } \\
\text { (IFRS) } \\
\end{array}$ \\
\hline \multirow[b]{10}{*}{ Média } & 0,0200 & 0,0006 & \begin{tabular}{|l|}
0,4541 \\
\end{tabular} & 0,4102 & 0,5813 & 0,5421 \\
\hline & 0,2246 & 0,2352 & 0,5865 & 0,5132 & 0,0402 & 0,1458 \\
\hline & 0,0500 & 0,0469 & 0,5998 & 0,4668 & 0,7903 & 0,7605 \\
\hline & 0,3969 & 0,4070 & & & 0,6941 & 0,6682 \\
\hline & 0,2354 & 0,1682 & & & 0,4465 & 0,4296 \\
\hline & 0,3485 & 0,3333 & & & 0,7702 & 0,6948 \\
\hline & 0,1966 & 0,1715 & & & & \\
\hline & 0,4997 & 0,4641 & & & & \\
\hline & 0,1718 & 0,1821 & & & & \\
\hline & $\mathbf{0 , 2 3 8 2}$ & 0,2232 & 0,5468 & 0,4634 & $\mathbf{0 , 5 5 3 8}$ & 0,5402 \\
\hline $\begin{array}{l}\text { Decréscimo médio do AC após a } \\
\text { adoção das IFRS (por país) }\end{array}$ & \multicolumn{2}{|c|}{$-6,28 \%]$} & \multicolumn{2}{|c|}{$-15,25 \%$} & \multicolumn{2}{|c|}{$-2,46 \%$} \\
\hline $\begin{array}{l}\text { Decréscimo médio do AC após a } \\
\text { adoção das IFRS (todos os países) }\end{array}$ & \multicolumn{6}{|c|}{$-8,00 \%$} \\
\hline
\end{tabular}

Se o ativo não-circulante havia sido, em média, acrescido, a consequiência para o ativo circulante teria que estar, naturalmente, na direção inversa. $\mathrm{O} A C$ das mineradoras decresceu dentro do ativo total em todos os países pesquisados: no Reino Unido, 6,28\%, na Alemanha, $15,25 \%$ e na França, $2,46 \%$.

Das médias gerais obtidas para o AC nas empresas de mineração, é considerada insignificante apenas a diferença média obtida para as mineradoras francesas, que ficou em $-2,46 \%$. $\mathrm{O}$ decréscimo médio do AC foi de $8 \%$. 
Tabela n 35 - Decréscimo médio do AC após a adoção das IFRS - Indústria Química

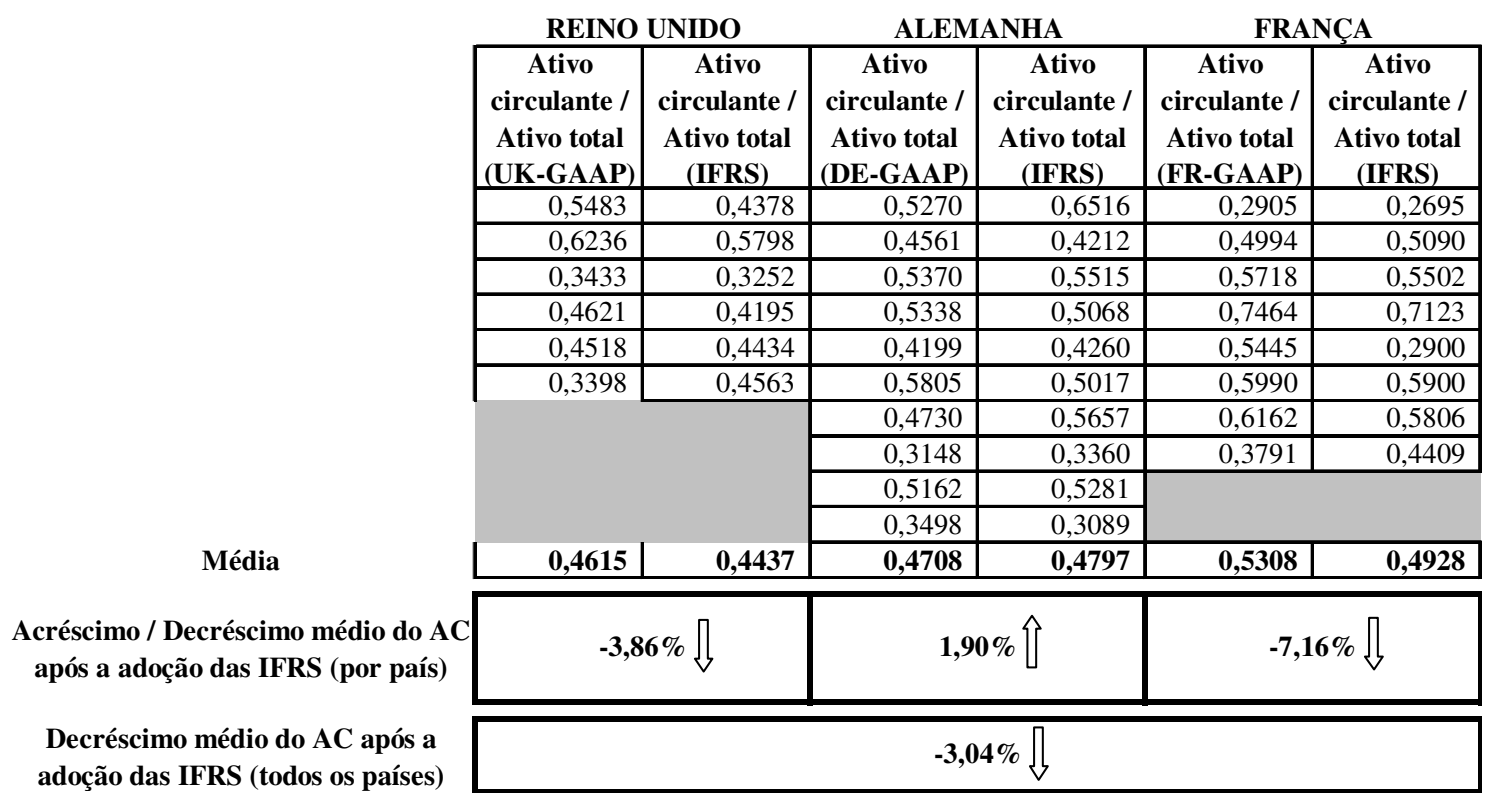

Já os resultados obtidos com a investigação das diferenças médias do AC para a amostra de empresas químicas analisadas, mostraram quase todos os resultados gerais dentro da tolerância de 5\%. Apenas a diferença média geral das químicas francesas será considerada significativa para efeito desta pesquisa, por ter ultrapassado os $5 \%$.

\subsection{Passivo circulante}

Os passivos circulantes ponderados pelos respectivos passivo + patrimônio líquido totais de cada uma das empresas dos três países e dos dois setores analisados, em norma local (UKGAAP, GER-GAAP e FR-GAAP) e em IFRS, no ano da adoção do padrão internacional, tiveram a seguinte performance geral: 
Tabela nº 36 - Decréscimo médio do PC após a adoção das IFRS - Indústria de Mineração

\begin{tabular}{|c|c|c|c|c|c|c|}
\hline & \multicolumn{2}{|c|}{ REINO UNIDO } & \multicolumn{2}{|c|}{ ALEMANHA } & \multicolumn{2}{|c|}{ FRANÇA } \\
\hline & $\begin{array}{c}\text { PC / PT + PL } \\
\text { (UK-GAAP) }\end{array}$ & $\begin{array}{c}\mathbf{P C} / \mathbf{P T}+\mathbf{P L} \\
\text { (IFRS) }\end{array}$ & $\begin{array}{c}\mathbf{P C} / \text { PT + PL } \\
\text { (DE-GAAP) }\end{array}$ & $\begin{array}{l}\mathbf{P C} / \mathbf{P T}+\mathbf{P L} \\
\quad(\text { IFRS })\end{array}$ & $\mid \begin{array}{c}\mathbf{P C} / \text { PT + PL } \\
(\text { FR-GAAP) }\end{array}$ & $\begin{array}{c}\mathrm{PC} / \mathrm{PT}+\mathrm{PL} \\
\quad \text { (IFRS) }\end{array}$ \\
\hline \multirow[b]{10}{*}{ Média } & 0,2643 & 0,2643 & \begin{tabular}{l|l|}
0,5330 \\
\end{tabular} & 0,5093 & \begin{tabular}{l|}
0,3177 \\
\end{tabular} & 0,2744 \\
\hline & 0,1945 & 0,1867 & 0,4625 & 0,2900 & 0,9122 & 0,1584 \\
\hline & 0,0494 & 0,0066 & \begin{tabular}{l|l|}
0,1505 \\
\end{tabular} & 0,2088 & \begin{tabular}{l|l|}
0,3899 \\
\end{tabular} & 0,4413 \\
\hline & 0,1677 & 0,1264 & & & 0,4489 & 0,4321 \\
\hline & 0,2144 & 0,1780 & & & 0,5660 & 0,5194 \\
\hline & 0,1494 & 0,1250 & & & \begin{tabular}{l|l|}
0,3098 \\
\end{tabular} & 0,4514 \\
\hline & 0,1320 & 0,1119 & & & & \\
\hline & 0,2093 & 0,2065 & & & & \\
\hline & 0,1039 & 0,1017 & & & & \\
\hline & 0,1650 & 0,1452 & \begin{tabular}{l|l|}
$\mathbf{0 , 3 8 2 0}$ \\
\end{tabular} & $\mathbf{0 , 3 3 6 0}$ & 0,4907 & 0,3795 \\
\hline $\begin{array}{l}\text { Decréscimo médio do PC após a } \\
\text { adoção das IFRS (por país) }\end{array}$ & \multicolumn{2}{|c|}{$-11,97 \%$ \ู } & \multicolumn{2}{|c|}{$-12,03 \%]$} & \multicolumn{2}{|c|}{$-22,67 \%]$} \\
\hline $\begin{array}{l}\text { Decréscimo médio do } P C \text { após a } \\
\text { adoção das IFRS (todos os países) }\end{array}$ & \multicolumn{6}{|c|}{$-15,56 \% \sqrt{ }$} \\
\hline
\end{tabular}

Tabela nº 37 - Decréscimo médio do PC após a adoção das IFRS - Indústria Química

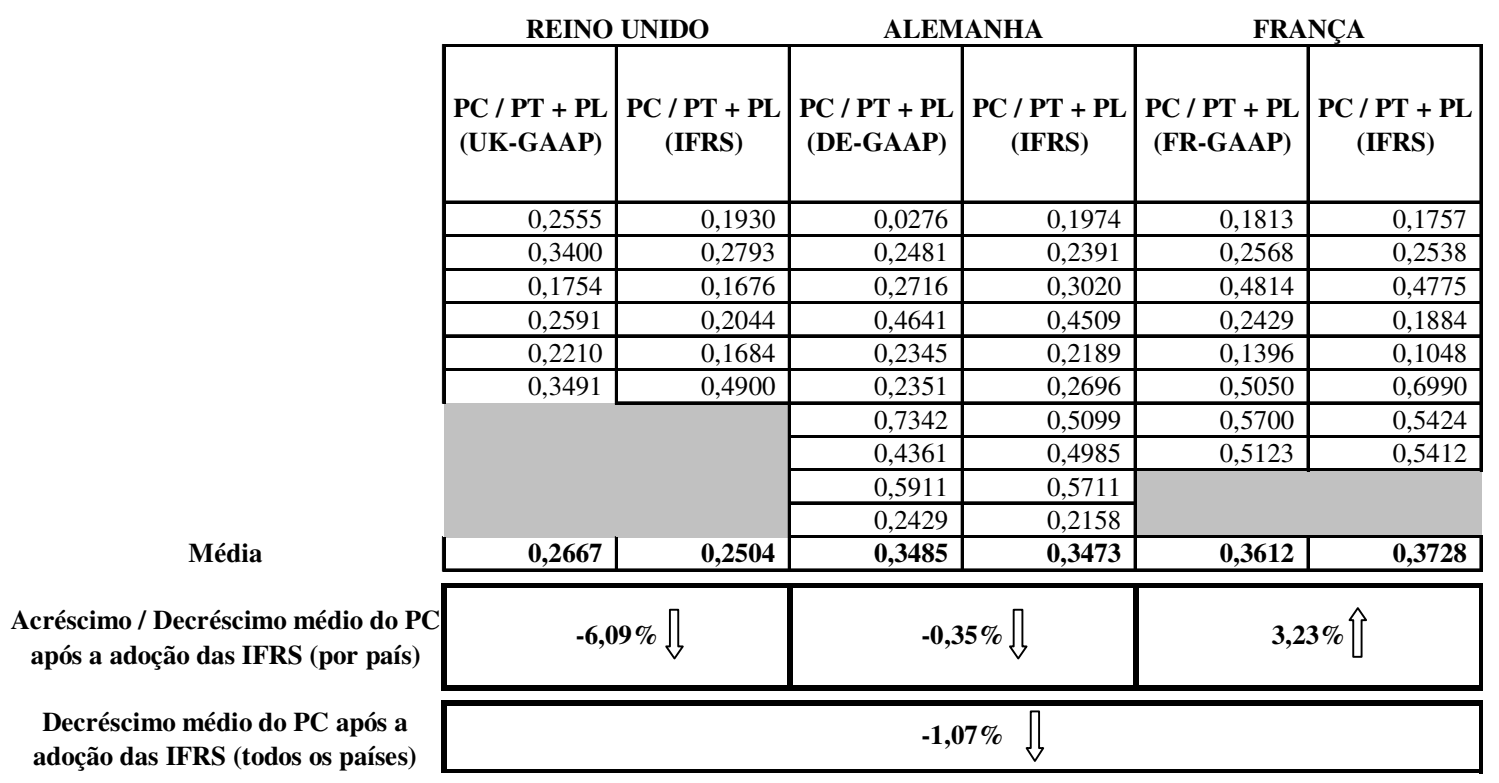

Comparativamente, os resultados das diferenças médias dos PC em função da primeira adoção das normas internacionais de contabilidade foram muito melhores para as empresas químicas deste estudo do que para as mineradoras. 
Na comparação país a país, todos os resultados obtidos com a análise da diferença média das empresas de mineração, no ano da primeira adoção das IFRS, são considerados significativos, ou seja, superiores ao teto de $5 \%$ para a tolerância da diferença. Em relação às químicas aconteceu o contrário, apenas o resultado com as empresas químicas do Reino Unido foi considerado significativo, ou seja, apenas estas apresentaram diferenças significativas para este segmento.

\subsection{Passivo não-circulante}

Dentre todos os grupos patrimoniais analisados, os resultados obtidos com o passivo nãocirculante foram os que apresentaram as maiores diferenças, tanto as individuais $(46,97 \%$ no PNC das mineradoras francesas e 60,66\% nas químicas do Reino Unido), quanto na comparação da média geral.

A exceção foi a Alemanha, cujas diferenças médias do PNC comparando os balanços da primeira adoção das IFRS e os últimos em GER-GAAP apresentaram diferenças nãosignificativas de $1 \%$ para ambos os setores.

Tabela no 38 - Acréscimo médio do PNC após a adoção das IFRS - Indústria de Mineração

\begin{tabular}{|c|c|c|c|c|c|c|}
\hline & \multicolumn{2}{|c|}{ REINO UNIDO } & \multicolumn{2}{|c|}{ ALEMANHA } & \multicolumn{2}{|c|}{ FRANÇA } \\
\hline & $\begin{array}{c}\text { PNC / PT + PL } \\
\text { (UK-GAAP) }\end{array}$ & $\begin{array}{c}\text { PNC / PT + PL } \\
\text { (IFRS) }\end{array}$ & $\begin{array}{c}\text { PNC / PT + PL } \\
\text { (DE-GAAP) }\end{array}$ & $\begin{array}{c}\text { PNC / PT + PL } \\
\text { (IFRS) }\end{array}$ & $\begin{array}{c}\text { PNC / PT + PL } \\
\text { (FR-GAAP) }\end{array}$ & $\begin{array}{c}\text { PNC / PT + PL } \\
\text { (IFRS) }\end{array}$ \\
\hline \multirow[b]{10}{*}{ Média } & - & - & 0,2035 & 0,2047 & 0,1437 & 0,2161 \\
\hline & 0,3279 & 0,3080 & 0,2031 & 0,2949 & 0,0831 & 0,8238 \\
\hline & 0,0037 & 0,1595 & 0,4670 & 0,3836 & 0,2389 & 0,1929 \\
\hline & 0,2339 & 0,2266 & & & 0,2028 & 0,2076 \\
\hline & 0,3734 & 0,3938 & & & 0,3318 & 0,3374 \\
\hline & 0,0803 & 0,1643 & & & 0,3448 & 0,1991 \\
\hline & 0,3700 & 0,4095 & & & & \\
\hline & 0,6471 & 0,4120 & & & & \\
\hline & 0,1825 & 0,3021 & & & & \\
\hline & $\mathbf{0 , 2 7 7 3}$ & 0,2970 & 0,2912 & 0,2944 & 0,2242 & $\mathbf{0 , 3 2 9 5}$ \\
\hline $\begin{array}{l}\text { Acréscimo médio do PNC por } \\
\text { país, após a adoção das IFRS }\end{array}$ & \multicolumn{2}{|c|}{$7,08 \% \uparrow$} & \multicolumn{2}{|c|}{$1,09 \% \Uparrow$} & \multicolumn{2}{|c|}{$46,97 \% \uparrow$} \\
\hline $\begin{array}{l}\text { Acréscimo médio do PNC de todos } \\
\text { os países após as IFRS }\end{array}$ & \multicolumn{6}{|c|}{$18,38 \% \hat{\jmath}$} \\
\hline
\end{tabular}


Tabela 39 - Acréscimo médio do PNC após a adoção das IFRS - Indústria Química

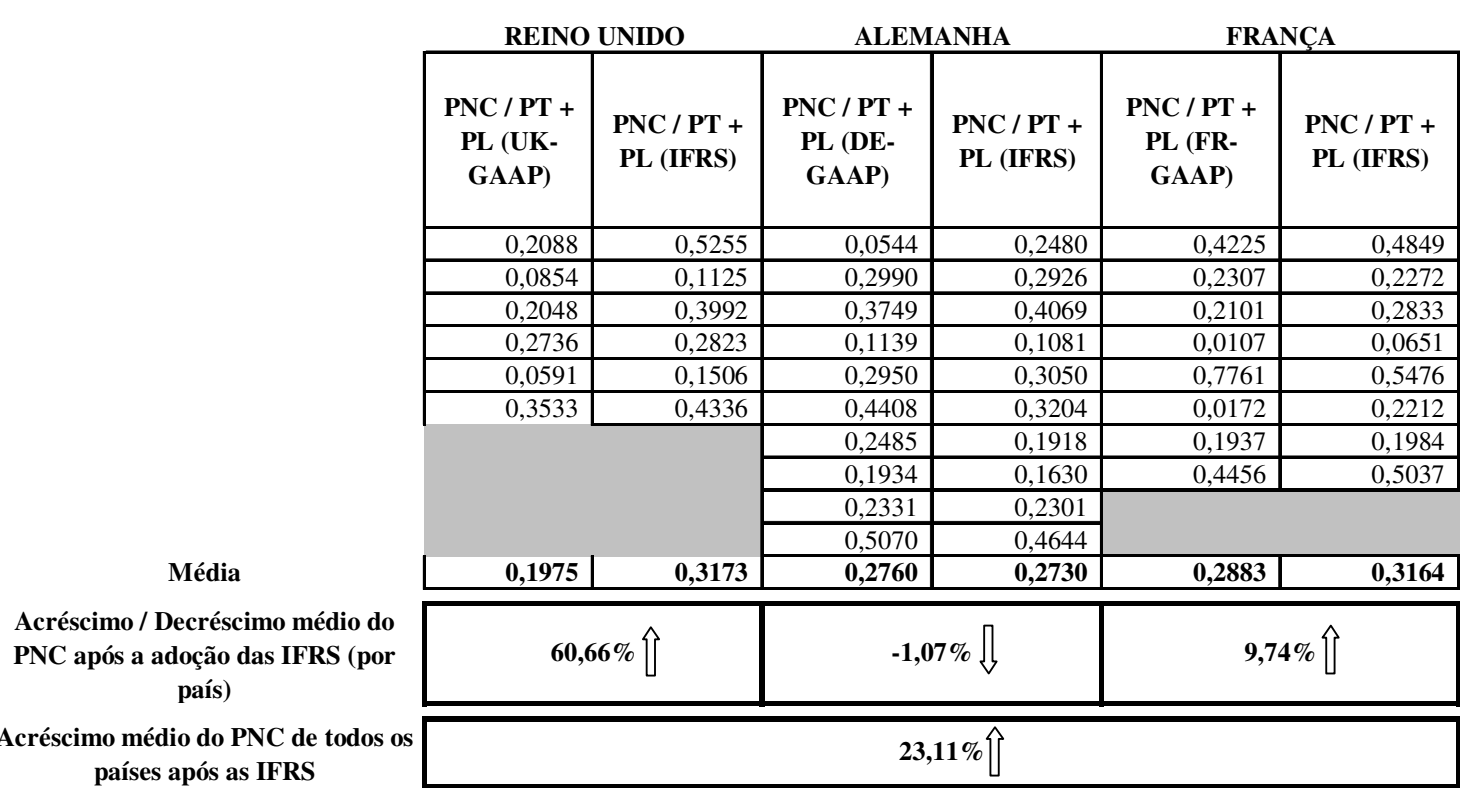

$\mathrm{Na}$ média geral dos dois setores, foram observadas as diferenças percentuais de $18,38 \%$ e 23,11\% para o PNC das empresas de mineração e químicas, respectivamente.

\subsection{Capital circulante líquido}

$\mathrm{Na}$ análise das diferenças médias do CCL para ambos os setores e os três países, constatou-se um resultado bastante positivo: é considerada significativa apenas a diferença média das empresas de mineração alemãs, cujo percentual foi um decréscimo no CCL de 11,01\% na primeira adoção das IFRS. 
Tabela no 40 - Decréscimo médio do CCL após a adoção das IFRS - Indústria de Mineração

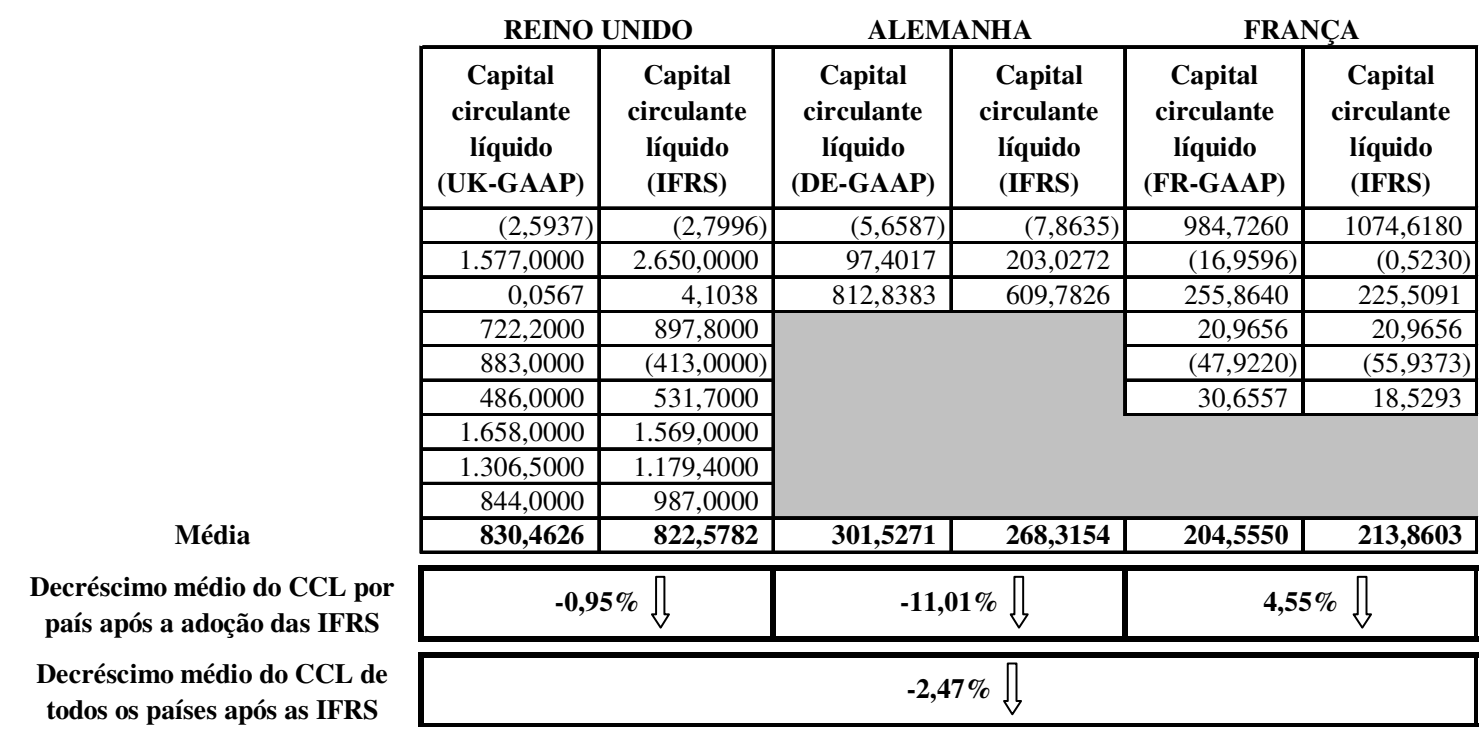

Tabela nº 41 - Decréscimo médio do CCL após a adoção das IFRS - Indústria Química

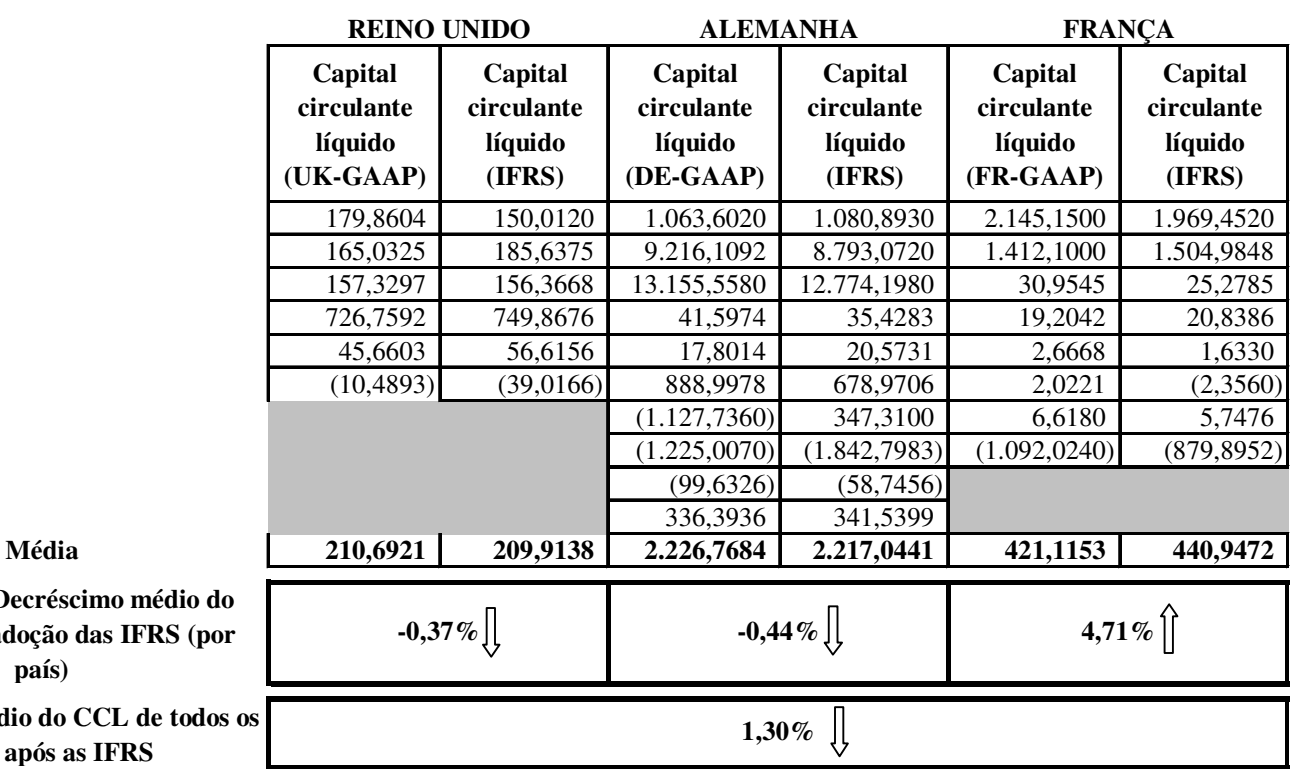

Dada a importância do índice CCL para qualquer análise de balanço, é importante constatar que a informação do capital do giro das empresas do Reino Unido, da Alemanha e da França, seja do setor químico, seja do setor de mineração, não foi fortemente influenciada quando da 
publicação do primeiro balanço em IFRS em comparação aos últimos balanços em normas contábeis locais exigidos em cada um dos três países.

A diferença média geral do CCL para os dois setores também ficou dentro da tolerância fixada de 5\%, o que é mais uma evidência positiva em comparação aos grupos patrimoniais que fizeram parte deste estudo, quais sejam o AC, ANC, PC e PNC, haja vista que em pelo menos um setor de cada um destes grupos, houve uma diferença média geral dos três países superior aos $5 \%$. 


\section{CONSIDERAÇÕES FINAIS E RECOMENDAÇÕES}

Neste capítulo se apresentam as conclusões da pesquisa como também as recomendações para futuros estudos sobre o tema.

\subsection{Considerações finais}

Esta pesquisa teve o objetivo principal de verificar se há diferença nos grupos das contas contábeis do balanço das companhias mineradoras e químicas listadas nas principais bolsas de valores da Europa calculados através das demonstrações em normas contábeis locais, em relação aos grupos de contas calculados a partir das demonstrações em normas internacionais, no ano da adoção das IFRS.

Tratando-se das empresas inglesas do setor de mineração listadas na LSE, constatou-se que as diferenças entre as ponderações dos grupos de contas patrimoniais do ativo e do passivo, calculadas através do balanço em norma contábil inglesa e em IFRS, são significativas. Neste censo, apenas o PC não demonstrou diferenças significativas quando da mudança para o padrão contábil internacional.

As companhias químicas do Reino Unido demonstraram diferenças significativas em todas as ponderações utilizadas nesta pesquisa, no ano da primeira adoção das IFRS.

Na comparação dos níveis de significância dos testes de ambos os setores para as empresas do Reino Unido, o resultado da média geral foi o mais discrepante entre os países, significando que a adoção das IFRS promoveu impactos diferentes nas mineradoras e nas companhias químicas inglesas, ou por razões normatizadoras que promoveram um efeito grande na transição do UK-GAAP para as IFRS ou porque as normas internacionais têm propriedades que podem alterar diferentemente os setores analisados.

Em relação às empresas alemãs do setor de mineração listadas na bolsa de Frankfurt, comprovou-se também que as diferenças entre as ponderações dos grupos de contas 
patrimoniais do ativo e do passivo, calculadas através do balanço em GER-GAAP e em IFRS, são significativas para todas as ponderações propostas por este estudo.

Para as empresas químicas alemãs, também não foi possível rejeitar a hipótese de que há diferenças significativas em todos os grupos patrimoniais analisados na primeira adoção das IFRS.

Entretanto, obteve-se um resultado melhor na comparação dos níveis de significância dos setores de mineração e químico para as empresas da Alemanha em relação àqueles encontrados com os censos da LSE. Isto significa que a adoção das IFRS promoveu impactos mais parecidos nos grupos patrimoniais das mineradoras e das companhias químicas alemãs.

Quanto às empresas francesas do setor de mineração listadas na Euronext, observou-se novamente que as diferenças entre as ponderações dos grupos de contas patrimoniais do ativo e do passivo, calculadas através do balanço em norma contábil francesa e em IFRS, são significativas. Tal qual no censo de mineradoras alemãs, todas as ponderações apresentaram diferenças significativas quando da aplicação das IFRS no primeiro ano de sua adoção.

Novamente, o mesmo efeito se repetiu para o outro setor analisado, o químico francês.

Como resultado, é possível afirmar que a hipótese nula de que a diferença observada no primeiro ano da substituição dos padrões contábeis inglês, alemão e francês para as IFRS promoveram mudanças significativas nas estruturas dos grupos patrimoniais, ao nível de significância de 5\%, deve ser aceita.

No que concerne ao primeiro e segundo objetivos secundários, constatou-se que as diferenças nas ponderações dos grupos do ativo e do passivo dos balanços das empresas do setor de mineração e químicas tiveram, em geral, magnitudes diferentes.

$\mathrm{Na}$ comparação da evolução média dos ANC, considerando as empresas mineradoras e químicas negociadas na bolsa de Frankfurt, enquanto o ANC das mineradoras foi acrescido em 18,4\%, o ANC das empresas químicas decresceu 1,69\% nos balanços da primeira adoção das IFRS, uma diferença de grandeza, em módulo, nove vezes maior para o ANC das mineradoras. Ao mesmo tempo, considerando a média individual dos países e a média geral 
de todos os países para o setor químico, os resultados demonstram que a diferença é significativa apenas para o setor químico da França.

Como efeito das elevações e diminuição média dos $\mathrm{ANC}$, os $\mathrm{AC}$ foram inversamente influenciados. Na média geral, os AC decresceram $8 \%$ para o setor de mineração ante o aumento de 7,81\% para os ANC referentes ao mesmo setor.

A mesma compensação de efeitos não se observou entre os PC e os PNC. Enquanto para o PC das mineradoras todos os decréscimos em função da adoção das IFRS foram considerados significativos, a comparação antes e depois das IFRS para os PC das químicas apresentou variações não-significativas, exceto para o Reino Unido. A diferença das médias gerais entre os dois setores de 15,56\% para as mineradoras e 1,07\% para as químicas expressa a baixa correlação entre os efeitos da adoção das IFRS de um setor para o outro.

As variações na comparação dos PNC tanto do setor de mineração quanto do setor químico, também apresentaram surpresas. Foi nesta ponderação que foram obtidas as maiores variações quando da adoção das IFRS: nas mineradoras francesas, o efeito da substituição dos balanços em FR-GAAP por IFRS acrescentou em $46,97 \%$ o PNC. De maneira equivalente, o PNC das companhias químicas inglesas foi acrescido em 60,66\% na primeira adoção das IFRS.

Foi identificado que a diferença média geral do CCL para os dois setores também ficou dentro da tolerância fixada de 5\%, o que é mais uma evidência positiva em comparação aos grupos patrimoniais que fizeram parte deste estudo, quais sejam o AC, ANC, PC e PNC, haja vista que em pelo menos um setor de cada um destes grupos, houve uma diferença média geral dos três países superior aos $5 \%$.

De fato, ao comparar qual dos dois setores apresentou mais efeitos de ordem não significantes (menores do que 5\%) quando da primeira adoção das IFRS, constata-se que o setor químico sempre colaborou com médias gerais para os três países inferiores a 5\%, exceto para o PNC.

Estas constatações permitiriam chamar este último capítulo de conclusões. No entanto, optouse por nomear esta seção de considerações finais, e destacar que os resultados obtidos apresentam teor de conclusões. 


\subsection{Recomendações}

Dadas as limitações da presente pesquisa, apresentam-se as recomendações para futuros estudos sobre a primeira adoção das IFRS e sua influência nos grupos patrimoniais. Diante disso, recomenda-se:

a) expandir a análise para outros setores

b) considerar empresas químicas e de mineração de outros países europeus para analisar a primeira adoção e os impactos nos grupos do ativo e do passivo

c) investigar o porquê das diferenças significativas entre os setores e entre países, considerando a investigação das normas locais peculiares aos setores

d) investigar como podem ser justificadas as diferenças de magnitudes para as variações entre os grupos pré e pós IFRS 


\section{REFERÊNCIAS}

10-K: HSBC USA INC /MD/." EDGAR Online-Glimpse (3 de março de 08): NA. Academic OneFile. Gale. FEA - USP. <http://find.galegroup.com/itx/start.do?prodId=AONE $>$. Acesso em 6 de março de 2008.

ACCOUNTING STANDARDS BOARD. Reporting Financial Performance: Proposals for Change. Discussion Paper. Junho de 1999.

ACCOUNTING STANDARDS BOARD. FRS 3. Reporting Financial Performance. Outubro de 1992.

ANDRADE, Maria M. Introdução à metodologia do trabalho científico. 7.ed. São Paulo: Atlas, 2006.

Paulo: Atlas, 1995.

Como Preparar Trabalhos para Cursos de Pós-Graduação. São

BALL, R. International Financial Reporting Standards (IFRS): Pros and Cons for Investors. Paper baseado no PD Leake Lectured entregue em 8 se setembro de 2005. Institute of Chartered Accountants in England and Wales, 2005.

Making accounting more international: Why, how, and how far will it go? Journal of Applied Corporate Finance, p.19, v.8, 1995.

BARKER, Richard. Reporting Financial Performance. Accounting Horizons. vol 8. No. 2. Junho 2004.

BEAVER, William H. Financial Reporting: an accounting revolution. Englewood Cliffs, NJ.: Prentice Hall, 1967.

BENABDELLAH S.; TELLER R. Immobilisations Corporelles et Immeubles de Placement em IFRS: le Coût Historique va-t-il Résister à la Juste Valeur ? Revue Française de Comptabilité. P. 40-44. Março de 2006.

CA - The Canadian Institute of Chartered Accountants. Reporting Financial Performance: Proposals for Change Recommendations of the G4+1. Invitation to Comment. Outubro de 1999.

CAMBRIA, Marcelo. A Qualidade da Informação Contábil das Empresas Brasileiras de Capital Aberto e o Retorno das Ações, um estudo empírico. Artigo. Disciplina Métodos Quantitativos Aplicados à Contabilidade do Curso de Pós-graduação da Faculdade de Economia, Administração e Contabilidade. 2006. 
CARVALHO, L. Nelson; MORAES, Fábio; LEMOS, Sirlei. Contabilidade Internacional: Aplicação das IFRS 2005. Ed. Atlas, 2005.

CARVAlHO, Nelson M. de. Hedge Accounting de Ativos Financeiros Segundo o Pronunciamento SFAS133: Análise dos Critérios de Reconhecimento de Receita em Face do Princípio da Realização da Receita e da Confrontação das Despesas. 2002. Dissertação (Mestrado em Controladoria e Contabilidade) - Faculdade de Economia, Administração e Contabilidade, Universidade de São Paulo.

CERVANTES, Felipe P. Comments to Amendments to IAS 1, Presentation of Financial Statements: A Revised Presentation. México. Julho de 2006.

CHAMBERS, Dennis. An Evaluation of SFAS No. 130 Comprehensive Income Disclosures. <acesso no www.ssrn.com em 10/08/2006>. Junho de 2006.

CONSELHO FEDERAL DE CONTABILIDADE. Sumário da Comparação das Práticas Contábeis Adotadas no Brasil com as Normas Internacionais de Contabilidade - IFRS. Janeiro de 2006. Disponível em: <http://www.cfc.org.br/uparq/sumario.pdf>. Acesso em jun. 2007.

CORRAR, L. J.; THEOPHILO, Carlos R. (coordenadores) Pesquisa Operacional para Decisão em Contabilidade e Administração (Contabilometria). São Paulo: Atlas, 2004.

ERNST YOUNG. Observations on the implementation of IAS/IFRS. Disponível em $<$ www.ey.com $>$. Acesso em outubro de 2006.

FASB Task Force on Financial Performance Reporting by Business Enterprises. Discussion Paper: Classification of Items of Comprehensive Income. In?

FRY, Elizabeth. Merits of switch still under debate. The Financial Times $(30$ de abril de 2008): 2. Academic OneFile. Gale. FEA - USP. Acesso em 1 de maio de 2008. $<$ http://find.galegroup.com/itx/start.do?prodId=AONE $>$.

GABRIEL, Fabiano; NETO, Alexandre Assaf; CORRAR, Luiz J. O Impacto do Fim da Correção Monetária na Rentabilidade e Adequação de Capital dos Bancos no Brasil. In:? 2003.

GIL, Antônio C. Como Elaborar Projetos de Pesquisa. 2. ed. São Paulo: Atlas, 1989.

GONZALEZ, Patrícia G. Estudo Empírico para Mensurar Aspectos de Harmonização entre as Práticas e Normas Contábeis Utilizadas pelas Empresas Argentinas, Brasileiras e Colombianas. 2001. Tese (Doutorado em Controladoria e Contabilidade) - Faculdade de Economia, Administração e Contabilidade, Universidade de São Paulo. 
HEFFES, Blen M.; GRAZIANO, Cheryl de M. Financial Executive. Periódico da Financial Reporting. Morristown: setembro de 2007. Vol. 23, Num. 7: p. 22, 5 p. Acesso em: $<$ http://proquest.umi.com//pqdweb?did=1335929611\&sid=1\&Fmt=4\&clientId=61611\&RQT $=309 \&$ VName $=$ PQD $>$ em 17 de setembro de 2007 .

HENDRIKSEN, Eldon S.; VAN BREDA, Michael F. Teoria da Contabilidade. Tradução de Antonio Zoratto Sanvicente. São Paulo: Atlas, 1999.

HUGHES, Jennifer. CEOs need to take account of IFRS. The Financial Times (30 de abril de 2008): 1. Academic OneFile. Gale. FEA - USP. Acesso em 1 de maio de 2008. $<$ http://find.galegroup.com/itx/start.do?prodId=AONE $>$.

IASB; FASB. A Roadmap for Convergence between IFRSs and US GAAP - 2006-2008.

; FASB. Action Alert No 06-30. Julho de 2006.

- Exposure Draft of Proposed Amendments to IAS 1 Presentation of Financial Statements - A Revised Presentation. Exposure Draft. Março de 2006.

Exposure Drafts. Junho de 2005.

Board Decisions on International Financial Reporting Standards. IASB UPDATE. Julho de 2006.

; FASB. Memorandum of Understanding between the FASB and the IASB. Memorandum. Fevereiro de 2006.

; FASB. Memorando da Reunião do $J I G$ sobre Performance Reporting. Nova Iorque. Memorandum. Junho de 2005.

; FASB. IASB and FASB October 2006. Observer Notes. 24/10/2006.

KERLINGER, Fred N. Metodologia da Pesquisa em Ciências Sociais. São Paulo: EPU, 1980.

KLANN, Roberto C. Impacto da Evidenciação Contábil Segundo as Normas Brasileiras, Americanas e Européias em Indicadores de Desempenho de Empresas. 2007. Dissertação (Mestrado em Ciências Contábeis) - Centro de Ciências Sociais Aplicadas, Universidade Regional de Blumenau.

LEITE, J. S. J. Normas Contábeis Internacionais - Uma Visão Para o Futuro. In: $17^{\text {a }}$ Convenção dos Contabilistas do Estado de São Paulo, São Paulo, setembro de 2001. 
LEMES, Sirlei. Harmonização das Normas Contábeis Brasileiras com as Internacionais do IASC - Um Estudo Comparativo Aplicado. 2000. Tese (Doutorado em Controladoria e Contabilidade) - Faculdade de Economia, Administração e Contabilidade, Universidade de São Paulo.

LEMES, Sirlei; CARVALHO, Luiz N. G. Efeito da Convergência das Normas Contábeis Brasileiras para as Normas Internacionais do IASB. Artigo apresentado ao Seminário USP de Contabilidade. Anais. 2004.

LISBOA, Nahor P. Harmonização de Normas e Práticas Contábeis no Mercosul. 2000. Tese (Doutorado em Controladoria e Contabilidade) - Faculdade de Economia, Administração e Contabilidade, Universidade de São Paulo.

LONDON STOCK EXCHANGE < http://www.londonstockexchange.com/ >. Acesso em agosto de 2007.

LOPES, Alexsandro B. A informação contábil e o mercado de capitais. 1.ed. São Paulo: Pioneira Thomson Learning, 2002.

MAINES, Laureen A; MCDANIEL, Linda S. Effects of Comprehensive-Income Characteristics on Nonprofessional Investors' Judgements: The Role of FinancialStatement Presentation Format. Dezembro de 1999.

MARCONI, Marina A.; LAKATOS, Eva M.. Metodologia Científica. 4. ed. São Paulo: Atlas, 2004.

MAROCO, João. Análise Estatística Com Utilização do SPSS. 2.ed. Lisboa: Editora Silabo, Abril de 2003.

MARTINS, Gilberto de A. Manual para Elaboração de Monografias e Dissertações. $3^{\mathrm{a}}$ ed. São Paulo: Atlas, 2002.

; Gilberto de Andrade; LINTZ, Alexandre. Guia para Elaboração de Monografias e Trabalhos de Conclusão de Curso. São Paulo, Atlas, 2000.

; PELISSARO, Joel. Sobre Conceitos, Definições e Constructos nas Ciências Contábeis. Revista de Administração e Contabilidade da Unisinos: p. 78-84, maio/agosto 2005 .

MATARAZZO, Dante C. Análise Financeira de Balanços: Abordagem Básica e Gerencial. São Paulo, 6.ed. Atlas, 2007. 
MELO LOPES, Christianne C. V de. Estudo Comparativo sobre as Formas de Combinações de Empresas Segundo as Normas Internacionais e Brasileiras de Contabilidade. 2001. Dissertação (Mestrado em Controladoria e Contabilidade) - Faculdade de Economia, Administração e Contabilidade, Universidade de São Paulo.

PLATIKANOVA, Petya; NOBES, Christopher. Was The Introduction of IFRS in Europe Value-Relevant? FMA European Doctoral Seminar 2006. 2006.

RICHARDSON, Roberto J. Pesquisa Social: Métodos e Técnicas. 3. ed. São Paulo: Atlas, 1999.

SCHATT, Alain; GROSS, Elise. Quelle est L'Incidence des Normes IAS/IFRS sur les Capitaux Propres des Entreprises Françaises ? Revue Francaise de Comptabilité; Feb 2007; 396; p.35. ABI/INFORM Global.

STEVEnSON, William J. Estatística Aplicada à Administração. São Paulo: Ed. Harbra, 2001.

SULLIVAN, Jenni; ZAMAN, Farhad; BARKER, Richard; KISPERT, Holly. History of the Performance Reporting Project. Papel de Trabalho no. 2 do Grupo Internacional de Discussão de Performance Reporting. Londres. Janeiro 2005.

TAYLOR, Paul. A single standard makes sense for global business. The Financial Times (30 de abril de 2008): 3. Academic OneFile. Gale. FEA - USP. Acesso em 1 de maio de 2008. <http://find.galegroup.com/itx/start.do?prodId=AONE>.

TORT, E. Etude d'Impact de la Conversion des Foncières Cotées aux Normes Comptables Internationales. Revue Française de Comptabilité. P.50-54. Setembro de 2005.

WEFFORT, Elionor F. J. O Brasil e a Harmonização Contábil Internacional: Influências dos Sistemas Jurídico e Educacional, da Cultura e do Mercado. 2003. Tese (Doutorado em Controladoria e Contabilidade) - Faculdade de Economia, Administração e Contabilidade, Universidade de São Paulo. 


\section{APÊNDICES}

APÊNDICE 1 - SETORES DAS EMPRESAS QUE CONSTAM DAS BOLSAS DE VALORES EUROPÉIAS. 92

APÊNDICE 2 - RESULTADO DOS TESTES T-STUDENT NAS PONDERAÇÕES DOS GRUPOS DE CONTAS DOS BALANÇOS DAS EMPRESAS DE MINERAÇÃO DA LSE (IFRS X UK-GAAP).

APÊNDICE 3 - RESULTADO DOS TESTES T-STUDENT NAS PONDERAÇÕES DOS GRUPOS DE CONTAS DOS BALANÇOS DAS EMPRESAS QUÍMICAS DA LSE (IFRS X UK-GAAP). 96

APÊNDICE 4 - RESULTADO DOS TESTES T-STUDENT NAS PONDERAÇÕES DOS GRUPOS DE CONTAS DOS BALANÇOS DAS EMPRESAS ALEMÃS DE MINERAÇÃO NA BOLSA DE FRANKFURT (IFRS X GER-GAAP). 99

APÊNDICE 5 - RESULTADO DOS TESTES T-STUDENT NAS PONDERAÇÕES DOS GRUPOS DE CONTAS DOS BALANÇOS DAS EMPRESAS ALEMÃS DO SETOR QUÍMICO NA BOLSA DE FRANKFURT (IFRS X GER-GAAP). 102

APÊNDICE 6 - RESULTADO DOS TESTES T-STUDENT NAS PONDERAÇÕES DOS GRUPOS DE CONTAS DOS BALANÇOS DAS EMPRESAS FRANCESAS DO SETOR DE MINERAÇÃO NA EURONEXT (IFRS X FRA-GAAP). 105

APÊNDICE 7 - RESULTADO DOS TESTES T-STUDENT NAS PONDERAÇÕES DOS GRUPOS DE CONTAS DOS BALANÇOS DAS EMPRESAS FRANCESAS DO SETOR QUÍMICO NA EURONEXT (IFRS X FRA-GAAP). 108 


\begin{tabular}{|c|c|}
\hline \multicolumn{2}{|c|}{ Setores } \\
\hline Aerospace & Home Construction \\
\hline Airlines & Home Improvement Retailers \\
\hline Apparel Retailers & Hotels \\
\hline Asset Managers & Industrial Machinery \\
\hline Auto Parts & Industrial Suppliers \\
\hline Banks & Insurance Brokers \\
\hline Biotechnology & Integrated Oil \& Gas \\
\hline Brewers & Internet \\
\hline Broadcasting \& Entertainment & Investment Services \\
\hline Broadline Retailers & Life Insurance \\
\hline Building Materials \& Fixtures & Media Agencies \\
\hline Business Support Services & Medical Equipment \\
\hline Business Training \& Employment Agencies & Medical Supplies \\
\hline Clothing \& Accessories & Mobile Telecommunications \\
\hline Coal & Mortgage Finance \\
\hline Commercial Vehicles \& Trucks & Multiutilities \\
\hline Company Bonds & Nondurable Household Products \\
\hline Computer Hardware & Nonequity Investment Instruments \\
\hline Computer Services & Oil Equipment \& Services \\
\hline Consumer Electronics & Paper \\
\hline Consumer Finance & Personal Products \\
\hline Containers \& Packaging & Pharmaceuticals \\
\hline Convertibles & Platinum \& Precious Metals \\
\hline Debentures \& Loans & Preference \\
\hline Defence & Property \& Casualty Insurance \\
\hline Delivery Services & Publishing \\
\hline Distillers \& Vintners & Railroads \\
\hline Diversified Industrials & Real Estate Holding \& Development \\
\hline Drug Retailers & Real Estate Investment Trusts \\
\hline Durable Household Products & Recreational Products \\
\hline Electrical Components \& Equipment & Recreational Services \\
\hline Electricity & Restaurants \& Bars \\
\hline Electronic Equipment & Semiconductors \\
\hline Electronic Office Equipment & Soft Drinks \\
\hline Equity Investment Instruments & Software \\
\hline Exploration \& Production & Specialized Consumer Services \\
\hline Farming \& Fishing & Specialty Chemicals \\
\hline Financial Administration & Specialty Finance \\
\hline Fixed Line Telecommunications & Specialty Retailers \\
\hline Food Products & Steel \\
\hline Food Retailers \& Wholesalers & Sub-sector \\
\hline Full Line Insurance & Telecommunications Equipment \\
\hline Furnishings & Tobacco \\
\hline Gambling & Toys \\
\hline Gas Distribution & Transportation Services \\
\hline General Mining & Travel \& Tourism \\
\hline Gold Mining & Trucking \\
\hline Health Care Providers & Waste \& Disposal Services \\
\hline Heavy Construction & Water \\
\hline
\end{tabular}


ATIVO NÃO-CIRCULANTE / ATIVO TOTAL

Paired Samples Statistics

\begin{tabular}{|c|c|c|c|c|c|}
\hline & & Mean & $\mathrm{N}$ & Std. Deviation & $\begin{array}{l}\text { Std. Error } \\
\text { Mean }\end{array}$ \\
\hline \multirow[t]{2}{*}{$\begin{array}{l}\text { Pair } \\
1\end{array}$} & $\begin{array}{l}\text { Ativo não-circulante / } \\
\text { Ativo - IFRS }\end{array}$ & ,776784 & 9 & ,1549745 & ,0516582 \\
\hline & $\begin{array}{l}\text { Ativo não-circulante / } \\
\text { Ativo - UK-GAAP }\end{array}$ & ,761830 & 9 & ,1561723 & ,0520574 \\
\hline
\end{tabular}

\begin{tabular}{|c|c|c|c|c|c|c|c|c|c|}
\hline \multicolumn{10}{|c|}{ Paired Samples Test } \\
\hline & & \multicolumn{5}{|c|}{ Paired Differences } & \multirow[b]{3}{*}{$t$} & \multirow[b]{3}{*}{ df } & \multirow[b]{3}{*}{ Sig. (2-tailed) } \\
\hline & & \multirow[b]{2}{*}{ Mean } & \multirow[b]{2}{*}{ Std. Deviation } & \multirow{2}{*}{$\begin{array}{c}\text { Std. Error } \\
\text { Mean }\end{array}$} & \multicolumn{2}{|c|}{$\begin{array}{l}95 \% \text { Confidence } \\
\text { Interval of the } \\
\text { Difference }\end{array}$} & & & \\
\hline & & & & & Lower & Upper & & & \\
\hline $\begin{array}{l}\text { Pair } \\
1\end{array}$ & $\begin{array}{l}\text { Ativo não-circulante / } \\
\text { Ativo - IFRS - Ativo } \\
\text { não-circulante / Ativo } \\
\text { - UK-GAAP }\end{array}$ &, 0149542 &, 0258601 &, 0086200 &,- 0049237 &, 0348321 & 1,735 & 8 & ,121 \\
\hline
\end{tabular}

ATIVO CIRCULANTE / ATIVO TOTAL

Paired Samples Statistics

\begin{tabular}{|c|c|c|c|c|c|}
\hline & & Mean & $\mathrm{N}$ & Std. Deviation & $\begin{array}{c}\text { Std. Error } \\
\text { Mean }\end{array}$ \\
\hline \multirow[t]{2}{*}{$\begin{array}{l}\text { Pair } \\
1\end{array}$} & $\begin{array}{l}\text { Ativo circulante / } \\
\text { Ativo - IFRS }\end{array}$ & ,223216 & 9 & , 1549745 & ,0516582 \\
\hline & $\begin{array}{l}\text { Ativo circulante / } \\
\text { Ativo - UK-GAAP }\end{array}$ & ,238170 & 9 &, 1561721 & ,0520574 \\
\hline
\end{tabular}

Paired Samples Test

\begin{tabular}{|c|c|c|c|c|c|c|c|c|c|}
\hline & & \multicolumn{5}{|c|}{ Paired Differences } & \multirow[b]{3}{*}{$t$} & \multirow[b]{3}{*}{ df } & \multirow[b]{3}{*}{ Sig. (2-tailed) } \\
\hline & & \multirow[b]{2}{*}{ Mean } & \multirow[b]{2}{*}{ Std. Deviation } & \multirow{2}{*}{$\begin{array}{l}\text { Std. Error } \\
\text { Mean }\end{array}$} & \multicolumn{2}{|c|}{$\begin{array}{l}95 \% \text { Confidence } \\
\text { Interval of the } \\
\text { Difference }\end{array}$} & & & \\
\hline & & & & & Lower & Upper & & & \\
\hline $\begin{array}{l}\text { Pair } \\
1\end{array}$ & $\begin{array}{l}\text { Ativo circulante / Ativo - } \\
\text { IFRS - Ativo circulante } \\
\text { / Ativo - UK-GAAP }\end{array}$ &,- 0149534 & ,0258640 &, 0086213 &,- 0348342 & ,0049274 & $-1,734$ & 8 & , 121 \\
\hline
\end{tabular}


PASSIVO CIRCULANTE / PASSIVO TOTAL + PATRIMÔNIO LÍQUIDO

Paired Samples Statistics

\begin{tabular}{|c|c|c|c|c|c|}
\hline & & Mean & $\mathrm{N}$ & Std. Deviation & $\begin{array}{l}\text { Std. Error } \\
\text { Mean }\end{array}$ \\
\hline \multirow[t]{2}{*}{$\begin{array}{l}\text { Pair } \\
1\end{array}$} & $\begin{array}{l}\text { Passivo circulante / } \\
\text { Pasivo + PL - IFRS }\end{array}$ & ,145236 & 9 & ,0739166 & ,0246389 \\
\hline & $\begin{array}{l}\text { Passivo circulante / } \\
\text { Pasivo + PL - UK-GAAP }\end{array}$ & ,164989 & 9 & ,0647682 & ,0215894 \\
\hline
\end{tabular}

Paired Samples Test

\begin{tabular}{|c|c|c|c|c|c|c|c|c|c|}
\hline & & \multicolumn{5}{|c|}{ Paired Differences } & \multirow[b]{3}{*}{$\mathrm{t}$} & \multirow[b]{3}{*}{ df } & \multirow[b]{3}{*}{ Sig. (2-tailed) } \\
\hline & & \multirow[b]{2}{*}{ Mean } & \multirow[b]{2}{*}{ Std. Deviation } & \multirow{2}{*}{$\begin{array}{l}\text { Std. Error } \\
\text { Mean }\end{array}$} & \multicolumn{2}{|c|}{$\begin{array}{l}95 \% \text { Confidence } \\
\text { Interval of the } \\
\text { Difference }\end{array}$} & & & \\
\hline & & & & & Lower & Upper & & & \\
\hline $\begin{array}{l}\text { Pair } \\
1\end{array}$ & $\begin{array}{l}\text { Passivo circulante / } \\
\text { Pasivo + PL - IFRS - } \\
\text { Passivo circulante / } \\
\text { Pasivo + PL - UK-GAAP }\end{array}$ &,- 0197529 & ,0174005 & ,0058002 &,- 0331281 &,- 0063778 & $-3,406$ & 8 &, 009 \\
\hline
\end{tabular}

CCL

Paired Samples Statistics

\begin{tabular}{|c|c|c|c|c|c|}
\hline & & Mean & $\mathrm{N}$ & Std. Deviation & $\begin{array}{l}\text { Std. Error } \\
\text { Mean }\end{array}$ \\
\hline \multirow{2}{*}{$\begin{array}{l}\text { Pair } \\
1\end{array}$} & CCL - IFRS & 822,5782 & 9 & 936,6858545 & 312,2286 \\
\hline & CCL - UK-GAAP & 830,4626 & 9 & 610,9033604 & 203,6345 \\
\hline
\end{tabular}

Paired Samples Test

\begin{tabular}{|c|c|c|c|c|c|c|c|c|c|}
\hline & & \multicolumn{5}{|c|}{ Paired Differences } & \multirow[b]{3}{*}{$t$} & \multirow[b]{3}{*}{$\mathrm{df}$} & \multirow[b]{3}{*}{ Sig. (2-tailed) } \\
\hline & & \multirow[b]{2}{*}{ Mean } & \multirow[b]{2}{*}{ Std. Deviation } & \multirow{2}{*}{$\begin{array}{c}\text { Std. Error } \\
\text { Mean }\end{array}$} & \multicolumn{2}{|c|}{$\begin{array}{l}95 \% \text { Confidence } \\
\text { Interval of the } \\
\text { Difference }\end{array}$} & & & \\
\hline & & & & & Lower & Upper & & & \\
\hline $\begin{array}{l}\text { Pair } \\
1\end{array}$ & $\begin{array}{l}\mathrm{CCL} \text { - IFRS - } \\
\mathrm{CCL} \text { - UK-GAAP }\end{array}$ & $-7,88431$ & 602,8940848 & 200,9647 & $-471,310$ & 455,5411 &,- 039 & 8 & ,970 \\
\hline
\end{tabular}




\section{PASSIVO NÃO-CIRCULANTE / PASSIVO TOTAL + PATRIMÔNIO LÍQUIDO}

Paired Samples Statistics

\begin{tabular}{|ll|l|r|r|c|}
\hline & & Mean & N & Std. Deviation & \multicolumn{1}{c|}{$\begin{array}{c}\text { Std. Error } \\
\text { Mean }\end{array}$} \\
\hline $\begin{array}{l}\text { Pair } \\
1\end{array}$ & $\begin{array}{l}\text { Passivo não-circulante / } \\
\text { Passivo + PL - IFRS } \\
\text { Passivo não-circulante / } \\
\text { Passivo + PL - UK-GAAP }\end{array}$ &, 263979 & 9 &, 1393125 &, 0464375 \\
& ,246532 & 9 &, 2091836 &, 0697279 \\
\hline
\end{tabular}

Paired Samples Test

\begin{tabular}{|c|c|c|c|c|c|c|c|c|c|}
\hline & & \multicolumn{5}{|c|}{ Paired Differences } & \multirow[b]{3}{*}{$t$} & \multirow[b]{3}{*}{ df } & \multirow[b]{3}{*}{ Sig. (2-tailed) } \\
\hline & & \multirow[b]{2}{*}{ Mean } & \multirow[b]{2}{*}{ Std. Deviation } & \multirow{2}{*}{$\begin{array}{l}\text { Std. Error } \\
\text { Mean }\end{array}$} & \multicolumn{2}{|c|}{$\begin{array}{l}95 \% \text { Confidence } \\
\text { Interval of the } \\
\text { Difference }\end{array}$} & & & \\
\hline & & & & & Lower & Upper & & & \\
\hline $\begin{array}{l}\text { Pair } \\
1\end{array}$ & $\begin{array}{l}\text { Passivo não-circulante / } \\
\text { Passivo + PL - IFRS - } \\
\text { Passivo não-circulante / } \\
\text { Passivo + PL - UK-GAAP }\end{array}$ &, 0174467 & ,1121387 & ,0373796 &,- 0687507 & ,1036441 & ,467 & 8 & ,653 \\
\hline
\end{tabular}

PASSIVO TOTAL / PASSIVO TOTAL + PATRIMÔNIO LÍQUIDO

Paired Samples Statistics

\begin{tabular}{|ll|l|r|r|r|}
\hline & & Mean & N & Std. Deviation & $\begin{array}{c}\text { Std. Error } \\
\text { Mean }\end{array}$ \\
\hline $\begin{array}{l}\text { Pair } \\
1\end{array}$ & $\begin{array}{l}\text { Passivo / Passivo } \\
+ \text { PL - IFRS } \\
\text { Passivo / Passivo } \\
+ \text { PL - UK-GAAP }\end{array}$ &, 409214 & 9 &, 1532216 &, 0510739 \\
\hline
\end{tabular}

Paired Samples Test

\begin{tabular}{|c|c|c|c|c|c|c|c|c|c|}
\hline & & \multicolumn{5}{|c|}{ Paired Differences } & \multirow[b]{3}{*}{$\mathrm{t}$} & \multirow[b]{3}{*}{$\mathrm{df}$} & \multirow[b]{3}{*}{ Sig. (2-tailed) } \\
\hline & & \multirow[b]{2}{*}{ Mean } & \multirow[b]{2}{*}{ Std. Deviation } & \multirow{2}{*}{$\begin{array}{c}\text { Std. Error } \\
\text { Mean }\end{array}$} & \multicolumn{2}{|c|}{$\begin{array}{l}95 \% \text { Confidence } \\
\text { Interval of the } \\
\text { Difference }\end{array}$} & & & \\
\hline & & & & & Lower & Upper & & & \\
\hline $\begin{array}{l}\text { Pair } \\
1\end{array}$ & $\begin{array}{l}\text { Passivo / Passivo + PL - } \\
\text { IFRS - Passivo / Passivo } \\
+ \text { PL - UK-GAAP }\end{array}$ &, 0056459 & ,0790760 & ,0263587 &,- 0551373 & ,0664292 & ,214 & 8 & ,836 \\
\hline
\end{tabular}


ATIVO NÃO-CIRCULANTE / ATIVO TOTAL

Paired Samples Statistics

\begin{tabular}{|c|c|c|c|c|c|}
\hline & & Mean & $\mathrm{N}$ & Std. Deviation & $\begin{array}{l}\text { Std. Error } \\
\text { Mean }\end{array}$ \\
\hline \multirow[t]{2}{*}{$\begin{array}{l}\text { Pair } \\
1\end{array}$} & $\begin{array}{l}\text { Ativo não-circulante / } \\
\text { Ativo - IFRS }\end{array}$ &, 556329 & 6 & 0816496, & ,0333333 \\
\hline & $\begin{array}{l}\text { Ativo não-circulante / } \\
\text { Ativo - UK-GAAP }\end{array}$ & ,538520 & 6 & 1119953, & ,0457219 \\
\hline
\end{tabular}

Paired Samples Test

\begin{tabular}{|c|c|c|c|c|c|c|c|c|c|}
\hline & & \multicolumn{5}{|c|}{ Paired Differences } & \multirow[b]{3}{*}{$\mathrm{t}$} & \multirow[b]{3}{*}{ df } & \multirow[b]{3}{*}{ Sig. (2-tailed) } \\
\hline & & \multirow[b]{2}{*}{ Mean } & \multirow[b]{2}{*}{ Std. Deviation } & \multirow{2}{*}{$\begin{array}{l}\text { Std. Error } \\
\text { Mean }\end{array}$} & \multicolumn{2}{|c|}{$\begin{array}{c}95 \% \text { Confidence } \\
\text { Interval of the } \\
\text { Difference }\end{array}$} & & & \\
\hline & & & & & Lower & Upper & & & \\
\hline $\begin{array}{l}\text { Pair } \\
1\end{array}$ & $\begin{array}{l}\text { Ativo não-circulante } \\
\text { Ativo - IFRS - Ativo } \\
\text { não-circulante / Ativo } \\
\text { - UK-GAAP }\end{array}$ &, 0178090 & ,0748581 & ,0305607 &,- 0607498 & ,0963678 &, 583 & 5 & ,585 \\
\hline
\end{tabular}

ATIVO CIRCULANTE / ATIVO TOTAL

Paired Samples Statistics

\begin{tabular}{|ll|l|r|r|r|}
\hline & Mean & N & Std. Deviation & $\begin{array}{c}\text { Std. Error } \\
\text { Mean }\end{array}$ \\
\hline $\begin{array}{l}\text { Pair } \\
1\end{array}$ & $\begin{array}{l}\text { Ativo circulante / } \\
\text { Ativo - IFRS } \\
\text { Ativo circulante / } \\
\text { Ativo - UK-GAAP }\end{array}$ &, 443671 & 6 &, 0816496 &, 0333333 \\
\hline
\end{tabular}

Paired Samples Test

\begin{tabular}{|c|c|c|c|c|c|c|c|c|c|}
\hline & & \multicolumn{5}{|c|}{ Paired Differences } & \multirow[b]{3}{*}{$t$} & \multirow[b]{3}{*}{ df } & \multirow[b]{3}{*}{ Sig. (2-tailed) } \\
\hline & & \multirow[b]{2}{*}{ Mean } & \multirow[b]{2}{*}{ Std. Deviation } & \multirow{2}{*}{$\begin{array}{l}\text { Std. Error } \\
\text { Mean }\end{array}$} & \multicolumn{2}{|c|}{$\begin{array}{l}95 \% \text { Confidence } \\
\text { Interval of the } \\
\text { Difference }\end{array}$} & & & \\
\hline & & & & & Lower & Upper & & & \\
\hline $\begin{array}{l}\text { Pair } \\
1\end{array}$ & $\begin{array}{l}\text { Ativo circulante / Ativo - } \\
\text { IFRS - Ativo circulante } \\
\text { / Ativo - UK-GAAP }\end{array}$ &,- 0178090 & ,0748581 & ,0305607 &,- 0963678 & ,0607498 &,- 583 & 5 &, 585 \\
\hline
\end{tabular}


CCL

Paired Samples Test

\begin{tabular}{|c|c|c|c|c|c|c|c|c|c|}
\hline & \multicolumn{5}{|c|}{ Paired Differences } & \multirow[b]{3}{*}{$\mathrm{t}$} & \multirow[b]{3}{*}{$\mathrm{df}$} & \multirow[b]{3}{*}{ Sig. (2-tailed) } \\
\hline & & \multirow[b]{2}{*}{ Mean } & \multirow[b]{2}{*}{ Std. Deviation } & \multirow{2}{*}{$\begin{array}{l}\text { Std. Error } \\
\text { Mean }\end{array}$} & \multicolumn{2}{|c|}{$\begin{array}{l}95 \% \text { Confidence } \\
\text { Interval of the } \\
\text { Difference }\end{array}$} & & & \\
\hline & & & & & Lower & Upper & & & \\
\hline $\begin{array}{l}\text { Pair } \\
1\end{array}$ & $\begin{array}{l}\mathrm{CCL} \text { - IFRS - } \\
\mathrm{CCL} \text { - UK-GAAP }\end{array}$ &,- 7783038 & 23,5822265 & 9,6274037 & $-25,5263$ & 23,96973 &,- 081 & 5 & ,939 \\
\hline
\end{tabular}

PASSIVO CIRCULANTE / PASSIVO TOTAL + PATRIMÔNIO LÍQUIDO

Tests of Normality

\begin{tabular}{|ll|r|r|r|r|r|r|}
\hline & \multicolumn{3}{|c|}{ Kolmogorov-Smirnov $^{\text {a }}$} & \multicolumn{3}{c|}{ Shapiro-Wilk } \\
\cline { 2 - 8 } & GAAP & Statistic & df & \multicolumn{1}{c|}{ Sig. } & Statistic & df & \multicolumn{1}{c|}{ Sig. } \\
\hline Pass Circ / P + PL & 0 &, 211 & 6 &, $200^{*}$ &, 929 & 6 &, 570 \\
& 1 &, 311 & 6 &, 071 &, 742 & 6 &, 017 \\
\hline
\end{tabular}

*. This is a lower bound of the true significance.

a. Lilliefors Significance Correction

Test of Homogeneity of Variance

\begin{tabular}{|ll|r|r|r|r|}
\hline & & Levene & & & \\
& & Statistic & df1 & df2 & \multicolumn{1}{c|}{ Sig. } \\
\hline Pass Circ / P + PL & Based on Mean & 1,184 & 1 & 10 &, 302 \\
& Based on Median &, 266 & 1 & 10 &, 617 \\
& Based on Median and &, 266 & 1 & 6,405 &, 623 \\
& with adjusted df &, 912 & 1 & 10 &, 362 \\
\hline
\end{tabular}


PASSIVO NÃO-CIRCULANTE / PASSIVO TOTAL + PATRIMÔNIO LÍQUIDO

Case Processing Summary

\begin{tabular}{|c|c|c|c|c|c|c|c|}
\hline & \multirow[b]{3}{*}{ GAAP } & \multicolumn{6}{|c|}{ Cases } \\
\hline & & \multicolumn{2}{|c|}{ Valid } & \multicolumn{2}{|c|}{ Missing } & \multicolumn{2}{|c|}{ Total } \\
\hline & & $\mathrm{N}$ & Percent & $\mathrm{N}$ & Percent & $\mathrm{N}$ & Percent \\
\hline \multirow[t]{2}{*}{ Pass não-circ / P + PL } & 0 & 6 & $100,0 \%$ & 0 &, $0 \%$ & 6 & $100,0 \%$ \\
\hline & 1 & 6 & $100,0 \%$ & 0 &, $0 \%$ & 6 & $100,0 \%$ \\
\hline
\end{tabular}

Tests of Normality

\begin{tabular}{|ll|r|r|r|r|r|r|}
\hline & \multicolumn{3}{|c|}{ Kolmogorov-Smirnov } & \multicolumn{3}{|c|}{ Shapiro-Wilk } \\
\cline { 2 - 8 } & GAAP & Statistic & df & \multicolumn{1}{|c|}{ Sig. } & Statistic & \multicolumn{1}{c|}{ df } & \multicolumn{1}{c|}{ Sig. } \\
\hline Pass não-circ / P + PL & 0 &, 193 & 6 &, $200^{*}$ &, 948 & 6 &, 722 \\
& 1 &, 191 & 6 &, $200^{*}$ &, 938 & 6 &, 645 \\
\hline
\end{tabular}

${ }^{*}$. This is a lower bound of the true significance.

a. Lilliefors Significance Correction

PASSIVO TOTAL / PASSIVO TOTAL + PATRIMÔNIO LÍQUIDO

Paired Samples Statistics

\begin{tabular}{|c|c|c|c|c|c|}
\hline & & Mean & $\mathrm{N}$ & Std. Deviation & $\begin{array}{l}\text { Std. Error } \\
\text { Mean }\end{array}$ \\
\hline \multirow[t]{2}{*}{$\begin{array}{l}\text { Pair } \\
1\end{array}$} & $\begin{array}{l}\text { Passivo / Passivo } \\
+ \text { PL - IFRS }\end{array}$ & ,567718 & 6 & 2230451 & ,0910578 \\
\hline & $\begin{array}{l}\text { Passivo / Passivo } \\
+ \text { PL - UK-GAAP }\end{array}$ & ,464178 & 6 & ,1441314 &, 0588414 \\
\hline
\end{tabular}

\begin{tabular}{|c|c|c|c|c|c|c|c|c|c|}
\hline \multicolumn{10}{|c|}{ Paired Samples Test } \\
\hline & & \multicolumn{5}{|c|}{ Paired Differences } & \multirow[b]{3}{*}{$t$} & \multirow[b]{3}{*}{ df } & \multirow[b]{3}{*}{ Sig. (2-tailed) } \\
\hline & & \multirow[b]{2}{*}{ Mean } & \multirow[b]{2}{*}{ Std. Deviation } & \multirow{2}{*}{$\begin{array}{l}\text { Std. Error } \\
\text { Mean }\end{array}$} & \multicolumn{2}{|c|}{$\begin{array}{l}\text { 95\% Confidence } \\
\text { Interval of the } \\
\text { Difference }\end{array}$} & & & \\
\hline & & & & & Lower & Upper & & & \\
\hline & $\begin{array}{l}\text { Passivo / Passivo + PL- } \\
\text { IFRS - Passivo / Passivo } \\
+ \text { + PL - UK-GAAP }\end{array}$ & 1035398 & 1332605 & ,0544034 & - -0363085 & 2433881 & 1,903 & 5 & 115 \\
\hline
\end{tabular}


ATIVO NÃO-CIRCULANTE / ATIVO TOTAL

\begin{tabular}{|l|l|r|r|c|} 
Paired Samples Statistics \\
\begin{tabular}{|ll|l|r|r|r|}
\hline & Mean & N & Std. Deviation & \multicolumn{1}{c|}{$\begin{array}{c}\text { Std. Error } \\
\text { Mean }\end{array}$} \\
\hline $\begin{array}{l}\text { Pair } \\
1\end{array}$ & $\begin{array}{l}\text { Ativo não-circulante / } \\
\text { Ativo - IFRS } \\
\text { Ativo não-circulante / } \\
\text { Ativo - DE-GAAP }\end{array}$ &, 536605 & 3 &, 0515631 &, 0297700 \\
\end{tabular}
\end{tabular}

\begin{tabular}{|c|c|c|c|c|c|c|c|c|c|}
\hline \multicolumn{10}{|c|}{ Paired Samples Test } \\
\hline & & \multicolumn{5}{|c|}{ Paired Differences } & \multirow[b]{3}{*}{$t$} & \multirow[b]{3}{*}{ df } & \multirow[b]{3}{*}{ Sig. (2-tailed) } \\
\hline & & \multirow[b]{2}{*}{ Mean } & \multirow[b]{2}{*}{ Std. Deviation } & \multirow{2}{*}{$\begin{array}{c}\text { Std. Error } \\
\text { Mean }\end{array}$} & \multicolumn{2}{|c|}{$\begin{array}{l}95 \% \text { Confidence } \\
\text { Interval of the } \\
\text { Difference }\end{array}$} & & & \\
\hline & & & & & Lower & Upper & & & \\
\hline $\begin{array}{l}\text { Pair } \\
1\end{array}$ & $\begin{array}{l}\text { Ativo não-circulante / } \\
\text { Ativo - IFRS - Ativo } \\
\text { não-circulante / Ativo } \\
\text { - DE-GAAP }\end{array}$ & , 0834008 & ,0453965 & , 0262097 & - & 1961718 & 3,182 & 2 & 086 \\
\hline
\end{tabular}

ATIVO CIRCULANTE / ATIVO TOTAL

Paired Samples Statistics

\begin{tabular}{|ll|l|r|r|c|}
\hline & & Mean & $\mathrm{N}$ & Std. Deviation & $\begin{array}{c}\text { Std. Error } \\
\text { Mean }\end{array}$ \\
\hline $\begin{array}{l}\text { Pair } \\
1\end{array}$ & $\begin{array}{l}\text { Ativo circulante / } \\
\text { Ativo - IFRS } \\
\text { Ativo circulante / } \\
\text { Ativo - DE-GAAP }\end{array}$ &, 463395 & 3 &, 0515631 &, 0297700 \\
\hline
\end{tabular}

Paired Samples Test

\begin{tabular}{|c|c|c|c|c|c|c|c|c|c|}
\hline & & \multicolumn{5}{|c|}{ Paired Differences } & \multirow[b]{3}{*}{$t$} & \multirow[b]{3}{*}{ df } & \multirow[b]{3}{*}{ Sig. (2-tailed) } \\
\hline & & \multirow[b]{2}{*}{ Mean } & \multirow[b]{2}{*}{ Std. Deviation } & \multirow{2}{*}{$\begin{array}{l}\text { Std. Error } \\
\text { Mean }\end{array}$} & \multicolumn{2}{|c|}{$\begin{array}{l}95 \% \text { Confidence } \\
\text { Interval of the } \\
\text { Difference }\end{array}$} & & & \\
\hline & & & & & Lower & Upper & & & \\
\hline $\begin{array}{l}\text { Pair } \\
1\end{array}$ & $\begin{array}{l}\text { Ativo circulante / Ativo - } \\
\text { IFRS - Ativo circulante } \\
\text { / Ativo - DE-GAAP }\end{array}$ &,- 0834008 & ,0453965 & ,0262097 &,- 1961718 &, 0293703 & $-3,182$ & 2 & ,086 \\
\hline
\end{tabular}


PASSIVO CIRCULANTE / PASSIVO TOTAL + PATRIMÔNIO LÍQUIDO

Paired Samples Statistics

\begin{tabular}{|ll|l|r|r|c|}
\hline & & Mean & N & Std. Deviation & $\begin{array}{c}\text { Std. Error } \\
\text { Mean }\end{array}$ \\
\hline $\begin{array}{l}\text { Pair } \\
1\end{array}$ & $\begin{array}{l}\text { Passivo circulante / } \\
\text { Pasivo + PL - IFRS } \\
\begin{array}{l}\text { Passivo circulante / } \\
\text { Pasivo + PL - DE-GAAP }\end{array}\end{array}$ &, 336040 & 3 &, 1554893 &, 0897718 \\
\hline
\end{tabular}

Paired Samples Test

\begin{tabular}{|c|c|c|c|c|c|c|c|c|c|}
\hline & & \multicolumn{5}{|c|}{ Paired Differences } & \multirow[b]{3}{*}{$\mathrm{t}$} & \multirow[b]{3}{*}{ df } & \multirow[b]{3}{*}{ Sig. (2-tailed) } \\
\hline & & \multirow[b]{2}{*}{ Mean } & \multirow[b]{2}{*}{ Std. Deviation } & \multirow{2}{*}{$\begin{array}{l}\text { Std. Error } \\
\text { Mean }\end{array}$} & \multicolumn{2}{|c|}{$\begin{array}{l}\text { 95\% Confidence } \\
\text { Interval of the } \\
\text { Difference }\end{array}$} & & & \\
\hline & & & & & Lower & Upper & & & \\
\hline $\begin{array}{l}\text { Pair } \\
1\end{array}$ & $\begin{array}{l}\text { Passivo circulante / } \\
\text { Pasivo + PL - IFRS - } \\
\text { Passivo circulante / } \\
\text { Pasivo + PL - DE-GAAP }\end{array}$ &,- 0459622 & ,1169615 & ,0675278 &,- 3365106 & ,2445863 &,- 681 & 2 & ,566 \\
\hline
\end{tabular}

CCL

Paired Samples Statistics

\begin{tabular}{|c|c|c|c|c|c|}
\hline & & Mean & $\mathrm{N}$ & Std. Deviation & $\begin{array}{c}\text { Std. Error } \\
\text { Mean }\end{array}$ \\
\hline \multirow{2}{*}{$\begin{array}{l}\text { Pair } \\
1\end{array}$} & CCL - IFRS & 268,3154 & 3 & 313,9563294 & 181,2628 \\
\hline & CCL - DE-GAAP & 301,5271 & 3 & 445,7967670 & 257,3809 \\
\hline
\end{tabular}

Paired Samples Test

\begin{tabular}{|c|c|c|c|c|c|c|c|c|c|}
\hline & & \multicolumn{5}{|c|}{ Paired Differences } & \multirow[b]{3}{*}{$t$} & \multirow[b]{3}{*}{ df } & \multirow[b]{3}{*}{ Sig. (2-tailed) } \\
\hline & & \multirow[b]{2}{*}{ Mean } & \multirow[b]{2}{*}{ Std. Deviation } & \multirow{2}{*}{$\begin{array}{l}\text { Std. Error } \\
\text { Mean }\end{array}$} & \multicolumn{2}{|c|}{$\begin{array}{l}95 \% \text { Confidence } \\
\text { Interval of the } \\
\text { Difference }\end{array}$} & & & \\
\hline & & & & & Lower & Upper & & & \\
\hline $\begin{array}{l}\text { Pair } \\
1\end{array}$ & $\begin{array}{l}\mathrm{CCL} \text { - IFRS - } \\
\mathrm{CCL} \text { - DE-GAAP }\end{array}$ & $-33,2117$ & 156,6591923 & 90,44723 & $-422,375$ & 355,9513 &,- 367 & 2 & ,749 \\
\hline
\end{tabular}


PASSIVO NÃO-CIRCULANTE / PASSIVO TOTAL + PATRIMÔNIO LÍQUIDO

Paired Samples Statistics

\begin{tabular}{|c|c|c|c|c|c|}
\hline & & Mean & $\mathrm{N}$ & Std. Deviation & $\begin{array}{l}\text { Std. Error } \\
\text { Mean }\end{array}$ \\
\hline \multirow[t]{2}{*}{$\begin{array}{l}\text { Pair } \\
1\end{array}$} & $\begin{array}{l}\text { Passivo não-circulante / } \\
\text { Passivo + PL - IFRS }\end{array}$ & ,294375 & 3 & 0894499, & ,0516439 \\
\hline & $\begin{array}{l}\text { Passivo não-circulante / } \\
\text { Passivo + PL - DE-GAAP }\end{array}$ & 291193 & 3 & ,1522552 & ,0879046 \\
\hline
\end{tabular}

Paired Samples Test

\begin{tabular}{|c|c|c|c|c|c|c|c|c|c|}
\hline & & \multicolumn{5}{|c|}{ Paired Differences } & \multirow[b]{3}{*}{$\mathrm{t}$} & \multirow[b]{3}{*}{$\mathrm{df}$} & \multirow[b]{3}{*}{ Sig. (2-tailed) } \\
\hline & & \multirow[b]{2}{*}{ Mean } & \multirow[b]{2}{*}{ Std. Deviation } & \multirow{2}{*}{$\begin{array}{l}\text { Std. Error } \\
\text { Mean }\end{array}$} & \multicolumn{2}{|c|}{$\begin{array}{l}95 \% \text { Confidence } \\
\text { Interval of the } \\
\text { Difference }\end{array}$} & & & \\
\hline & & & & & Lower & Upper & & & \\
\hline $\begin{array}{l}\text { Pair } \\
1\end{array}$ & $\begin{array}{l}\text { Passivo não-circulante / } \\
\text { Passivo + PL - IFRS - } \\
\text { Passivo não-circulante / } \\
\text { Passivo + PL - DE-GAAP }\end{array}$ & ,0031823 & ,0876277 & ,0505919 &,- 2144970 & ,2208616 & ,063 & 2 & ,956 \\
\hline
\end{tabular}

PASSIVO TOTAL / PASSIVO TOTAL + PATRIMÔNIO LÍQUIDO

Paired Samples Statistics

\begin{tabular}{|ll|l|r|r|r|}
\hline & & Mean & N & Std. Deviation & $\begin{array}{c}\text { Std. Error } \\
\text { Mean }\end{array}$ \\
\hline $\begin{array}{l}\text { Pair } \\
1\end{array}$ & $\begin{array}{l}\text { Passivo / Passivo } \\
+ \text { PL - IFRS } \\
\text { Passivo / Passivo } \\
+ \text { PL - DE-GAAP }\end{array}$ &, 630415 & 3 &, 0725015 &, 0418588 \\
\hline
\end{tabular}

\begin{tabular}{|c|c|c|c|c|c|c|c|c|c|}
\hline \multicolumn{10}{|c|}{ Paired Samples Test } \\
\hline & & \multicolumn{5}{|c|}{ Paired Differences } & \multirow[b]{3}{*}{$t$} & \multirow[b]{3}{*}{ df } & \multirow[b]{3}{*}{ Sig. (2-tailed) } \\
\hline & & \multirow[b]{2}{*}{ Mean } & \multirow[b]{2}{*}{ Std. Deviation } & \multirow{2}{*}{$\begin{array}{l}\text { Std. Error } \\
\text { Mean }\end{array}$} & \multicolumn{2}{|c|}{$\begin{array}{l}95 \% \text { Confidence } \\
\text { Interval of the } \\
\text { Difference }\end{array}$} & & & \\
\hline & & & & & Lower & Upper & & & \\
\hline $\begin{array}{l}\text { Pair } \\
1\end{array}$ & $\begin{array}{l}\text { Passivo / Passivo + PL - } \\
\text { IFRS - Passivo / Passivo } \\
+ \text { PL - DE-GAAP }\end{array}$ &,- 0427798 & ,0328384 &, 0189593 &,- 1243550 & ,0387953 & $-2,256$ & 2 & ,153 \\
\hline
\end{tabular}


ATIVO NÃO-CIRCULANTE / ATIVO TOTAL

Paired Samples Statistics

\begin{tabular}{|c|c|c|c|c|c|}
\hline & & Mean & $\mathrm{N}$ & Std. Deviation & $\begin{array}{l}\text { Std. Error } \\
\text { Mean }\end{array}$ \\
\hline \multirow[t]{2}{*}{$\begin{array}{l}\text { Pair } \\
1\end{array}$} & $\begin{array}{l}\text { Ativo não-circulante / } \\
\text { Ativo - IFRS }\end{array}$ & ,482227 & 7 & ,0811255 & ,0306626 \\
\hline & $\begin{array}{l}\text { Ativo não-circulante / } \\
\text { Ativo - DE-GAAP }\end{array}$ & ,496090 & 7 & ,0557891 & ,0210863 \\
\hline
\end{tabular}

Paired Samples Test

\begin{tabular}{|c|c|c|c|c|c|c|c|c|c|}
\hline & & \multicolumn{5}{|c|}{ Paired Differences } & \multirow[b]{3}{*}{$t$} & \multirow[b]{3}{*}{$\mathrm{df}$} & \multirow[b]{3}{*}{ Sig. (2-tailed) } \\
\hline & & \multirow[b]{2}{*}{ Mean } & \multirow[b]{2}{*}{ Std. Deviation } & \multirow{2}{*}{$\begin{array}{l}\text { Std. Error } \\
\text { Mean }\end{array}$} & \multicolumn{2}{|c|}{$\begin{array}{l}95 \% \text { Confidence } \\
\text { Interval of the } \\
\text { Difference } \\
\end{array}$} & & & \\
\hline & & & & & Lower & Upper & & & \\
\hline $\begin{array}{l}\text { Pair } \\
1\end{array}$ & $\begin{array}{l}\text { Ativo não-circulante / } \\
\text { Ativo - IFRS - Ativo } \\
\text { não-circulante / Ativo } \\
\text { - DE-GAAP }\end{array}$ &,- 0138629 & ,0720850 &, 0272456 &,- 0805304 & ,0528046 &,- 509 & 6 & ,629 \\
\hline
\end{tabular}

ATIVO CIRCULANTE / ATIVO TOTAL

Paired Samples Statistics

\begin{tabular}{|ll|l|r|r|r|}
\hline & & Mean & N & Std. Deviation & $\begin{array}{c}\text { Std. Error } \\
\text { Mean }\end{array}$ \\
\hline $\begin{array}{l}\text { Pair } \\
1\end{array}$ & $\begin{array}{l}\text { Ativo circulante / } \\
\text { Ativo - IFRS } \\
\text { Ativo circulante / } \\
\text { Ativo - DE-GAAP }\end{array}$ &, 517773 & 7 &, 0811255 &, 0306626 \\
&, 503910 & 7 &, 0557891 &, 0210863 \\
\hline
\end{tabular}

Paired Samples Test

\begin{tabular}{|c|c|c|c|c|c|c|c|c|c|}
\hline & & \multicolumn{5}{|c|}{ Paired Differences } & \multirow[b]{3}{*}{$\mathrm{t}$} & \multirow[b]{3}{*}{ df } & \multirow[b]{3}{*}{ Sig. (2-tailed) } \\
\hline & & \multirow[b]{2}{*}{ Mean } & \multirow[b]{2}{*}{ Std. Deviation } & \multirow{2}{*}{$\begin{array}{l}\text { Std. Error } \\
\text { Mean }\end{array}$} & \multicolumn{2}{|c|}{$\begin{array}{l}95 \% \text { Confidence } \\
\text { Interval of the } \\
\text { Difference } \\
\end{array}$} & & & \\
\hline & & & & & Lower & Upper & & & \\
\hline $\begin{array}{l}\text { Pair } \\
1\end{array}$ & $\begin{array}{l}\text { Ativo circulante / Ativo - } \\
\text { IFRS - Ativo circulante } \\
\text { / Ativo - DE-GAAP }\end{array}$ &, 0138629 & ,0720850 &, 0272456 &,- 0528046 &, 0805304 &, 509 & 6 & ,629 \\
\hline
\end{tabular}


PASSIVO CIRCULANTE / PASSIVO TOTAL + PATRIMÔNIO LÍQUIDO

Paired Samples Statistics

\begin{tabular}{|c|c|c|c|c|c|}
\hline & & Mean & $\mathrm{N}$ & Std. Deviation & $\begin{array}{l}\text { Std. Error } \\
\text { Mean }\end{array}$ \\
\hline \multirow[t]{2}{*}{$\begin{array}{l}\text { Pair } \\
1\end{array}$} & $\begin{array}{l}\text { Passivo circulante / } \\
\text { Pasivo + PL - IFRS }\end{array}$ & ,312533 & 7 & ,1207720 & ,0456475 \\
\hline & $\begin{array}{l}\text { Passivo circulante / } \\
\text { Pasivo + PL - DE-GAAP }\end{array}$ & ,316463 & 7 & ,2235088 & ,0844784 \\
\hline
\end{tabular}

Paired Samples Test

\begin{tabular}{|c|c|c|c|c|c|c|c|c|c|}
\hline & & \multicolumn{5}{|c|}{ Paired Differences } & \multirow[b]{3}{*}{$t$} & \multirow[b]{3}{*}{ df } & \multirow[b]{3}{*}{ Sig. (2-tailed) } \\
\hline & & \multirow[b]{2}{*}{ Mean } & \multirow[b]{2}{*}{ Std. Deviation } & \multirow{2}{*}{$\begin{array}{l}\text { Std. Error } \\
\text { Mean }\end{array}$} & \multicolumn{2}{|c|}{$\begin{array}{l}95 \% \text { Confidence } \\
\text { Interval of the } \\
\text { Difference }\end{array}$} & & & \\
\hline & & & & & Lower & Upper & & & \\
\hline $\begin{array}{l}\text { Pair } \\
1\end{array}$ & $\begin{array}{l}\text { Passivo circulante / } \\
\text { Pasivo + PL - IFRS - } \\
\text { Passivo circulante / } \\
\text { Pasivo + PL - DE-GAAP }\end{array}$ &,- 0039299 & ,1166101 & ,0440745 &,- 1117762 & ,1039164 &,- 089 & 6 & ,932 \\
\hline
\end{tabular}

CCL

Paired Samples Statistics

\begin{tabular}{|c|c|c|c|c|c|}
\hline & & Mean & $\mathrm{N}$ & Std. Deviation & $\begin{array}{c}\text { Std. Error } \\
\text { Mean }\end{array}$ \\
\hline Pair & CCL - IFRS & 3390,064 & 7 & 5192,9786962 & 1962,761 \\
\hline 1 & CCL - DE-GAAP & 3322,276 & 7 & 5536,8186881 & 2092,721 \\
\hline
\end{tabular}

Paired Samples Test

\begin{tabular}{|c|c|c|c|c|c|c|c|c|c|}
\hline & & \multicolumn{5}{|c|}{ Paired Differences } & \multirow[b]{3}{*}{$t$} & \multirow[b]{3}{*}{$\mathrm{df}$} & \multirow[b]{3}{*}{ Sig. (2-tailed) } \\
\hline & & \multirow[b]{2}{*}{ Mean } & \multirow[b]{2}{*}{ Std. Deviation } & \multirow{2}{*}{$\begin{array}{l}\text { Std. Error } \\
\text { Mean }\end{array}$} & \multicolumn{2}{|c|}{$\begin{array}{l}95 \% \text { Confidence } \\
\text { Interval of the } \\
\text { Difference }\end{array}$} & & & \\
\hline & & & & & Lower & Upper & & & \\
\hline $\begin{array}{l}\text { Pair } \\
1\end{array}$ & $\begin{array}{l}\mathrm{CCL} \text { - IFRS - } \\
\mathrm{CCL} \text { - DE-GAAP }\end{array}$ & 67,78788 & 647,1020523 & 244,5816 & $-530,682$ & 666,2575 & ,277 & 6 & ,791 \\
\hline
\end{tabular}


PASSIVO NÃO-CIRCULANTE / PASSIVO TOTAL + PATRIMÔNIO LÍQUIDO

Paired Samples Statistics

\begin{tabular}{|ll|l|r|r|c|}
\hline & & Mean & N & Std. Deviation & $\begin{array}{c}\text { Std. Error } \\
\text { Mean }\end{array}$ \\
\hline $\begin{array}{l}\text { Pair } \\
1\end{array}$ & $\begin{array}{l}\text { Passivo não-circulante / } \\
\text { Passivo + PL - IFRS } \\
\begin{array}{l}\text { Passivo não-circulante / } \\
\text { Passivo + PL - DE-GAAP }\end{array}\end{array}$ &, 267546 & 7 &, 0964185 &, 0364428 \\
\hline
\end{tabular}

Paired Samples Test

\begin{tabular}{|c|c|c|c|c|c|c|c|c|c|}
\hline & & \multicolumn{5}{|c|}{ Paired Differences } & \multirow[b]{3}{*}{$t$} & \multirow[b]{3}{*}{ df } & \multirow[b]{3}{*}{ Sig. (2-tailed) } \\
\hline & & \multirow[b]{2}{*}{ Mean } & \multirow[b]{2}{*}{ Std. Deviation } & \multirow{2}{*}{$\begin{array}{l}\text { Std. Error } \\
\text { Mean }\end{array}$} & \multicolumn{2}{|c|}{$\begin{array}{l}95 \% \text { Confidence } \\
\text { Interval of the } \\
\text { Difference }\end{array}$} & & & \\
\hline & & & & & Lower & Upper & & & \\
\hline $\begin{array}{l}\text { Pair } \\
1\end{array}$ & $\begin{array}{l}\text { Passivo não-circulante / } \\
\text { Passivo + PL - IFRS - } \\
\text { Passivo não-circulante / } \\
\text { Passivo + PL - DE-GAAP }\end{array}$ &, 0066236 & ,0966836 &, 0365430 &,- 0827938 &, 0960411 & , 181 & 6 & ,862 \\
\hline
\end{tabular}

PASSIVO TOTAL / PASSIVO TOTAL + PATRIMÔNIO LÍQUIDO

Paired Samples Statistics

\begin{tabular}{|c|c|c|c|c|c|}
\hline & & Mean & $\mathrm{N}$ & Std. Deviation & $\begin{array}{l}\text { Std. Error } \\
\text { Mean }\end{array}$ \\
\hline \multirow[t]{2}{*}{$\begin{array}{l}\text { Pair } \\
1\end{array}$} & $\begin{array}{l}\text { Passivo / Passivo } \\
+ \text { PL - IFRS }\end{array}$ & ,580078 & 7 & ,0962573 & ,0363818 \\
\hline & $\begin{array}{l}\text { Passivo / Passivo } \\
+ \text { PL - DE-GAAP }\end{array}$ & ,577385 & 7 & 2668921 & ,1008757 \\
\hline
\end{tabular}

Paired Samples Test

\begin{tabular}{|c|c|c|c|c|c|c|c|c|c|}
\hline & & \multicolumn{5}{|c|}{ Paired Differences } & \multirow[b]{3}{*}{$t$} & \multirow[b]{3}{*}{ df } & \multirow[b]{3}{*}{ Sig. (2-tailed) } \\
\hline & & \multirow[b]{2}{*}{ Mean } & \multirow[b]{2}{*}{ Std. Deviation } & \multirow{2}{*}{$\begin{array}{c}\text { Std. Error } \\
\text { Mean }\end{array}$} & \multicolumn{2}{|c|}{$\begin{array}{l}95 \% \text { Confidence } \\
\text { Interval of the } \\
\text { Difference } \\
\end{array}$} & & & \\
\hline & & & & & Lower & Upper & & & \\
\hline & $\begin{array}{l}\text { Passivo / Passivo + PL - } \\
\text { IFRS - Passivo / Passivo } \\
+ \text { PL - DE-GAAP }\end{array}$ &, 0026937 & , 1927012 & ,0728342 &,- 1755251 & ,1809126 & ,037 & 6 & ,972 \\
\hline
\end{tabular}


ATIVO NÃO-CIRCULANTE / ATIVO TOTAL

\begin{tabular}{|c|c|c|c|c|c|}
\hline \multicolumn{6}{|c|}{ Paired Samples Statistics } \\
\hline & & Mean & $\mathrm{N}$ & Std. Deviation & $\begin{array}{l}\text { Std. Error } \\
\text { Mean }\end{array}$ \\
\hline \multirow[t]{2}{*}{$\begin{array}{l}\text { Pair } \\
1\end{array}$} & $\begin{array}{l}\text { Ativo não-circulante / } \\
\text { Ativo - IFRS }\end{array}$ & ,459831 & 6 & ,2265177 & ,0924755 \\
\hline & $\begin{array}{l}\text { Ativo não-circulante / } \\
\text { Ativo - FR-GAAP }\end{array}$ & ,446208 & 6 & ,2823362 & ,1152633 \\
\hline
\end{tabular}

Paired Samples Test

\begin{tabular}{|c|c|c|c|c|c|c|c|c|c|}
\hline & & \multicolumn{5}{|c|}{ Paired Differences } & \multirow[b]{3}{*}{$t$} & \multirow[b]{3}{*}{ df } & \multirow[b]{3}{*}{ Sig. (2-tailed) } \\
\hline & & \multirow[b]{2}{*}{ Mean } & \multirow[b]{2}{*}{ Std. Deviation } & \multirow{2}{*}{$\begin{array}{l}\text { Std. Error } \\
\text { Mean }\end{array}$} & \multicolumn{2}{|c|}{$\begin{array}{l}95 \% \text { Confidence } \\
\text { Interval of the } \\
\text { Difference }\end{array}$} & & & \\
\hline & & & & & Lower & Upper & & & \\
\hline $\begin{array}{l}\text { Pair } \\
1\end{array}$ & $\begin{array}{l}\text { Ativo não-circulante / } \\
\text { Ativo - IFRS - Ativo } \\
\text { não-circulante / Ativo } \\
\text { - FR-GAAP }\end{array}$ &, 0136224 & ,0618677 & ,0252574 &,- 0513039 & ,0785486 & ,539 & 5 & ,613 \\
\hline
\end{tabular}

ATIVO CIRCULANTE / ATIVO TOTAL

Paired Samples Statistics

\begin{tabular}{|c|c|c|c|c|c|}
\hline & & Mean & $\mathrm{N}$ & Std. Deviation & $\begin{array}{l}\text { Std. Error } \\
\text { Mean }\end{array}$ \\
\hline \multirow[t]{2}{*}{$\begin{array}{l}\text { Pair } \\
1\end{array}$} & $\begin{array}{l}\text { Ativo circulante / } \\
\text { Ativo - IFRS }\end{array}$ &, 540169 & 6 & 2265177 & ,0924755 \\
\hline & $\begin{array}{l}\text { Ativo circulante / } \\
\text { Ativo - FR-GAAP }\end{array}$ &, 553792 & 6 & ,2823362 & ,1152633 \\
\hline
\end{tabular}

Paired Samples Test

\begin{tabular}{|c|c|c|c|c|c|c|c|c|c|}
\hline & & \multicolumn{5}{|c|}{ Paired Differences } & \multirow[b]{3}{*}{$t$} & \multirow[b]{3}{*}{ df } & \multirow[b]{3}{*}{ Sig. (2-tailed) } \\
\hline & & \multirow[b]{2}{*}{ Mean } & \multirow[b]{2}{*}{ Std. Deviation } & \multirow{2}{*}{$\begin{array}{c}\text { Std. Error } \\
\text { Mean }\end{array}$} & \multicolumn{2}{|c|}{$\begin{array}{l}95 \% \text { Confidence } \\
\text { Interval of the } \\
\text { Difference }\end{array}$} & & & \\
\hline & & & & & Lower & Upper & & & \\
\hline $\begin{array}{l}\text { Pair } \\
1\end{array}$ & $\begin{array}{l}\text { Ativo circulante / Ativo } \\
\text { IFRS - Ativo circulante } \\
\text { / Ativo - FR-GAAP }\end{array}$ &,- 0136224 & ,0618677 & ,0252574 &,- 0785486 & ,0513039 &,- 539 & 5 &, 613 \\
\hline
\end{tabular}


PASSIVO CIRCULANTE / PASSIVO TOTAL + PATRIMÔNIO LÍQUIDO

Paired Samples Statistics

\begin{tabular}{|ll|l|r|r|r|}
\hline & & Mean & $\mathrm{N}$ & Std. Deviation & \multicolumn{1}{c|}{$\begin{array}{c}\text { Std. Error } \\
\text { Mean }\end{array}$} \\
\hline $\begin{array}{l}\text { Pair } \\
1\end{array}$ & $\begin{array}{l}\text { Passivo circulante / } \\
\text { Pasivo + PL - IFRS } \\
\begin{array}{l}\text { Passivo circulante / } \\
\text { Pasivo + PL - FR-GAAP }\end{array}\end{array}$ &, 379499 & 6 &, 1350850 &, 0551482 \\
\hline
\end{tabular}

Paired Samples Test

\begin{tabular}{|c|c|c|c|c|c|c|c|c|c|}
\hline & & \multicolumn{5}{|c|}{ Paired Differences } & \multirow[b]{3}{*}{$t$} & \multirow[b]{3}{*}{$\mathrm{df}$} & \multirow[b]{3}{*}{ Sig. (2-tailed) } \\
\hline & & \multirow[b]{2}{*}{ Mean } & \multirow[b]{2}{*}{ Std. Deviation } & \multirow{2}{*}{$\begin{array}{l}\text { Std. Error } \\
\text { Mean }\end{array}$} & \multicolumn{2}{|c|}{$\begin{array}{l}95 \% \text { Confidence } \\
\text { Interval of the } \\
\text { Difference } \\
\end{array}$} & & & \\
\hline & & & & & Lower & Upper & & & \\
\hline $\begin{array}{l}\text { Pair } \\
1\end{array}$ & $\begin{array}{l}\text { Passivo circulante / } \\
\text { Pasivo + PL - IFRS - } \\
\text { Passivo circulante / } \\
\text { Pasivo + PL - FR-GAAP }\end{array}$ &,- 1112420 & ,3227917 & ,1317792 &,- 4499911 & ,2275071 &,- 844 & 5 & , 437 \\
\hline
\end{tabular}

CCL

Paired Samples Statistics

\begin{tabular}{|c|c|c|c|c|c|}
\hline & & Mean & $\mathrm{N}$ & Std. Deviation & $\begin{array}{c}\text { Std. Error } \\
\text { Mean }\end{array}$ \\
\hline Pair & CCL - IFRS & 213,8603 & 6 & 432,4703593 & 176,5553 \\
\hline 1 & CCL - FR-GAAP & 204,5550 & 6 & 397,0034666 & 162,0760 \\
\hline
\end{tabular}

Paired Samples Test

\begin{tabular}{|c|c|c|c|c|c|c|c|c|c|}
\hline & & \multicolumn{5}{|c|}{ Paired Differences } & \multirow[b]{3}{*}{$\mathrm{t}$} & \multirow[b]{3}{*}{$\mathrm{df}$} & \multirow[b]{3}{*}{ Sig. (2-tailed) } \\
\hline & & \multirow[b]{2}{*}{ Mean } & \multirow[b]{2}{*}{ Std. Deviation } & \multirow{2}{*}{$\begin{array}{l}\text { Std. Error } \\
\text { Mean }\end{array}$} & \multicolumn{2}{|c|}{$\begin{array}{l}95 \% \text { Confidence } \\
\text { Interval of the } \\
\text { Difference }\end{array}$} & & & \\
\hline & & & & & Lower & Upper & & & \\
\hline $\begin{array}{l}\text { Pair } \\
1\end{array}$ & $\begin{array}{l}\mathrm{CCL} \text { - IFRS - } \\
\mathrm{CCL}-\mathrm{FR}-\mathrm{GAAP}\end{array}$ & 9,3053108 & 42,3412768 & 17,28575 & $-35,1291$ & 53,73976 &, 538 & 5 & ,613 \\
\hline
\end{tabular}




\section{PASSIVO NÃO-CIRCULANTE / PASSIVO TOTAL + PATRIMÔNIO LÍQUIDO}

\begin{tabular}{|c|c|c|c|c|c|c|c|c|c|}
\hline \multicolumn{10}{|c|}{ Paired Samples Test } \\
\hline & & \multicolumn{5}{|c|}{ Paired Differences } & \multirow[b]{3}{*}{$\mathrm{t}$} & \multirow[b]{3}{*}{ df } & \multirow[b]{3}{*}{ Sig. (2-tailed) } \\
\hline & & \multirow[b]{2}{*}{ Mean } & \multirow[b]{2}{*}{ Std. Deviation } & \multirow{2}{*}{$\begin{array}{c}\text { Std. Error } \\
\text { Mean }\end{array}$} & \multicolumn{2}{|c|}{$\begin{array}{l}95 \% \text { Confidence } \\
\text { Interval of the } \\
\text { Difference }\end{array}$} & & & \\
\hline & & & & & Lower & Upper & & & \\
\hline $\begin{array}{l}\text { Pair } \\
1\end{array}$ & $\begin{array}{l}\text { Passivo não-circulante / } \\
\text { Passivo + PL - IFRS - } \\
\text { Passivo não-circulante / } \\
\text { Passivo + PL - FR-GAAP }\end{array}$ & ,1053041 & ,3195892 & ,1304717 &,- 2300842 & ,4406924 & ,807 & 5 & ,456 \\
\hline
\end{tabular}

PASSIVO TOTAL / PASSIVO TOTAL + PATRIMÔNIO LÍQUIDO

\begin{tabular}{|c|c|c|c|c|c|}
\hline \multicolumn{6}{|c|}{ Paired Samples Statistics } \\
\hline & & Mean & $\mathrm{N}$ & Std. Deviation & $\begin{array}{l}\text { Std. Error } \\
\text { Mean }\end{array}$ \\
\hline $\begin{array}{l}\text { Pair } \\
1\end{array}$ & $\begin{array}{l}\text { Passivo / Passivo } \\
+ \text { PL - IFRS }\end{array}$ & ,708978 & 6 & , 1777872 & ,0725813 \\
\hline & $\begin{array}{l}\text { Passivo / Passivo } \\
+ \text { PL - FR-GAAP }\end{array}$ & ,714916 & 6 & ,1956657 & ,0798802 \\
\hline
\end{tabular}

Paired Samples Test

\begin{tabular}{|c|c|c|c|c|c|c|c|c|c|}
\hline & & \multicolumn{5}{|c|}{ Paired Differences } & \multirow[b]{3}{*}{$t$} & \multirow[b]{3}{*}{ df } & \multirow[b]{3}{*}{ Sig. (2-tailed) } \\
\hline & & \multirow[b]{2}{*}{ Mean } & \multirow[b]{2}{*}{ Std. Deviation } & \multirow{2}{*}{$\begin{array}{c}\text { Std. Error } \\
\text { Mean }\end{array}$} & \multicolumn{2}{|c|}{$\begin{array}{l}95 \% \text { Confidence } \\
\text { Interval of the } \\
\text { Difference } \\
\end{array}$} & & & \\
\hline & & & & & Lower & Upper & & & \\
\hline & $\begin{array}{l}\text { Passivo / Passivo + PL - } \\
\text { IFRS - Passivo / Passivo } \\
+ \text { PL - FR-GAAP }\end{array}$ &,- 0059379 & ,0231602 &, 0094551 &,- 0302430 & ,0183673 &,- 628 & 5 &, 558 \\
\hline
\end{tabular}


ATIVO NÃO-CIRCULANTE / ATIVO TOTAL

Paired Samples Statistics

\begin{tabular}{|c|c|c|c|c|c|}
\hline & & Mean & $\mathrm{N}$ & Std. Deviation & $\begin{array}{c}\text { Std. Error } \\
\text { Mean }\end{array}$ \\
\hline \multirow[t]{2}{*}{$\begin{array}{l}\text { Pair } \\
1\end{array}$} & $\begin{array}{l}\text { Ativo não-circulante / } \\
\text { Ativo - IFRS }\end{array}$ & ,509498 & 7 & , 1644635 & ,0621614 \\
\hline & $\begin{array}{l}\text { Ativo não-circulante / } \\
\text { Ativo - FR-GAAP }\end{array}$ & ,464651 & 7 & ,1532662 & ,0579292 \\
\hline
\end{tabular}

Paired Samples Test

\begin{tabular}{|c|c|c|c|c|c|c|c|c|c|}
\hline & & \multicolumn{5}{|c|}{ Paired Differences } & \multirow[b]{3}{*}{$t$} & \multirow[b]{3}{*}{ df } & \multirow[b]{3}{*}{ Sig. (2-tailed) } \\
\hline & & \multirow[b]{2}{*}{ Mean } & \multirow[b]{2}{*}{ Std. Deviation } & \multirow{2}{*}{$\begin{array}{l}\text { Std. Error } \\
\text { Mean }\end{array}$} & \multicolumn{2}{|c|}{$\begin{array}{l}95 \% \text { Confidence } \\
\text { Interval of the } \\
\text { Difference }\end{array}$} & & & \\
\hline & & & & & Lower & Upper & & & \\
\hline $\begin{array}{l}\text { Pair } \\
1\end{array}$ & $\begin{array}{l}\text { Ativo não-circulante / } \\
\text { Ativo - IFRS - Ativo } \\
\text { não-circulante / Ativo } \\
\text { - FR-GAAP }\end{array}$ & ,0448463 & ,0982307 & ,0371277 &,- 0460019 & ,1356946 & 1,208 & 6 & ,273 \\
\hline
\end{tabular}

ATIVO CIRCULANTE / ATIVO TOTAL

Paired Samples Statistics

\begin{tabular}{|c|c|c|c|c|c|}
\hline & & Mean & $\mathrm{N}$ & Std. Deviation & $\begin{array}{c}\text { Std. Error } \\
\text { Mean }\end{array}$ \\
\hline \multirow[t]{2}{*}{$\begin{array}{l}\text { Pair } \\
1\end{array}$} & $\begin{array}{l}\text { Ativo circulante / } \\
\text { Ativo - IFRS }\end{array}$ & ,490502 & 7 & ,1644635 & ,0621614 \\
\hline & $\begin{array}{l}\text { Ativo circulante / } \\
\text { Ativo - FR-GAAP }\end{array}$ & ,535349 & 7 & ,1532662 & ,0579292 \\
\hline
\end{tabular}

Paired Samples Test

\begin{tabular}{|c|c|c|c|c|c|c|c|c|c|}
\hline & & \multicolumn{5}{|c|}{ Paired Differences } & \multirow[b]{3}{*}{$t$} & \multirow[b]{3}{*}{ df } & \multirow[b]{3}{*}{ Sig. (2-tailed) } \\
\hline & & \multirow[b]{2}{*}{ Mean } & \multirow[b]{2}{*}{ Std. Deviation } & \multirow{2}{*}{$\begin{array}{l}\text { Std. Error } \\
\text { Mean }\end{array}$} & \multicolumn{2}{|c|}{$\begin{array}{l}95 \% \text { Confidence } \\
\text { Interval of the } \\
\text { Difference }\end{array}$} & & & \\
\hline & & & & & Lower & Upper & & & \\
\hline $\begin{array}{l}\text { Pair } \\
1\end{array}$ & $\begin{array}{l}\text { Ativo circulante / Ativo - } \\
\text { IFRS - Ativo circulante } \\
\text { / Ativo - FR-GAAP }\end{array}$ &,- 0448463 & ,0982307 & ,0371277 &,- 1356946 & ,0460019 & $-1,208$ & 6 & ,273 \\
\hline
\end{tabular}


PASSIVO CIRCULANTE / PASSIVO TOTAL + PATRIMÔNIO LÍQUIDO

Paired Samples Statistics

\begin{tabular}{|ll|l|r|r|c|}
\hline & & Mean & N & Std. Deviation & $\begin{array}{c}\text { Std. Error } \\
\text { Mean }\end{array}$ \\
\hline $\begin{array}{l}\text { Pair } \\
1\end{array}$ & $\begin{array}{l}\text { Passivo circulante / } \\
\text { Pasivo + PL - IFRS } \\
\end{array}$ & Passivo circulante / \\
& Pasivo + PL - FR-GAAP &, 376847 & 7 &, 2299119 &, 0868985 \\
\hline
\end{tabular}

\begin{tabular}{|c|c|c|c|c|c|c|c|c|c|}
\hline \multicolumn{10}{|c|}{ Paired Samples Test } \\
\hline & & \multicolumn{5}{|c|}{ Paired Differences } & \multirow[b]{3}{*}{$t$} & \multirow[b]{3}{*}{ df } & \multirow[b]{3}{*}{ Sig. (2-tailed) } \\
\hline & & \multirow[b]{2}{*}{ Mean } & \multirow[b]{2}{*}{ Std. Deviation } & \multirow{2}{*}{$\begin{array}{l}\text { Std. Error } \\
\text { Mean }\end{array}$} & \multicolumn{2}{|c|}{$\begin{array}{l}95 \% \text { Confidence } \\
\text { Interval of the } \\
\text { Difference }\end{array}$} & & & \\
\hline & & & & & Lower & Upper & & & \\
\hline $\begin{array}{l}\text { Pair } \\
1\end{array}$ & $\begin{array}{l}\text { Passivo circulante / } \\
\text { Pasivo + PL - IFRS - } \\
\text { Passivo circulante / } \\
\text { Pasivo + PL - FR-GAAP }\end{array}$ &, 0137789 &, 0838086 & ,0316767 &,- 0637311 & ,0912890 & ,435 & 6 & ,679 \\
\hline
\end{tabular}

CCL

Paired Samples Statistics

\begin{tabular}{|c|c|c|c|c|c|}
\hline & & Mean & $\mathrm{N}$ & Std. Deviation & $\begin{array}{l}\text { Std. Error } \\
\text { Mean }\end{array}$ \\
\hline Pair & CCL - IFRS & 162,9569 & 7 & 862,9587193 & 326,1677 \\
\hline 1 & CCL - FR-GAAP & 159,2274 & 7 & 967,6512318 & 365,7378 \\
\hline
\end{tabular}

Paired Samples Test

\begin{tabular}{|c|c|c|c|c|c|c|c|c|c|}
\hline & & \multicolumn{5}{|c|}{ Paired Differences } & \multirow[b]{3}{*}{$t$} & \multirow[b]{3}{*}{ df } & \multirow[b]{3}{*}{ Sig. (2-tailed) } \\
\hline & & \multirow[b]{2}{*}{ Mean } & \multirow[b]{2}{*}{ Std. Deviation } & \multirow{2}{*}{$\begin{array}{l}\text { Std. Error } \\
\text { Mean }\end{array}$} & \multicolumn{2}{|c|}{$\begin{array}{l}95 \% \text { Confidence } \\
\text { Interval of the } \\
\text { Difference }\end{array}$} & & & \\
\hline & & & & & Lower & Upper & & & \\
\hline $\begin{array}{l}\text { Pair } \\
1\end{array}$ & $\begin{array}{l}\mathrm{CCL} \text { - IFRS - } \\
\mathrm{CCL} \text { - FR-GAAP }\end{array}$ & 3,7295674 & 112,4180664 & 42,49004 & $-100,240$ & 107,6989 & ,088 & 6 & ,933 \\
\hline
\end{tabular}


PASSIVO NÃO-CIRCULANTE / PASSIVO TOTAL + PATRIMÔNIO LÍQUIDO

Paired Samples Statistics

\begin{tabular}{|c|c|c|c|c|c|}
\hline & & Mean & $\mathrm{N}$ & Std. Deviation & $\begin{array}{c}\text { Std. Error } \\
\text { Mean }\end{array}$ \\
\hline \multirow[t]{2}{*}{$\begin{array}{l}\text { Pair } \\
1\end{array}$} & $\begin{array}{l}\text { Passivo não-circulante / } \\
\text { Passivo + PL - IFRS }\end{array}$ & ,329161 & 7 & ,1839656 & ,0695325 \\
\hline & $\begin{array}{l}\text { Passivo não-circulante / } \\
\text { Passivo + PL - FR-GAAP }\end{array}$ & 296546 & 7 & 2725825 & ,1030265 \\
\hline
\end{tabular}

Paired Samples Test

\begin{tabular}{|c|c|c|c|c|c|c|c|c|c|}
\hline & & \multicolumn{5}{|c|}{ Paired Differences } & \multirow[b]{3}{*}{$\mathrm{t}$} & \multirow[b]{3}{*}{ df } & \multirow[b]{3}{*}{ Sig. (2-tailed) } \\
\hline & & \multirow[b]{2}{*}{ Mean } & \multirow[b]{2}{*}{ Std. Deviation } & \multirow{2}{*}{$\begin{array}{l}\text { Std. Error } \\
\text { Mean }\end{array}$} & \multicolumn{2}{|c|}{$\begin{array}{l}\text { 95\% Confidence } \\
\text { Interval of the } \\
\text { Difference }\end{array}$} & & & \\
\hline & & & & & Lower & Upper & & & \\
\hline $\begin{array}{l}\text { Pair } \\
1\end{array}$ & $\begin{array}{l}\text { Passivo não-circulante / } \\
\text { Passivo + PL - IFRS - } \\
\text { Passivo não-circulante / } \\
\text { Passivo + PL - FR-GAAP }\end{array}$ &, 0326148 & ,1303618 &, 0492721 &,- 0879497 & , 1531794 & ,662 & 6 &, 533 \\
\hline
\end{tabular}

PASSIVO TOTAL / PASSIVO TOTAL + PATRIMÔNIO LÍQUIDO

Paired Samples Statistics

\begin{tabular}{|ll|l|r|r|c|}
\hline & & Mean & N & Std. Deviation & $\begin{array}{c}\text { Std. Error } \\
\text { Mean }\end{array}$ \\
\hline $\begin{array}{l}\text { Pair } \\
1\end{array}$ & $\begin{array}{l}\text { Passivo / Passivo } \\
\text { + PL - IFRS } \\
\text { Passivo / Passivo } \\
\text { + PL - FR-GAAP }\end{array}$ &, 719009 & 7 &, 2495129 &, 0943070 \\
\hline
\end{tabular}

Paired Samples Test

\begin{tabular}{|c|c|c|c|c|c|c|c|c|c|}
\hline & & \multicolumn{5}{|c|}{ Paired Differences } & \multirow[b]{3}{*}{$t$} & \multirow[b]{3}{*}{ df } & \multirow[b]{3}{*}{ Sig. (2-tailed) } \\
\hline & & \multirow[b]{2}{*}{ Mean } & \multirow[b]{2}{*}{ Std. Deviation } & \multirow{2}{*}{$\begin{array}{l}\text { Std. Error } \\
\text { Mean }\end{array}$} & \multicolumn{2}{|c|}{$\begin{array}{l}95 \% \text { Confidence } \\
\text { Interval of the } \\
\text { Difference }\end{array}$} & & & \\
\hline & & & & & Lower & Upper & & & \\
\hline $\begin{array}{l}\text { Pair } \\
1\end{array}$ & $\begin{array}{l}\text { Passivo / Passivo + PL - } \\
\text { IFRS - Passivo / Passivo } \\
+ \text { PL - FR-GAAP }\end{array}$ &, 0463938 & , 1952744 & ,0738068 &,- 1342049 & ,2269924 & ,629 & 6 &, 553 \\
\hline
\end{tabular}

